\title{
The evaluation of a nutrition education and fitness program with a contest component among college students using the RE-AIM framework
}

\author{
Michelle L. Bartlett \\ West Virginia University
}

Follow this and additional works at: https://researchrepository.wvu.edu/etd

\author{
Recommended Citation \\ Bartlett, Michelle L., "The evaluation of a nutrition education and fitness program with a contest \\ component among college students using the RE-AIM framework" (2009). Graduate Theses, \\ Dissertations, and Problem Reports. 2875. \\ https://researchrepository.wvu.edu/etd/2875
}

This Dissertation is protected by copyright and/or related rights. It has been brought to you by the The Research Repository @ WVU with permission from the rights-holder(s). You are free to use this Dissertation in any way that is permitted by the copyright and related rights legislation that applies to your use. For other uses you must obtain permission from the rights-holder(s) directly, unless additional rights are indicated by a Creative Commons license in the record and/ or on the work itself. This Dissertation has been accepted for inclusion in WVU Graduate Theses, Dissertations, and Problem Reports collection by an authorized administrator of The Research Repository @ WVU.

For more information, please contact researchrepository@mail.wvu.edu. 
The Evaluation of a Nutrition Education and Fitness Program with a Contest Component Among College Students Using the RE-AIM Framework

Michelle L. Bartlett

Dissertation submitted to
The College of Physical Activity and Sport Sciences
at West Virginia University
in partial fulfillment of the requirements for the degree of

Doctor of Philosophy

in

Kinesiology

with a major in Sport and Exercise Psychology

Samuel Zizzi, Ed.D., Chair

Christiaan Abildso, Ph.D.

Edward Etzel, Ed.D.

Ed Jacobs, Ph.D.

Bill Reger-Nash, Ed.D.

Morgantown, WV

2009

Keywords: College Students, Weight Loss, Program Evaluation, RE-AIM 


\begin{abstract}
The Evaluation of a Nutrition Education and Fitness Program with a Contest Component Among College Students Using the RE-AIM Framework
\end{abstract}

Michelle L. Bartlett

Only recently have practitioners and researchers targeted the population of college students in studying interventions aimed at increasing health behaviors. There is evidence that a proportion of college students are making attempts on their own to remedy weight gain and poor physical fitness with little or no guidance, which is reflected in consistently rising obesity rates in this population. Thus, the need for organized and effective interventions is illustrated. The impact of an intervention can be determined through evaluation research. Although the RE-AIM model has not yet been used to evaluate single-site, university-sponsored, college-student weight-loss/fitness programs, it provided a useful model to guide the evaluation of an 8-week nutrition education and fitness program with a contest component among college students $(n=$ 93) via both quantitative and qualitative methods. The effectiveness outcome variables were body fat, resting heart rate, and nutrition knowledge. Results indicated that program reach, effectiveness, and 19-week maintenance were low, with moderate implementation on the individual level and high implementation on the organizational level. However, such programs often suffer from diminished effectiveness when delivered in the real world, as evident in the present study. Suggestions for using the RE-AIM framework to guide similar research and for practice are included. 


\section{Acknowledgements}

I would like to express my immense gratitude to my chair and advisor Dr. Sam Zizzi for his patience, guidance, expertise and insight throughout this entire process. From the very beginning, the time and effort that you put into helping me complete this project was pivotal, as was the encouragement that kept me in the "dissertation haze" to its completion.

Thank you to Dr. Edward Etzel, Dr. Ed Jacobs, and Dr. Bill Reger-Nash for serving on my committee and providing me with support, feedback, and assistance - it has been a pleasure working with you; and especially to Dr. Christiaan Abildso for venturing into the RE-AIM world and providing an exemplary model to follow. Your willingness to share your knowledge and resources was paramount during this process.

I would also like to thank Colleen Harshbarger and Nancy Oliverio for opening up their program to me, lending their time and facilities, and supporting my study. Without you and the information that you allowed me to access, this study would not have been possible.

To the sport and exercise psychology graduate students (current and former), thank you. I am grateful to be among such intelligent and motivated individuals. I would like to credit all of you who have shown me the ways of getting the job done and provided me with feedback, resources, and encouragement.

I would also like to thank my colleagues at West Texas A\&M University for their kindness and for always providing words of encouragement during the long hours of writing in my office.

Thank you to the West Virginia University Office of Graduate Education and Life for the award of the Dissertation Fellowship to fund the writing phase of this project.

Lastly, I would like to thank my mother whose support throughout this process cannot be expressed in words. Thank you so very much. 
Introduction

Purpose

Research Questions

Methods

Program Design

Participants

Research Design

Instrumentation

Procedures

Data Analysis .

Results.

Discussion

Reach .

Effectiveness .

Implementation

Maintenance

Limitations

Evaluation of the RE-AIM Framework

Future Suggestions for Research and Practice

Conclusions

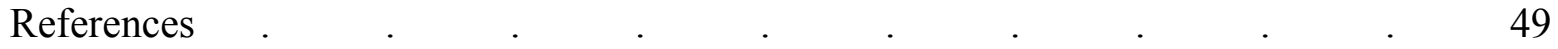

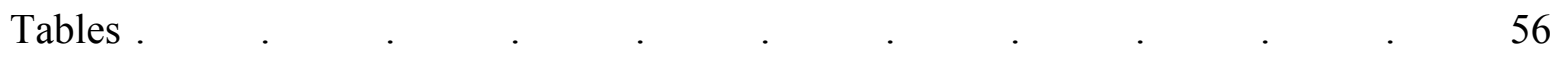

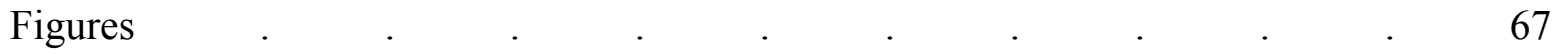

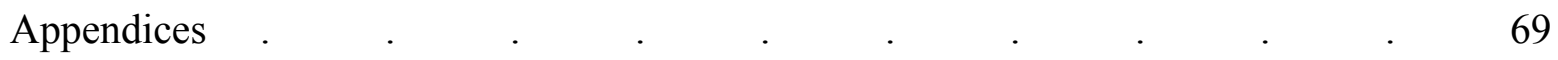

APPENDIX A. Review of the Literature $\quad$. $\quad$. $\quad$. $\quad$. $\quad$. $\quad$. 69

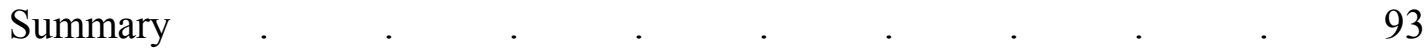

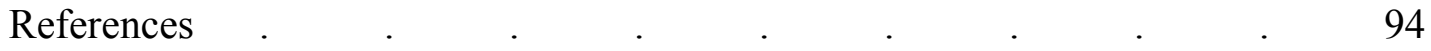

APPENDIX B. Pre-Program Nutrition \& Exercise Assessment $\quad$. $\quad$. $\quad$. 104

APPENDIX C. Post-Program Evaluation Survey \& Nutrition \& Exercise Assessment 108

APPENDIX D. Exercise \& Nutrition Behavior Survey . . . . . . . 112

APPENDIX E. Focus Group Script . . . . . . . . . . . 115

APPENDIX F. Follow-up Study Cover Letter $\quad$. $\quad$. $\quad$. $\quad$. $\quad$. 117

APPENDIX G. Focus Group Cover Letter . $\quad$. $\quad$. $\quad$. $\quad$. $\quad$. 118

APPENDIX H. Focus Group Demographic Questionnaire . . . . . 119

APPENDIX I. Qualitative Code Book and Definitions ․ . . . . . 120 


\section{LIST OF TABLES}

Table 1. Participant baseline characteristics and physiological data . $\quad$. $\quad$. 56

Table 2. Focus group results of program completers and non-completers $\quad$. $\quad$. 57

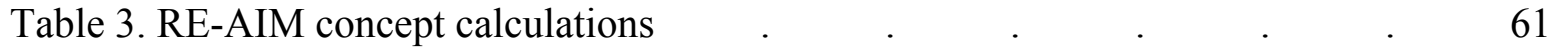

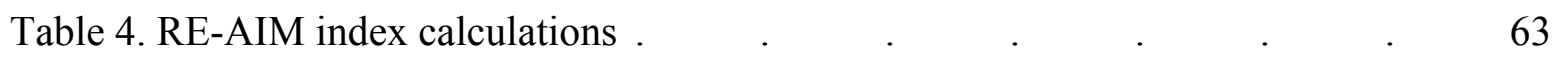

Table 5. Program completers characteristics and physiological data . $\quad$. $\quad$. $\quad 64$

Table 6. Follow-up Time 3 characteristics and physiological data . . . . $\quad 65$

Table 7. Follow-up Time 4 characteristics and physiological data . . . . 66 


\section{LIST OF FIGURES}

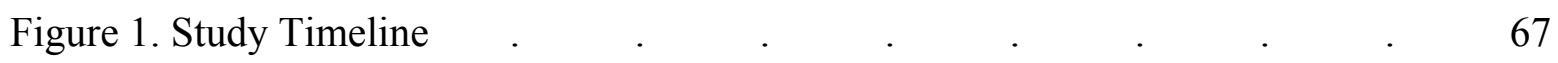

Figure 2. Body for Break RE-AIM Indices . $\quad$. $\quad$. $\quad$. $\quad$. $\quad$. 68 


\section{Introduction}

Inactivity, excess caloric intake and subsequently, obesity are significant problems in the United States. Currently, $61.6 \%$ of US adults are currently overweight or obese (CDC, 2007). Among all children and adolescents aged 2-19 years, $17.1 \%$ were overweight and 33.6\% were at risk of obesity or overweight (Ogden, Caroll, Curtin, et al. 2006). Data from the National Health and Nutrition Examination Survey (NHANES) revealed that between 1980 and 2002, obesity prevalence doubled in adults aged 20 years or older and tripled in children and adolescents aged 6 to 19 years (Flegal, Caroll, Ogden, \& Johnson, 2002). As the prevalence of obesity has increased, so too have the prevalence and cost of associated co-morbidities such as diabetes, high blood pressure, high cholesterol, asthma, arthritis, and poor health status. An estimated 300,000 adults die each year of causes related to obesity (Mokdad et al., 2003). In addition to physical health problems, overweight and obesity can cause significant emotional distress, depression, decreases in self-esteem and overall quality of life (Puhl \& Heuer, 2009).

College students are not impervious to the epidemic. The 1995 National College Health Risk Behavior Survey (NCHRBS) classified 20.5\% of college students as being overweight (Lowry et al., 2000). Analyses of the Behavioral Risk Factor Surveillance Survey System (BRFSS: CDC, 2007) indicate that the greatest increases in overweight and obesity are occurring in persons between the ages of 18 and 29 years of age - at a time when many individuals are attending college (Racette, Deusinger, Strube, Highstein, \& Deusinger, 2005). Many studies attempting to document the phenomenon of the "Freshman 15" (the idea that the average college freshman gains 15 pounds during their first year of college) have shown that during college many students do, in fact, gain weight. The average weight gain pertaining to the "Freshman 15" is approximately 4 pounds (Hull, Morrow, Dinger, Han, \& Fields, 2007), which is still nearly 
five times what is reported for the general population (Mihalopoulos et al., 2008). If such a rate was sustained within several years many would become overweight or obese.

Understanding the behavioral changes contributing to weight gain during the adolescentto-adult developmental period is critical. Contributing factors suggested include eating in cafeteria-style buffets, lack of knowledge/poor food choices, decreases in physical activity (Hoffman, Policastro, Quick, \& Lee, 2006; Holm-Denoma, Joiner, Vohs, \& Heatherton, 2008; Hull et al., 2007; Levitsky, Halbmaier, \& Mrdjenovid, 2004), and increases in alcohol intake (American College Health Association, 2007; Hoffman et al., 2006). As a result, college students are more likely to gain weight and body fat than the general population (e.g., Anderson, Shapiro, \& Lundgren, 2003; Butler, Black, Blue \& Gretebeck, 2004; Graham \& Jones, 2002; Hoffman et al., 2006).

\section{College Students and Weight Control}

Most people attempting to control their weight, including college students, are not using recommended combinations of caloric restriction and adequate levels of physical activity to sufficiently do so (Weiss, Galuska, Kahn, \& Serdula, 2006). Data from the 1995 National College Health Risk Behavior Survey, indicated that among the $46.6 \%$ of college students trying to lose weight, more than half of all students (53.6\%) reported using only exercise to lose weight and $30.8 \%$ reported using only diet to do so, with only $53.8 \%$ of females and $40.9 \%$ of males reporting the use of both diet and exercise (Lowry, Galuska, \& Fulton, et al., 2000). In addition, $15 \%$ of female students were using potentially harmful methods to lose weight such as diet pills, vomiting or laxatives. Lowry et al. (2000) also found that neither moderate physical activity or consuming five or more servings of fruits/vegetables per day were associated with trying to lose weight among college students. 
In the US, $67 \%$ of obese young adults (18-24 years) report trying to lose weight, yet only $24.3 \%$ have received professional advice on how to go about doing so (McCracken, Jiles, \& Blanck, 2007). Lowry et al. (2000) determined that nearly half of all college students were trying to lose weight, yet only about one-third reported receiving information from their university on topics of nutrition and physical activity recommendations. Hence, without proper support or structure many fail to adopt successful, sustainable, and healthy weight-management methods. The need to combat the lack of knowledge among college students concerning health practices is evident in several studies. McArthur and Raedeke (2009) determined that only $40 \%$ of college students in their study were aware that adults should accumulate 30 minutes of moderate intensity physical activity on most days of the week for health benefits. Further, Behrens, Dinger, Heesch, and Sission (2005) determined via qualitative methods that college students expressed considerable confusion pertaining to physical activity recommendations and suggest that the recommendations still may not be reaching college students, supporting Morrow et al.'s (1999), finding that only $16 \%$ of those aged $18-25$ years had heard of the recommendations.

Concerning nutrition, in a study of female first year college students, Matvienko, Lewis, and Schafer (2001) found that the subjects had insufficient baseline levels of knowledge pertaining to nutrients, food labels, dietary recommendations, and energy metabolism. As well, Kolodinsky et al. (2007) found that the college students in their study that reported consuming the recommended amounts of fruits, dairy, and protein had a higher knowledge of dietary guidelines than those that did not. Therefore, it can be assumed that if college students do not know how much physical activity they should be getting or how to manage their dietary intake appropriately, they may be less motivated to seek help or change. 


\section{The Role of Colleges in Preventing and Treating Obesity}

The college years can be an ideal time for implementing programs to decrease inactivity, increase nutritional and physical activity knowledge and decrease obesity. McTigue, Garrett, and Popkin (2002) demonstrated the importance of obesity interventions targeting young adults by illustrating that over $80 \%$ of the obese adults in their longitudinal study of 9179 participants became obese during early adulthood and that it is during this time that social patterning in obesity strongly emerges. Considering that many college students are still developing their lifestyle patterns, the college years may provide the best opportunity to provide wide-reaching, cost-effective interventions necessary for healthy lifestyle changes. In 2007 , there were approximately 17.5 million students enrolled in postsecondary degree-granting institutions with $39 \%$ of all 18-24 year-olds enrolled in college (US Department of Education, 2007). With access to a large proportion of young adults, as well as adequate resources and funding to provide services, college campuses provide an excellent medium for reaching a large number of diverse young adults with education and preventative programs for weight management and active lifestyles.

Jozkowski (2007) evaluated an eight-week peer-led weight loss intervention titled "Follow Me: Students Helping Students to Better Health," which was designed as an 8 weeklong peer-led weight loss intervention geared toward college students using social support as the main component. The program consisted of weekly weigh-ins and educational meetings addressing various avenues of weight loss such as nutrition, physical activity, and how to incorporate those health behaviors into a daily routine. Results were less than desirable, with only 12 of the original 26 participants staying in the program. Although none of the participants gained weight, significant weight-loss was not achieved. However, participants agreed that the 
program increased their self-efficacy for healthy eating/exercising and $100 \%$ of the 12 completers were satisfied with the program material, format, peer-lead facilitation and social support. Limitations of the program and analysis included a potentially inadequate program length of 8 weeks, a small sample size, and the lack of professional knowledge of the leaders needed to ensure effective dissemination of valid information to participants.

Ferrara, St.Laurent, and Wilson (2008) evaluated a three month-long weight loss contest for overweight and obese college students. The contest consisted of monthly weigh-ins, education and exercise sessions with a prize (gift certificate worth $\$ 150$ to $\$ 500$ ) for the top three finishers as determined by reductions in body weight, BMI, percent body fat and circumference measurements. Results indicated that weight loss was significantly correlated with attending the educational classes $(r=-.39, p<.05)$ and exercise sessions $(r=-.41, p<.05)$. However, less than half (40\%) of the participants attended the monthly weigh-ins, educational classes, and exercise sessions. The authors concluded that future research is necessary to determine why the contest incentive worked for some, but not all, of the participants and cautioned that, although there was not evidence of such, a contest format may foster unhealthy weight loss behaviors in order to win. Further, they suggested that future research on college weight loss programs examine the factors that contribute to any observed weight loss and adherence to the program, as well the long-term effects of the program.

In general, research suggests that effective obesity prevention and weight management programs are difficult to design and implement. A knowledge gap is especially evident concerning the traditional "college years", as there is insufficient epidemiologic literature on the determinants of weight gain for this population and even less on effective interventions (Gokee- 
Larose, Gorin, \& Wing, 2009b; Nelson et al., 2008), thus, supporting the need for the systematic evaluations of those interventions.

RE-AIM Framework

One way in which such programs could be evaluated is with the RE-AIM framework (see Glasgow, Vogt, \& Boles, 1999), which provides an outline to evaluate interventions. The evaluation is conducted on individual and organizational levels across five dimensions: (1) reach, (2) effectiveness, (3) adoption, (4) implementation, and (5) maintenance, with reach and efficacy/effectiveness comprising the individual level and adoption comprising the organizational level of the assessment. Implementation and maintenance can be assessed at both the individual and organizational levels as well (Estabrooks \& Gyurcsik, 2003; Glasgow et al., 1999). Each of the five dimensions is assessed on a $0-1$ scale (or a $0 \%$ to $100 \%$ scale). A central tenet of the REAIM model is that the public health impact of an intervention is the combination of its effects on all five dimensions. The data collected via the RE-AIM model can be used for several appraisals: (1) an intervention's overall public health impact; (2) comparing the intervention's effects over settings or time; (3) comparing two or more interventions across one or more of the dimensions; (4) guiding decisions pertaining to effective resource allocation (Glasgow et al., 1999); (5) assessing the translatability of an intervention from research to practice (Estabrooks \& Gyurcsik, 2003).

Previous researchers have demonstrated that the RE-AIM framework is sufficient to use for the evaluation of physical activity lifestyle management interventions and that using qualitative methods may enhance quantitative data gathered on the RE-AIM dimensions. In a targeted review of school health promotion studies, Estabrooks, Dzewltowski, Glasgow \& Klesges (2003) reported that although well-controlled studies of these programs show that they 
have positive effects, little evidence suggests that these programs translate into sustained benefits or general practice due to a lack of thorough evaluation on all RE-AIM dimensions. Further, relatively little research has been conducted to test interventions changing multiple lifestyle behaviors simultaneously (e.g. changing diet, increasing physical activity, and decreasing body fat) (Glasgow, Klesges, Dzewaltowski, Bull, \& Estabrooks, 2004; Toobert et al., 2005).

\section{Purpose}

The purpose of this study was to evaluate a nutrition education and fitness program implemented at a large mid-Atlantic university student recreation center. Several theoreticallybased factors that potentially correlate with outcomes of the program will be assessed using qualitative and quantitative data to answer the following research questions addressing four dimensions of the RE-AIM model (excluding adoption).

\section{Research Questions}

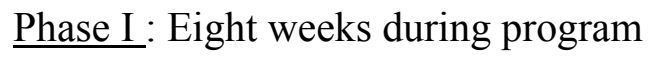

Reach:

- RQ1a. What is the absolute number of participants in the program?

- RQ1b. What is the percentage of the eligible population (24,986 full-time students) that participated in the program?

- RQ1c. Are program participants representative of the population of the student body (denoted by age, gender, and year in school)?

\section{Effectiveness:}

- RQ2a. What is the average change in target variables among participants who complete the program $(\mathrm{T}=1$ to $\mathrm{T}=2)$ ? 
- RQ2b. Do completers of different gender and year in school experience different outcome changes for target outcomes?

- RQ2c. What positive results of the intervention were experienced by participants?

- RQ2d. What negative results of the intervention were experienced by participants? Implementation:

a) Individual level:

- RQ3a. To what extent did the participants implement the Body for Break Program components?

- RQ3b. Did participants use all program components offered to them?

b) Organizational level:

- RQ3c. How did participants rate the quality of program components?

Phase II: Two follow-up points: 1) Four weeks post-program ( $\mathrm{T}=3)$; 2) 19 weeks post-program $(\mathrm{T}=4)$

Maintenance:

a) Individual level:

- RQ4a. What were the effects of the intervention (in weight, meeting physical activity recommendations, exercise self-efficacy and barrier self-efficacy) during the follow-up?

o At 4 weeks post intervention $(\mathrm{T}=3)$ ?

o At 19 weeks post intervention $(\mathrm{T}=4)$ ?

- RQ4b. Do completers of different gender and year in school experience different outcome changes for target variables after completing the program? 
Methods

The methods of the two-phase evaluation described in this chapter are divided into the following sections: (1) program design; (2) participants; (3) research design; (4) instrumentation; (5) procedures; and (6) data analyses.

\section{Program Design}

The Body for Break program was developed by the university student recreation center staff in 2006, and has been offered January through March in each subsequent year. The goal of the eight week program is to help college students attending a large mid-Atlantic university live a healthier lifestyle by providing them with free personal training, nutritional consultations, support groups, weekly motivational/informational emails, and prizes. Targeted outcomes included a decrease in body fat percentage, and an increase in fitness and nutrition knowledge. An additional component was added allowing for the option of entering the contest as a team (defined as having a group of 10 or more people).

Participants were able to sign-up for the program using the recreation center website. At the start of the 8-week program, targeted physiological outcomes of participants (weight, body fat, body size, resting heart rate and blood pressure) were assessed by personal trainers and "before" pictures were taken. There was an online nutritional and exercise knowledge assessment available for participants to determine the nutritional knowledge that they had upon entering the program. At the conclusion of the program, a panel of judges was assembled (independent of this study) to determine the winner of the contest based on these criteria: visual inspection of "before" and "after" photos, body fat loss, inches lost, and blood pressure/ heart rate. There were prizes given to the male and female first, second and third place finishers. Weekly prizes were also raffled off among all participants that exercised at the student recreation 
center at least three times during the week of the raffle. To be eligible to win the final prize, participants had to complete the pre- and post-test physiological assessments.

\section{Participants}

Eligibility for the Body for Break program included being a full-time undergraduate or graduate student at the university and paying the $\$ 10$ enrollment fee. The evaluation consisted of two phases. Participants involved in Phase $\mathrm{I}(\mathrm{T}=1$ to $\mathrm{T}=2)$ of the evaluation $(n=93)$ completed the Body for Break program denoted by returning for the post-program physiological assessment; therefore a purposive sample was used. Participants were recruited for focus groups in-person during the final assessment for the Body for Break program, which was held March 11-12, 2009, from 8am-8pm, in the wellness lab at the student recreation center. Additionally, focus group and interview participants were recruited via email from the pool of individuals that did not complete the Body for Break program ("non-completers"), but did complete at least one session with one of the program's personal trainers. Focus group/interview participants were $76 \%$ female, $35 \%$ graduate students, and $41 \%$ between the $20-21$ years of age.

Participants involved in Phase II of the evaluation met requisites for program participation (e.g. considered "completers"), denoted by completing five of the eight weeks of the program as measured by recreation center attendance and/or by having attended the final assessment. These participants took the Exercise \& Nutrition Behavior Survey at three time points (at the 8 week program's finish $(\mathrm{T}=2), 12$ weeks since the program started $(\mathrm{T}=3)$, and 27 weeks since the program started $(\mathrm{T}=4))$ (see Figure 1 for a timeline of the study).

Research Design

Phase I- Reach, Effectiveness, Implementation 
Phase I of the data collection used a non-experimental design, incorporating an external evaluation of the program. Mixed methods (qualitative and quantitative) were used to cross validate findings with a combination of formal and informal evaluation processes. Several evaluation approaches were utilized; (1) a goal attainment evaluation, which uses the program goals to determine whether outcomes have been reached; (2) a goal free evaluation, which does not evaluate on program goals but seeks to discern any resulting outcomes; and (3) a case study analysis, which uses interviews and/or focus groups to examine how people view the program (House, 1980).

\section{$\underline{\text { Phase II- Maintenance }}$}

Phase II of the program evaluation addressed the effects of the program on participant behavior using a non-experimental repeated measures design. A repeated-measures quantitative assessment of outcome variables were conducted at three time points - eight weeks after the start of the program, then again at twelve weeks and twenty-seven weeks. Focus groups were conducted at four weeks post-program using a combination of a goal attainment approach (concerning whether goals of the program were reached) and goal free evaluation approach (concerning all potential outcomes and what participants thought of the program) to gather information from participants.

\section{Instrumentation}

Phase I of the program evaluation included: (1) an online nutrition knowledge quiz (see Appendix B), which provided for the comparison of nutrition knowledge before and after the program (scored as percentage of correct answers); (2) a program evaluation survey administered online (see Appendix C) at the end of the program, (which was primarily used to address the REAIM dimensions of effectiveness and implementation [see research questions]); (3) physiological 
measurements [i.e., percent body fat; body size; weight; blood pressure; resting heart rate] taken before and after the program. Facility utilization was assessed by analyzing student records of visits, which were kept electronically by the student recreation center. Demographic information pertaining to the student body at large was available on the university website.

Phase II of the program evaluation included a survey assessing levels of physical activity and various psychosocial constructs such as social support, self-efficacy and expectations, which are known to correlate with health behaviors (see Appendix D). This survey is a modified version of a 95-item survey previously used in research on college recreation centers (Zizzi, Ayers, Watson, \& Keeler, 2004). Questions assessing constructs irrelevant to the current study were removed, leaving 51 items. Items remaining included a rating of the importance of proper nutrition, weight control, and physical activity on a scale from 1 (not at all important) to 4 (very important); intentions for physical activity over the next month on a scale of one (not at all or very infrequently) to 4 (very active [5 or more days a week]); actual physical activity - measured by two yes or no questions pertaining to meeting physical activity recommendations and two questions comparing current physical activity levels with those during high school; an openended question pertaining to use of the facility before the Body for Break program (e.g. "last month of the fall semester"), physical activity outside of the recreation center during the last month, and a stages of change exercise status question on a scale of 1 (precontemplation) to 5 (maintenance); self-efficacy for exercise on a scale of 1 (very unsure) to 4 (very sure); social support for physical activity and for eating healthier on a scale of 1 (not at all) to 4 (a lot); barrier self-efficacy on five selected barriers on a scale of 1 (not at all confident) to 5 (extremely confident), exercise goal motivations (11 items) scored on a scale of 1 (strongly disagree) to 5 (strongly agree); health behavior importance (16 items) on a scale of 1 (not at all important) to 5 
(extremely important). Two questions pertaining to fast food consumption and skipping breakfast, suggested by Neimeier, Raynor, Lloyd-Richardson, Rogers and Wing (2006) as being associated with increased weight gain between adolescence and adulthood, were added. Two open-ended questions assessing intentions for using the student recreation center and asking whether the final Body for Break assessment was attended were also added. This survey was administered in-person at the end of the Body for Break program $(T=2)$, then online during the first and second follow-up $(\mathrm{T}=3, \mathrm{~T}=4)$

\section{Procedures}

Prior to collecting data, approval was obtained from the West Virginia University Institutional Review Board (IRB) for the Protection of Human Subjects. A cover letter outlining participation was given to participants prior to participation in the program evaluation and subsequent follow-up components of the study.

Phase I

Results from the pre- and post-program assessments, nutrition knowledge quiz (see Appendix B) and the program evaluation survey (see Appendix C) were obtained from program staff at the conclusion of the program. Quantitative data from the online assessments and physiological data from the initial and final assessments were delivered in Microsoft Excel, then imported into SPSS for data analysis.

The online program evaluation survey was available at the end of the program $(\mathrm{T}=2)$ to all participants in the Body for Break program via a link on the facility website. To ensure that it was completed, two computers were available with access to the survey during the final assessment for the Body for Break program, which was held March 11-12, 2009, from 8am $8 \mathrm{pm}$, in the wellness lab at the student recreation center. Focus group participants were also 
recruited during this time by asking individuals for their voluntary participation in the qualitative component of an evaluation study of the program and providing a brief letter outlining participation (see Appendix G). They were verbally informed of the meeting of the focus group in approximately four weeks $(T=3)$. As recommended by Kruger and Casey (2000), emails were sent to focus group participants one week prior to remind them about the scheduled meeting and briefly reiterate the importance of the study. At approximately twelve weeks $(\mathrm{T}=3)$ after the start of the program, the focus groups for program completers who attended the final assessment were held in a private conference room at the student recreation center. Participants discussed both an evaluation of the program and the short-term maintenance of behaviors that they took from their participation in the program. Topics for focus groups included initial reasons for joining the program, facilitators and barriers to success, overall experiences with the program, post-program impact and suggestions for program improvement.

Traditionally, it is recommended that focus groups pertaining to non-commercial topics do not exceed eight individuals (Kruger \& Casey, 2000); therefore the number of focus groups to be conducted was determined with an attempt to not exceed eight individuals in any group for the program completers. Resulting were two focus groups consisting of seven and four individuals, respectively.

Additionally, during the week of the final assessments, focus group participants were recruited via email from the pool of individuals that did not complete the Body for Break program (less than four weeks of participation). The focus group for non-completers was conducted the week after spring break $(\mathrm{T}=3)$ in a private meeting room at the Student Recreation Center. Kruger and Casey (2000) report that focus groups for non-users of a program can be larger than those for users, since there is usually less depth to the information reported. 
Therefore, one focus group for non-completers was determined to be sufficient. As the focus group for "non-completers" had low attendance $(n=2)$, four additional individual phone interviews were conducted with "non-completers" who were willing to share their experiences but could not meet at the scheduled time of the focus group.

For all focus groups, participants were given a cover letter outlining participation (see Appendix G) and a brief demographic questionnaire (see Appendix H). Pizza, salad, and beverages were provided as an incentive to participate and to help create a comfortable, informal setting. Focus groups were recorded using a both a digital audio recorder and a tape recorder and transcribed for analysis by the researcher and a trained research assistant.

$\underline{\text { Phase II }}$

All participants that returned for the Body for Break final assessment were initially recruited for Phase II of the evaluation. During the final assessment, the first of three administrations of the Exercise \& Nutrition Behavior Survey (Appendix D) was given to all attendees to be completed (see Figure 1). Concurrently, the follow-up portion of the study was explained. Participants were notified up front that they would receive a monetary incentive (\$5) for their participation through all follow-up points. A follow-up administration of the Exercise \& Nutrition Behavior Survey took place four weeks after the program concluded $(T=3)$. A link for the online survey was sent via email to participants that had completed the first Exercise \& Nutrition Behavior Survey. The last follow-up administration of the survey took place approximately six months after the program began $(T=4)$. Additionally, for those participants who did not complete the survey at the first notice, a second reminder was sent in mid-August. Seven additional participants completed the survey at this time. After completing the three 
surveys, participants were notified that they could pick up the incentive (\$5) at an office on campus.

Data Analysis

Quantitative data analysis. As modeled by Abildso (2008) in a evaluation of an insurance-sponsored weight management program using the RE-AIM model, descriptive and inferential statistical procedures were used to calculate values pertaining to the research questions on the dimensions of the RE-AIM framework, as suggested by Glasgow, Klesges, et al. (2006). Calculating these indices involves using effect sizes from multiple statistical tests and subtracting and/or multiplying these from one another and/or percentage values (Abildso, 2008). Also, as recommended by Glasgow, Klesges, et al. (2006), values for RE-AIM indices are displayed on a scale from zero to 100 .

Descriptive statistics were reported for participants, including demographics and values on each of the following physiological variables: body fat, weight, body size, resting heart rate and blood pressure (see Table 1). Differences in pre-assessment and post-assessment physiological values were analyzed by paired t-test and mixed-model repeated measures $2 \times 2$ ANOVA's.

Analyses from Phase II of the study included repeated measures ANOVAs to assess the differences among individuals on variables measured by the Exercise \& Nutrition Behavior Survey over the three data collection points (weight; social support for physical activity and for eating healthier; exercise self-efficacy; and barrier self-efficacy). Chi square analyses were used to calculate changes over time assessed via dichotomous variables (e.g. meeting physical activity recommendations). 
Qualitative data analysis. Focus group discussion topics were guided by the research questions through the RE-AIM framework and generated data in accordance with that structure. Verbatim transcriptions from the recorded sessions were produced. Codes were not created beforehand, but were developed subsequently from a review of all transcripts thereafter (see Appendix I). In order to ensure that the interpretation of the transcripts reflected the reality and ideas of the participants, two additional independent reviewers read and coded the transcripts. From this, a consensus on the codes was established. After all data was coded and categorized, it was analyzed for major concepts via axial coding, or the reassembling of categorized data into larger categories (Holloway, 1997). Findings from focus groups and interviews were organized and presented following the format used by Tavares and Plotnikoff (2008; see Table 2). Constant comparison was used throughout the data analysis process where the data was compared with other data obtained throughout the evaluation for not only confirmation, but differences and relationships as well (Holloway, 1997). The final step of the data analysis combined the information obtained via all methods to evaluate the program and answer the research questions on the dimensions of the RE-AIM framework.

\section{Results}

Per the mixed method model, where the two methods of gathering data are used simultaneously, most of the research questions are addressed with both forms of data. In quantitative data, effect sizes for chi squares are denoted by Cramer's Phi $\left(\varphi^{2}\right)$ or Cramer's V, Cohen's $d$ for paired-samples t-test, and the squared curvilinear correlation coefficient (partial eta squared; $\eta^{2}$ ) for repeated measures ANOVA. Means and standard deviations are reported for all descriptive data. RE-AIM concept definitions and index calculations can be found in Tables 3 
and 4, with Figure 2 depicting RE-AIM indices on 0-100 scales. Quantitative data will be presented for each RE-AIM dimension with qualitative support to follow.

Reach

The Reach dimension gives an evaluation of individual participation in the program, which includes the percentage of and characteristics of participants in the program, as well as their representativeness of the intended population.

RQ1a. What is the absolute number of participants in the program? The Body for Break program had 547 potential participants sign up using the online registration in early 2009 . Of those 547 potential participants, 405 subsequently completed the initial physiological assessment. Of those 405 program participants, 23\% $(n=93)$ completed the eight week program, defined as returning for the post-assessment.

RQ1b. What is the percentage of the eligible population (24,986 full-time students) that participated in the program? Of the 24,986 full-time students that were eligible for participation in the Body for Break program, 1.6\% (405) initially participated in the program. Thus, the Individual Participation Rate (IPR) for the program was .016 (405/24986).

RQ1c. Are program participants representative of the population of the student body (denoted by gender and year in school)? The Demographic Representativeness was calculated by comparing program participants with the full-time student body. The average age for the overall student population is 23.4 years. The average age for the program participants was 21.2 years $(S D=4.64)$.

For gender comparisons, Yates chi-square analysis revealed that a significantly greater percentage of women participated in the program $(83.2 \%)$ than would be expected compared 
with the percentage of women in the population of the full-time student body $(48.3 \%), \chi^{2}(1$, $N=24,295)=199.36, p<.0001, E S=.089$.

Concerning participants' year in school, the program was comprised of $24 \%$ freshman, $18 \%$ sophomores, $20 \%$ juniors, $24 \%$ seniors, and $14 \%$ graduate / professional students.

However, Pearson chi-square analysis showed that a larger proportion of the overall junior class $(23 \%)$ could be expected to participate in the Body for Break program than any other year, with the smallest proportion expected from the graduate / professional level $(-25.9 \%), \chi^{2}(4, N=$ $27,009)=30.02, p<.0001, E S=.033$.

Therefore, the overall Demographic Representativeness was .061 ([.033+.089]/2). The reach index value was calculated to be 1.5 ( 0 to 100 scale)

Qualitative data from focus groups and individual interviews $(n=17)$ yielded reasons for initial attraction to join the program. The prominent sub-themes that emerged included for physical reasons $(n=7)$ such as "lose weight", "tone up", or "get in shape", for the competition component $(n=5)$, to take advantage of services (e.g. personal training, dietician; $n=7)$, and for extra motivation $(n=5)$. A program completer described their initial reasons for joining the program:

I wanted to take advantage of the dietician and the other services that [the program] had. Like with the personal training, I didn't want to create my own workout so I figured I might as well use their services and hopefully they could create something for me that was gonna be useful.

Another completer described their motivation for participating: "I remember last year I didn't do the competition but I remember there were posters with before and after pictures [of the program participants] outside the door and I think that is what motivated me to do it." 


\section{Effectiveness}

The Effectiveness dimension gives an evaluation of the degree in which the target variables of the program (e.g. body fat, fitness, nutrition knowledge) changed among participants as an immediate result of program participation. Positive and negative outcomes of the program among participants were assessed via quantitative and qualitative methods.

RQ2a. What is the average change in target variables among participants who complete the program? Of the 405 participants that completed the program's initial assessment, 93 returned to complete the post-assessment making the Individual Completion Rate .23 .

Paired-samples t-tests confirmed that all measures significantly differed from the initial assessment to the post-assessment (see Table 5), with effect sizes that ranged from small to large. The participants showed many significant changes including an average weight loss of 5.7 pounds $(S D=18.9), t(92)=2.91, p=.004$; an average decrease in BMI of $.57 \mathrm{~kg} / \mathrm{m}^{2}(S D=.91)$, $t(91)=6.02, p<.001$ an average decrease in resting heart rate of 8.8 beats per minute $(S D=$ $16.9), t(89)=4.95, p<.001, E S=.609$; an average decrease in systolic blood pressure of 5.77 $\operatorname{mmHg}(S D=13.2) t(89)=4.16, p<.001$; an average decrease in diastolic blood pressure of $4.41 \mathrm{mmHg}(S D=11.8), t(89)=3.55, p=.001$; an average decrease in body fat of $1.4 \%(S D=$ $2.7), t(88)=4.82, p<.001, E S=.155$; and an average decrease in waist girth of .77 inches $(S D$ $=2.12), t(91)=3.51, p=.001$. Results from the initial knowledge test compared with the posttest were not significant $(p=.758)$, thus there was no evidence that nutritional knowledge changed from pre- to post-program. It should be noted that the knowledge quiz consisted of 4 questions, which may not have provided for an appropriately sensitive measure. Therefore, the Outcome $_{\text {Eff }}=.25([.61+.155+-.013] / 3)$. By removing the knowledge target variable from the equation, the adjusted Outcome $\mathrm{Eff}=.38([.61+.155] / 2])$. 
$R Q 2 b$. Do completers of different gender and year in school experience different outcome changes for target variables? Several two-way univariate repeated measures ANOVA revealed no significant interactions over time for gender and year in school for body fat and gender $(E S=$ $.015)$, body fat and year in school $(E S=.013)$, resting heart rate and gender $(E S=.089)$, resting heart rate and year in school $(E S=.004)$, knowledge and gender $(E S=.005)$, and knowledge and year in school $(E S=.057)$. However, the moderate effect evident in changes in resting heart rate and gender exemplifies that the average change in resting heart rate is larger for males (-11 bpm) than females (-8 bpm), which may have been significant had a larger sample size been used. Thus, the value of the overall Effectiveness was calculated by multiplying the Individual Completion Rate $(\mathrm{ICR}=.23)$, the averaged Outcome $\mathrm{Eff}\left(\mathrm{O}_{\mathrm{Eff}}=.38\right)$, and the Differential Impact $(\mathrm{DI}=[1-.03])$ resulting in an overall effectiveness index of 8.5 (0 to 100 scale).

RQ2c. What positive results of the program were experienced by participants? From the qualitative data, the most prevalent sub-themes of positive results were physique improvements ( $n=11)$ (e.g., weight loss/ inches decrease/ body fat loss), increases in knowledge $(n=10)$, and increases in motivation $(n=7)$.

A program completer described positive physique effects: "My main goal... was to be more toned and build more muscle mass and I saw that happening throughout the whole time. Throughout the week, like look in the mirror and see, ya know, that was motivation" and another emphasized: "I lost weight like really, really quickly!" Some moderate positive effects were described, as well: "I had been trying to lose weight...I did have some progression but not as much as I thought" and "I did not have huge success with the program - I only lost $2 \%$ body fat. But my boyfriend said that he could notice the difference and that was really good." 
A program completer described an increase in knowledge: "My first couple of weeks were actually the best when I was meeting with my trainer. Because it was new to me, he was teaching me new things. I got into it and I started looking at classes.” Another program completer discussed knowledge: "I would tell [the trainers] what I was doing and ask for their advice and they would give me tips and everything, so that kept me going, as well" and "I learned exactly what I should be eating after a workout." A non-completer described an increase in motivation as a result of the program: It encouraged you to set goals for yourself...I didn't think I was going to be able to keep up with it, but I mean I got some encouragement so I kept up with it. They wanted you to go to the gym, I think, 3 times a week and I wasn't used to that, [but] I started going more.

Another completer summed up their experience: "Overall, the program did wonders for me."

RQ2d. What negative results of the program were experienced by participants? Data was gathered by qualitative analysis of interviews/focus groups with the addition of one question on the post-survey asking "Did you experience any injuries as a result of your participation in the Body for Break program?" and if so, to please explain. Concerning injuries obtained as a result of participating in the program, the post-program survey showed that $4.3 \%$ of completers reported an injury. These injuries were described as: "a back injury", "migraines", "shin splints from running", and "former knee injuries acted up". In addition, a program completer described an injury incurred during the program:

I hurt my back doing one of the workout things that the trainer had given me. I hurt my lower back and it still gives me trouble... I keep straining it every now and then...It was 
like the biggest thing because it's still affecting me now.

A program non-completer illustrated a similar experience: "I was in a car accident a few years ago and I have a bad back and I told [the trainer] that. And a lot of the exercises that he gave me to do really hurt."

The major sub-theme that emerged illustrated a perceived lack of effectiveness of the program. Most often, comments pertained to not losing weight and/or not seeing results in general. Interestingly, a majority of these comments came from individuals that completed the program. In example, program completers discussed their lack of results: "I didn't change my numbers, they stayed pretty much exactly the same so I didn't see any improvement or anything - kind of a bummer" and "I didn't change at all over the eight weeks...so I'm at a loss about what I need to do." Another completer summed up their experience: "I didn't get a lot out of it." In addition, one completer stated: "I gained weight! I don't know why."

\section{Implementation}

Implementation refers to the extent to which the program was implemented as anticipated. This dimension was examined on the individual level, which represents the "dose" of the intervention program they received (RQ3a, RQ3b).

RQ3a. To what extent did the participants implement the Body for Break Program components? The program was designed with four components: personal training, a dietician, weekly motivational / informational emails, and a support group. The use of any or all of the components was optional. Component utilization was assessed via two informational sources: the program evaluation survey, which was administered online at the end of the program, and through focus groups and interviews. 
Of the 100 individuals that completed the program evaluation survey, $72 \%$ read the motivational emails, $73 \%$ used the personal training component, and $37 \%$ used the dietician. Due to a lack of interest from participants, the support groups were cancelled and thus, not delivered as a program component. However, because the component would have been delivered had participants shown interest, it is calculated into the Component Participation Rate. The Component Participation Rate was calculated as the sum of the components actually used out of 400, which would have been the value if all participants used all components. If all 100 participants used all originally offered components, the index value would be 100 (e.g. 4 components $* 100 \%$ use $=400,400 / 4=100)$. The Implementation Indiv $_{\text {index }}$ was calculated to be 45.5 ( 0 to 100 scale).

Reasons for the extent of the component utilization not related to quality were gathered from qualitative data. For the personal training component, the most common sub-themes from participants were that they did not use the service $(n=7)$ and an equal number reported consistently using the service $(n=7)$. Other sub-themes described varying use (e.g. used once $(n=4)$, only used early in program $(n=3)$. For the dietician component, the prominent subtheme was that they did not use the service $(n=10)$. Half of the individuals who did not use the dietician cited that it was because they used their own diet plan $(n=5)$. For the weekly emails, use was determined to be reading the email. The major sub-themes were that participants either read fully $(n=7)$ or read through a few $(n=5)$. For those reporting not fully utilizing the weekly emails, the major reason cited was that they already knew the information $(n=5)$.

RQ3b. Did participants use all program components offered to them? As a result of the cancellation of the support groups, zero $(0 \%)$ of the participants utilized that component. Thus, none of the participants used all program components originally offered to them. Approximately 
$15 \%$ of individuals that completed the program evaluation survey utilized all of the three offered components.

Because there were several items on the program evaluation survey to evaluate the support groups even though they were not conducted, several participants indicated that was the first time they heard of them. One response stated: "I didn't know anything about the support groups and I was trying to see if there was one." As well, a program completer commented: "I don't know how they had [the support groups] set up but that could have been useful."

Enough of the participants commented on effectiveness having to do with fully utilizing the program - either for themselves or as advice to others - that it emerged as a sub-theme in the qualitative data. An individual that did not complete the program lamented: "I should've been more involved with the program." Several program completers offered a recommendation from their experience: "I would recommend for someone to take advantage of all of the components at least once... to make sure that your head is in the right place and that you have a clear path to reaching your goals" and "Take advantage of the resources that are here for you...you may think that something may not be helpful for you, but try it at least once, you never know. Utilize resources."

RQ3c. How did participants rate the quality of program components? The personal training component had an average quality rating of $4.56(S D=.12)$, the dietician component had an average quality rating of $3.54(S D=.27)$, and the weekly emails component had an average quality rating of $3.71(S D=.14)$. For the undelivered support groups, the average quality rating was not calculated. Therefore, the average quality rating of the three delivered components was $3.94(S D=.72)$, leading to an overall value for Implementation Org $_{\text {of }} 79(0$ to 100 scale). 
Concerning the personal training component, the most common positive sub-theme was that the participants liked the workout $(n=7)$ given by the trainers. Another sub-theme common among the program completers was that trainer was "good" $(n=12)$ (e.g. knowledgeable, motivating, and/ or "nice"). For example:

[The trainer] always told me if I was doing something wrong and [he/ she] wasn't just there to spot me. [He/she] made sure everything I was doing was right and the proper weight, made sure really any little technique thing that I did wrong [he/she] would correct me on it.

And: "I really liked [my trainer]. [He/she] motivated me, telling me to keep coming to the gym."

Of all of the qualitative codes generated during the analysis, negative personal training experiences $(n=58)$ occurred most frequently. The participants unanimously agreed that a foremost negative factor was that the appointments were hard to schedule $(n=17)$ due to several reasons including a high demand for the service and coordinating availability with their schedules. Several program non-completers described: "I remember being upset that I could not get a personal trainer. One was just never assigned to me" and "I was like 'this is pointless'. The whole scheduling was a nightmare - just trying to get a trainer to begin with was a nightmare." Another issue related to scheduling was pointed out by a program completer: "I had a trainer and [he/she] was good, but I wasn't able to meet with them at that time so I had to switch trainers again. That was not so great."

Another prominent negative factor affecting the quality of the personal training services was the trainer's lack of knowledge ( $n=13$; e.g. about program, training, and/ or injury). This 
reason was almost unanimously cited by program non-completers. A participant relayed an adverse experience with a trainer:

I was just really turned off by the fact that my trainer didn't know what [he/she] was talking about. I just had surgery on my upper body and I told [the trainer] about that and he was just like showing me all of these upper body exercises, and my muscles were really sore and I wasn't supposed to be working them out. You know, I had to tell [the trainer] like 2 or 3 times like "I can't be doing upper body just lower body" and I was turned off by [the trainer's] lack of knowledge and [by] the fact that someone wouldn't be meeting with me three times a week...My experience was negative as a result of my trainer not being knowledgeable.

Another similar experience was stated by a program completer: I was stretching by the upstairs weight room and I saw this trainer training this poor girl who kept putting, well they were doing squats and the girl kept putting her knees over her toes and the trainer didn't say anything so that really turned me off. I was really concerned that the trainer was training people like that.

In addition, not happy with training routine $(n=7)$ and trainer disregarded client's concerns $(n=7)$ were also frequently cited sub-themes.

Concerning the dietician component, the positive dietician experiences $(n=4)$ that emerged from the data were scarce. However, one completer did describe a positive experience with the dietician: "I did really like the dietician. I got a lot out of her. I'll probably go see her again before the end of the semester. I really liked her services and I thought she was very knowledgeable." 
The negative dietician experiences $(n=14)$ that were most frequently cited were hard to schedule $(n=5)$ and not helpful $(n=7)$. It should be noted that not helpful was exclusively stated by program completers. Concerning scheduling trouble, reasons cited had to do with not knowing how to get in contact with the dietician as opposed to the shortage of availability that was cited for the personal training service. A program completer described his/her trouble:

It was hard to schedule with the dietician. You had to email her to get signed up and then she emailed you and then you had to go back and forth and she's like well when do you have time and then you're like well when are you there. It would have been easier if there would have just been a sign-up sheet at the rec center where you could sign up in [an available] time slot. I think it would have made that process easier to go through and easier to access the dietician.

Concerning the dietician service not being helpful, several participants described their encounter: "I knew the dietician but she really didn't help me in the sense I was looking for...Because I was doing Body for Break I was looking for a more intense kind of thing, she didn't help in that regard" and "even when I tried to do the extra stuff like the dietician I wasn't satisfied with it. I didn't get a whole lot out of it" and more specifically:

I thought I would get a more descriptive and precise way of planning meals instead of “substitute turkey for ground beef then you'll save some calories and it's healthier for you." It was stuff that everyone knows. It didn't help at all. It was too generic and it was to the point where it was just made for someone who doesn't know anything about eating healthy...so if you had any knowledge past base level it was pretty pointless.

Throughout the focus groups and interviews, the weekly email was not a frequently discussed component. Therefore, there were not any positive codes generated in the qualitative 
data. The two negative factors associated with the weekly emails were that there was too much $(n=3)$ in them (e.g. attachments, links) and that participants did not like that they were required to use their university email accounts $(n=2)$ as opposed to being able to choose the email address that they provided.

One participant described: "I remember opening one of the emails, like the first one they sent out, and it had some stuff on it and I said 'what is all of this information?!' It was overwhelming."

Concerning participants being "turned off" by the program early on, the primary subtheme revolved around general confusion at the start of the program and negative experiences with the personal training component of the program.

A program non-completer acknowledged an initial "turn off" related to the personal training component of the program:

I just think that the program the she set me up with and the response that I got as far as "why are you here?" type of thing. It wasn't necessarily like "why are you here" to figure out what type of program I should be on but more of like a "you really don't need to lose weight" type of thing... I just think that that kinda set the whole tone for the program for me.

Another program non-completer described a misconception about the program: "I was under the impression that I was going to be meeting with someone every time I go to the gym, 3 days a week, you know, and that really wasn't the case at all."

A program completer describes something that was a "turn off”: "...I thought it 
started off a little weak. The made it sound like it was a big thing for Body for Break...then the second it started it was like "I'm here for Body for Break" and no one even knew what you were talking about".

In agreement, another program completer described initial confusion: "Yea, they didn't say what to do...maybe a little more personalized attention [for program participants] in the beginning".

\section{Maintenance}

The maintenance dimension gives an evaluation of the degree in which the target variables of the program (e.g. body fat, fitness, nutrition knowledge) changed among participants over time after the program concluded. Positive and negative outcomes of the program among participants were assessed via quantitative (at two longitudinal time points) and qualitative methods (at the first of the two longitudinal time points). This dimension was examined on the individual level (RQ4a, RQ4b).

RQ4a. What were the effects of the intervention (in weight, meeting physical activity recommendations, exercise self-efficacy and barrier self-efficacy) during the follow-up? At 4 weeks post intervention ( $T=12$ weeks)? At 19 weeks post intervention ( $T=27$ weeks)? Of the 93 participants that completed the program's final assessment, 26 completed all three of the assessments comprising the Maintenance dimension of this study making the Individual Completion Rate .28. The Individual Completion Rate pertains only to this study, and not to the completion of additional participation in any aspect of the program post-program.

Self-reported weight changes among participants were analyzed using a univariate repeated measures ANOVA corrected for violating the assumption of sphericity with the Greenhouse-Geiser method. With the sub-sample of participants who completed all data points 
$(n=26)$, no significant differences were evident in weight changes post-program across all three time points, $F(1.402)=2.471, p=.115, E S=.093$, although trends indicated a moderate regain effect of 1.78 pounds $(S D=5.0)$. However, since participants exhibited a slight weight loss of .17 pounds $(S D=3.2)$ from the first to second assessment, pairwise comparisons did reveal a significant average weight gain of 2.1 pounds $(S D=.96), p=.037$ between time points two and three.

Chi-square comparisons revealed no significant difference in participants meeting recommended levels of physical activity between the time points, $\chi^{2}(2, N=159)=4.39, p=$ $.112, E S=.17$, indicating that meeting physical activity levels is independent of time elapsed since the program. However, trends showed sizable decreases in percentages meeting recommended levels of physical activity from four-weeks post-program to 12 -weeks postprogram for all $(n=26)(-23.2 \%)$, females $(n=18)(-9.5 \%)$, and males $(n=8)(-46.5 \%)$. Although non-significant due to sample size issues, the strength of this relationship is moderate, as denoted by Cramer's V.

Univariate repeated measures ANOVA revealed no significant changes over time for both exercise self-efficacy, $F(2)=1.271, n s, E S=.048$, and barrier self-efficacy (corrected for violations of sphericity using Greenhouse-Geiser estimates of sphericity), $F(1.336)=3.639$, $n s$, $E S=.054$, with both showing decreasing trends. Although not significant, the effect illustrates a relationship of moderate strength among both variables indicating that the lapse of time since the program is moderately related to the decrease in exercise self efficacy and barrier self efficacy.

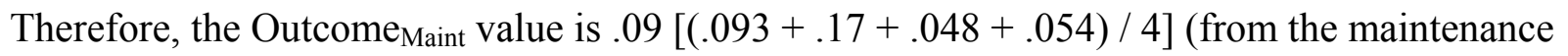
equation $[.28 * .09 *$ [average of $[1-\mathrm{ES}]$ for the 4 variables] $* 100])$. Therefore, a Maintenance index value of 2.6 / 100 was yielded. 
Qualitative data obtained one month after program completion revealed that most participants were still keeping up with at least some portion of the program (e.g. continuing to exercise/ follow their trainer's plan, following diet) and barriers to doing so included time constrictions and decreases in motivation. A completer shared: "I'm still meeting with my swim trainer and everything. But it's just not motivating for me at all.” A non-completer accounted advantageous effects of Body for Break:

I developed some really good habits; like I still go to the gym everyday and I come home and do my class work...so I found a really good balance, and I can [attribute] that to the Body for Break program because getting into a routine sometimes is kind of hard, but I found one.

RQ4b. Do completers of different gender and year in school experience different outcome changes for target variables? Because of the low return rate of follow-up surveys, year in school was removed from the analysis. Concerning gender and weight, a 3 (Time) x 2 (Gender) mixed model repeated measures ANOVA revealed the interaction of time and gender was not significant (corrected for violations of sphericity using Greenhouse-Geiser estimates of sphericity), $F(1.355)=.706, p=.081, E S=.30$. However, a large effect size $(E S=.30)$ indicates a meaningful interaction between gender and weight changes over time where males lost an average of 1.9 pounds between the end of the program and four weeks later, but gained an average of 3.8 pounds at the end of the 19 week maintenance period. The weight of females showed a very small change $\left(M_{1}=154.1, M_{2}=153.9, M_{3}=155.3\right)$ throughout the three data collection points (see Tables 6 and 7).

Chi-square analysis revealed no significant difference between gender for meeting physical activity recommendations between time one and two, $\chi^{2}(1, N=94)=.58, p=.446, E S$ 
$=.11$. Due to the low response rate for males at the final testing point, analyses could not be run for comparing the second and third time by gender.

A 3 (Time) x 2 (Gender) mixed-model repeated measures ANOVA was run for exercise self efficacy and barrier self efficacy. The interaction between exercise self efficacy and gender was not significant, $F(2)<1, n s, E S=.003$. The interaction between barrier self efficacy and gender was also not significant (corrected for violations of sphericity using Greenhouse-Geiser estimates of sphericity), $F(1.356)=1.339, p=.267, E S=.053$. Thus, changes in exercise and barrier self efficacy over time are not different per gender (see Tables 6 and 7).

Correlations run between dependent variables showed that exercise self-efficacy, barrier self efficacy, and meeting recommended levels of physical activity were not significantly correlated with weight changes over any of the three time periods.

\section{Discussion}

Many program evaluations focus solely on changes in variables assessed immediately before and after the intervention, thus focusing solely on the effectiveness dimension. Problematically, this mainly addresses internal validity while neglecting external validity. Dzewaltowski et al. (2004) illustrated this when they reviewed 119 outcome studies and found that $92 \%$ of those studies addressed the effectiveness of a program (effectiveness) and $76 \%$ assessed the sample size and participation rate (reach). However, the other RE-AIM dimensions were assessed in less than $50 \%$ of the studies.

The Body for Break program was evaluated on the reach, effectiveness, implementation (both individual and organizational level), and maintenance dimensions of the RE-AIM model. Reach $(\mathrm{R}=1.5)$, effectiveness $(\mathrm{E}=8.5)$, and maintenance $(\mathrm{M}=2.6)$ were low, with moderate implementation on the individual level $\left(\mathrm{I}_{\text {Indiv }}=45.5\right)$ and high implementation on the 
organizational level $\left(\mathrm{I}_{\text {org }}=79\right)$. The overall measure of the intervention impact was calculated to be 27.4 out of 100. Explanations for these values will be described in subsequent sections of this discussion. Finally, advantages and disadvantages of using the RE-AIM model for small scale, single-site program evaluation will be highlighted, as well as suggestions for program improvement.

Reach

The population effect of the Body for Break program was very low with a reach index value of 1.5. The program recruited participants from the collective student population via advertisements in the school newspaper and postings on the school webmail page, as well as flyers hung around various high-traffic areas on campus. The program also included incentives (prizes) for participation, which have been shown to have beneficial effects on reach in other behavioral nutrition and physical activity programs (Robroek, van Lenthe, van Empelen, \& Burdoff, 2009). Although the program required payment of a ten dollar fee, the review by Robroek et al. (2009) also found that fees were not identified as a barrier to participate in such programs and this was not named as a barrier by participants in the current study either.

Concerning gender representativeness, the participants of the program were overwhelmingly female (83.2\%), compared with the percent females in the target population (48.3\%). A similar percentage of female participation (80\%) in an insurance sponsored weight management program was reported by Abildso (2008) and, as he noted, also in that of the National Weight Control Registry (Klem, Wing, McGuire, Seagle, \& Hill, 1997). Thus, this ratio of gender participation may be a function of gender preference for lifestyle interventions across multiple samples and not a function of recruiting or advertising of this program. However, one sub-theme emerging in the qualitative data illustrated a need for prizes for both genders, as it was 
suggested by half of the focus group participants that the prizes were overwhelmingly femaleoriented (e.g. a bikini wax at a local salon), which may have not served as an effective incentive for men to participate. Additionally, as U.S. females report lower levels of physical activity than do males across all age groups (USDHHS, 2008), this may lend support to the reach of this study in that the program was used by those needing it most. There is sufficient evidence, however, supporting that males' needs concerning nutrition education and remediation are greater than those of women (Cousineau, Franko, Ciccazzo, \& Goldstein, 2006), in which case this program could need to adjust recruitment to increase male participation.

Because the program used a fairly intensive, specialized intervention requiring sufficient staff resources, it would not have been feasible for the program to accommodate enough of the target population to achieve significantly higher reach. Hypothetically, a low-moderate reach index value of 33.3 could be achieved only if the program had 8,860 participants, which would be 22 times the actual number of participants. As evident in the qualitative data, prominent subthemes were the lack of available personal trainers, overcrowded facilities, and scheduling difficulties while accommodating only $1.6 \%$ of the full-time student population. Further, one participant summarized: "They seemed overwhelmed." This hypothetical example can be extrapolated to conclude that, likely due to availability and resource allocation, the program could not accommodate a sufficient amount of the population to arrive at even a low-moderate reach (assuming in-person service delivery and similar program structure). It is possible, as well, that an increase in reach could reduce an already low effectiveness if intervention staff and resources are not also increased. 


\section{Effectiveness}

The effectiveness of the program was low at an index value of 8.5. The targeted variables of body fat loss and resting heart rate both significantly decreased among participants $(1.4 \%$ and 8.8 beats per minute respectively), however, there were not any changes in nutrition knowledge. This lack of effect could potentially be due to several reasons: (1) the instrument, using only four questions, may not have been sensitive enough to identify changes in knowledge; (2) the use of the dietician, as with all other components, was optional and only $37 \%$ reported using the dietician; and (3) the dietician service received the lowest quality rating of all offered components.

In addition to the target variables, all other measured variables demonstrated significant changes from baseline to the end of the eight week program including weight (-5.7 pounds), BMI $\left(-.57 \mathrm{~kg} / \mathrm{m}^{2}\right)$, systolic blood pressure $(-5.8 \mathrm{mmHg})$, diastolic blood pressure $(-4.4 \mathrm{mmHg})$, and waist (-.8 inches). These changes are similar to those shown in Ferrara et al. (2008) at the end of their semester-long weight loss contest program $(n=39)\left(-3.2\right.$ pounds, $-1 \mathrm{~kg} / \mathrm{m}^{2} \mathrm{BMI},-1.6 \%$ body fat) and the authors suggest that changes may be due to increases in self-efficacy and social support. Jozkowski (2007) noted that although changes in outcome measures as a result of participation in a weight loss intervention program were not significant, participants all reported increases in self efficacy and social support. In the current sample, exercise self efficacy, barrier self efficacy and social support at the end of the program were not significantly correlated with changes among any of the outcome variables and trends over time did not show increases in selfefficacy scores.

While the physiological changes for those who completed the program were satisfactory, the RE-AIM index calculation for effectiveness takes into account the completion rate, or those 
receiving the treatment for the pre-determined duration of the program (Glasgow et al., 2006). The overall effectiveness was substantially decreased by the high rate of dropout $(77 \%)$. This rate is substantially greater than the dropout rate in other similar programs for college students that ranged from 54-60\% (Ferrara et al., 2008; Jozkowski, 2007; Scott, Murray, Pellerito \& Schaffer, 2000). A potential limitation in the calculation toward the overall effectiveness of the intervention is that participants who participated in the program for the full eight weeks but then did not return for the final assessment were included in this dropout rate. However, from facility attendance records for 396 of the program's initial participants, 188 participants did not attend during both the six and seventh week of the program (complete data for the eighth week was unavailable). Further, the program defined the desired rate of attendance at a minimum of three times per week in order to be eligible for the weekly prize drawing. During weeks six and seven, on average, 98 individuals enrolled in the program were meeting this requisite, which is only five more than the number of participants returning for the final assessment, thus the program completion rate $(23 \%)$ seems fairly accurate.

As defined by Glasgow et al. (2006), to be effective a program must do more good than harm illustrating the need to assess both desired outcomes (e.g. program goals) and possible negative outcomes as well. While negative results of the program were scarce it should be noted that $4.3 \%$ of the 93 program completers experienced some type of injury during the program. A suggestion by a program completer suggested having a physical therapy or athletic training intern on-site for participants during the program.

\section{Implementation}

The implementation dimension was measured on two levels: the individual level and the organizational level. Index scores on both of these levels were the highest among all the indices 
examined in this study at 45.5 and 79 , respectively. These rates were similar to Abildso (2008) and Glasgow, Nelson, Strycker, and King (2006), who found implementation indices higher than the other indices examined (rates for implementation exceeded 90 in each case). This finding may have to do with the fact that this is primarily a setting-level dimension and does not depend on the participants of the program (and all of their potential extraneous variables) for the values in the calculations as heavily as the individual-level dimensions.

On the individual level, the nutrition component of the Body for Break program was the least implemented of the offered components among the participants. Suggestions for improving the accessibility of this component arose from the qualitative data, which included making the scheduling procedure for the service less difficult by using a signup sheet with available time slots versus emailing back and forth with the dietician. An additional suggestion could be to deliver the nutrition education component online, such as in an online course format. Several studies support the efficacy of internet-based nutrition and physical activity education on increasing nutrition knowledge (e.g. Franko et al., 2008) and show that these programs are feasible (Cousineau et al., 2006). The convenience of an online component may also help participants deal with time restraints, which was cited as the most common barrier among participants.

Also, the use of program components was optional. Therefore, it is difficult to determine the dose of the program that participants received, potentially affecting the overall effectiveness of the program. Implementation on the organizational level was measured as the only dimension with a "high" impact value. This value was calculated using the quality ratings given by participants on the program evaluation survey and appraised how well the components were implemented by the organization. Though quantitative data supported a high implementation 
(quality) rating, there was some discrepancy when this result was triangulated with focus group data as the qualitative data indicated that participants may have had more negative experiences related to component quality. The most frequently occurring theme throughout the qualitative data pertained to negative experiences with personal trainers, more specifically that appointments were hard to schedule and trainer's lack of knowledge (e.g. about program, training, and/ or injury). This drawback could have been especially detrimental to retention, as physical reasons (e.g."lose weight", "tone up", or "get in shape") and wanting to use personal training service were commonly stated as reasons for program participation. Suggestions for improvement include increase number of trainers, educate trainers on Body for Break program, and generally increase quality of trainers. It may be cost-effective to also administer a component of the personal training service online, such as suggested for the dietician service. This strategy would maximize the amount of participants that could utilize personal training services in a given amount of time, especially when the participant is already knowledgeable on how to perform the exercises but simply needs a training plan. In-person trainers could be made available for individuals who are less knowledgeable or who are at higher risk (e.g,. obese or diabetic).

While overall levels of implementation were high compared to the indices of the other dimensions in this study, the negative effects of removing support groups may have contributed to the low effectiveness and low completion rates. There is ample support in relevant literature highlighting the need for social support in health behavior adherence and in minimizing program attrition rates. Wing and Jeffrey (1999) described a successful weight management intervention that incorporated social support by not only encouraging participants to sign up with their friends, but by offering social support interventions throughout, which would have been covered by the support groups. Strong et al. (2008) concluded from their study on college students that 
interventions for this population should instill skills in goal setting and planning while incorporating social support to facilitate adherence. The reason cited for not implementing the social support groups was a lack of interest among participants even though one-third of the focus group participants cited lack of social support as a major barrier. In fact, most participants reported that they did not even know groups were being offered. Some even accounted that they were looking for something meeting such needs. Qualitative suggestions for improvements frequently had to do with scheduling training in groups and set up with work-out buddy. Further, better advertising for support groups, have trainers call clients to check in, and advice to do the program with friends were also mentioned illustrating the participants' need for an increase in social support.

The implementation dimension, as evident in this study, is the least sensitive of the dimensions with regard to sample size. The sample size of participants was very small in all dimensions being evaluated in this study, and thus, this limited impact is evident in the low values for indices. However, implementation (as defined by this study) is not dependent on sample size and may be the most translatable of the indices when using the RE-AIM model to evaluate a smaller scale program.

\section{Maintenance}

By definition, the maintenance dimension aims to measure the long-term effectiveness of a program, such that the longer time after the intervention that an individual maintains the intended behavior(s), the longer the efficacy of the intervention (Estabrooks \& Gyurcsik, 2003). Using a modified formula, the individual maintenance index value of this study was calculated to be the low at a value of 2.6, indicating that in addition to the low efficacy of the study, the longterm efficacy was even lower. It should be noted, however, that this index was calculated using 
the individual completion rate with the ratio of participants that completed the follow-up study (28\%), and was not related to the continuation of any part of the program. While others studies have calculated values in terms of research objectives (e.g. Courneya, Estabrooks, \& Nigg, 1997), this attempt at calculating program maintenance likely missed the mark, and represents a limitation in the current measurement approach.

It is assumed that most programs targeting health behavior change want long-term effectiveness. However, for this particular program the name itself may deter clients from thinking of this intervention as a long-term lifestyle change and more as preparation for a oneshot event. "Body for Break" was primarily advertised as an eight week program starting early in the semester and concluding the week before spring break that could help college students get their physiques fit for spring break and for wearing a bathing suit. Inherent in this advertisement and in the portrayal of the program may be the idea that the end goal of the program is spring break and not meant to be sustained for additional time thereafter. It should be noted that the program administrators were contemplating adding a 'beyond' component to the Body for Break program (e.g. Body for Break and Beyond) but decided not to as they were ending the program before spring break. In the future, there is the possibility that this component would be added to the program to continue after spring break (C. Harshbarger, personal communication, February 3, 2009). An addition of a component focusing on long-term goals could help to increase the maintenance of program results.

\section{Limitations of the Study}

First, procedures and measurements by which evaluations are based were not standardized. Namely, body measurements (e.g., thigh and waist circumference) were conducted by several individuals potentially utilizing different techniques both within assessments and 
between assessments. Also, body fat and weight were measured using electrical impedance with a Tanita-brand scale. This equipment had an option to account for clothing weight, as well as different settings for 'athlete' and 'normal'. As these specific settings were not recorded at baseline, it is unknown if these settings were kept constant between the initial and final assessment. In addition, the maintenance dimension of this study was assessed using a survey that may not have been sensitive enough to identify changes in variables when administered over multiple time-points.

Concerning the purpose of the program as a "fitness and nutrition education program", measuring the effectiveness of the program on these particular variables was limited in that there were not any direct measures of fitness taken, such as $\mathrm{VO}_{2}$ max or a more comprehensive fitness test such as the ACSM Fitness Testing Battery (American College of Sports Medicine, 2003). Nutrition knowledge was assessed by only four questions. In line with this, suggestions include incorporating direct measurements of fitness and analyzing nutrition knowledge via a validated questionnaire, such as the 63-question modified Nutrition Knowledge Test (Franko et al., 2008). Evaluating the RE-AIM Framework as a Model for Single-Site Evaluation

Although it provided a useful framework for program evaluation in the current study, the model is limited in single-site evaluations. The framework provides an outline for assessing the individual level impact (reach, effectiveness, implementation $_{\text {Indiv }}$, maintenance $_{\text {Indiv }}$ ) and

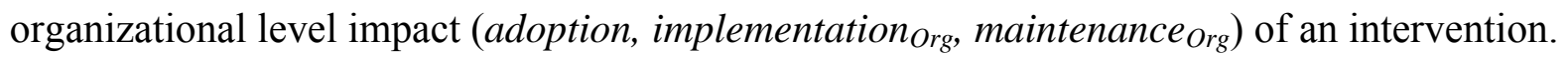
Since the Body for Break program was delivered at one site and was time delineated, it was not possible to measure adoption and maintenance on the organizational level as defined in the framework. Thus, the model lends itself to assessing individual-level impact versus organizational-level impact in small-scale intervention evaluations. These three organizational- 
level dimensions, while equally important, are less often reported throughout the literature (Bull, Gillette, Glasgow, \& Estabrooks, 2003; Glasgow et al., 2006). In addition, a major feature of the RE-AIM framework is its focus on the long-term sustainability and effectiveness in real-world settings instead of a short-term focus on a small sample (Glasgow, McKay, Piette, \& Reynolds, 2001), like with the Body for Break program evaluation. However, while some of the utility of the RE-AIM framework may be diminished when using it to evaluate a small-scale, single-site program, it provides for a more thorough evaluation than would a simple post-program survey taken by the retained participants. The RE-AIM framework might best be used in conjunction with qualitative assessments on each of the dimensions to ameliorate such shortcomings and ascertain information that may not come through in the quantitative evaluation.

\section{Future Suggestions for Research and Practice}

The RE-AIM model does not provide methods to change the evaluated outcomes. Thus, the onus is placed on the evaluator to make suggestions for improvement. Few programs have targeted college students in particular (Gokee-Larose, et al., 2009b; Nelson et al., 2008) and most research on weight-loss and/or fitness programs efficacy is conducted on other populations such as children, adolescents and older adults (Gokee-LaRose et al., 2009a). Thus, since most individuals over the age of 18 are considered 'adults' they are delivered the standard 'adult' (ages 18 - 65) intervention, which may not be the most efficacious for young adults given their unique developmental considerations. In fact, Gokee-Larose et al. (2009a) determined that young adults are dramatically underrepresented in weight-loss trials, showed significantly less weightloss than older participants, and that lower attendance and retention among young adults contributed to those findings. They suggested strategies such as shorter duration of treatment and tailoring topics to the age group were effective in drastically increasing attendance and retention, 
as well significantly decreasing weight over the 10 -week program and maintaining this loss to the 20-week follow-up (Gokee-LaRose, et al., 2009b). Gokee-LaRose et al. (2009a) also suggested that program advertising focusing on health-messages may not be as effective for recruiting young adults as is it for older adults. Interestingly, Body for Break did all of these things: although there was not an age-limit on eligibility, the average age of participants was 21.2 years; the program was a short duration of eight weeks; and the primary marketing strategy appealed to vanity and not health. Even with all of these suggestions covered, the Body for Break program exhibited a low impact on this population of young adults. Gokee-LaRose et al. (2009a) acknowledged that the above suggestions have not been adequately researched within the target population and called for future studies to address these issues via qualitative research. Thus, the information ascertained by the qualitative component of this study could serve to fill a deficiency in the relevant literature and help inform suggestions for the Body for Break program and similar programs for young adults and college students.

These suggestions for program improvements were compiled from a review of relevant literature and the qualitative findings of this study:

1. Provide social support. As previously discussed, participants suggestions for improvement illustrated a lack of social support. These suggestions include setting participants up with a "buddy" in the program, conducting training in groups, and advertising for support groups. The need to reinstate the support group component in future deliveries of the Body for Break program is sufficiently supported. Participant suggestions in conjunction with the support provided in the literature on the benefits of social support illustrate the need of such programs for young adults to meet this provision. In addition, the support groups could also serve as the arena where the 
behavioral component of the intervention is delivered (e.g. goal-setting, time management, other cognitive-behavioral strategies), which was lacking in the Body for Break program but have been shown to be critical components of effective lifestyle change.

2. Increase the dose of the program. Because component use was optional, individual implementation of the program varied greatly. In such programs, there must be enough resources of sufficient quality so that all participants could receive the maximal (and most effective) dose of the program. Suggestions highlighting the need for more and better quality dieticians and personal trainers were prevalent throughout the focus groups/ interviews of this study. As previously discussed, putting some of these components online or providing to multiple individuals at once (e.g., support or training group) could alleviate stress on program staff/resources and facilitate more participants accessing the multiple arms of the intervention. With this addition, the intervention may have a greater reach, effectiveness, implementation and maintenance, and thus, a greater public health impact. Any incentives used in the future might be most effective if tied to overall participation in the program instead of using the student recreation center and attending the pre- and post-measurements.

3. Increase variety of offerings. Instead of using a canned approach, it was suggested by participants that the program offer different track programs based on exercise history and fitness/weight-loss goals. These options could also be done in conjunction with determining the intensity of the personal training component needed (e.g., one-on-one supervision versus online training program), which would help to efficiently allocate resources. Other ways that variety could be increased includes suggestions for having 
specific Body for Break activities and/or utilizing the other programs that the student recreation center offers into the Body for Break program (e.g., group exercise classes for participants). This strategy could serve to provide opportunities to increase self-efficacy and provide additional social support within the program, as well. One-third of the focus group/interview participants lamented that exercise done at home was not counted toward participation in the program. If it could be possible to include this, through online logs for example, it would allow participants to vary the environments in which they receive the intervention. Lastly, it was the popular opinion within the qualitative data that prizes were overwhelming female-oriented. Offering a variety of prizes that appeal to both genders may help to increase extrinsic motivation and possibly retention.

4. Increase feedback and accountability. Body for Break offered assessments before the program and after the eight-week program. Participants expressed a need for receiving more feedback on their progress throughout the program such as more assessments (e.g., a four-week assessment), and additional weekly weigh-ins, especially when motivation started to wane in the latter weeks of the program. Some commented that they wanted a more thorough assessment that includes aspects of fitness. As suggested by Abildso (2008), it may also be beneficial to have participants' complete self-report questionnaires on concepts such as self-esteem, self-efficacy and exercise barriers at multiple times throughout the program to discern changes in these variables in addition to body composition. Participants also expressed that there was a significant amount of confusion early on concerning what to do during the program and how to access services. Providing a more comprehensive orientation at the onset could minimize confusion pertaining to program participation. Estabrooks and Gyurcsik (2003) suggest assessing participant 
knowledge and understanding of the intervention components at the start of the intervention to remedy misunderstandings before they interfere with intervention effectiveness.

\section{Conclusions}

This study is the first to use the RE-AIM framework to systematically evaluate the overall impact of a health promotion program delivered on a college campus. The index values obtained indicate that the 2009 Body for Break program had a low reach, low effectiveness, moderate individual level implementation (use) of program components, and a high organizational level implementation (quality) of program components. Qualitative data provided possible explanations for the values and suggestions for improvement, illustrating the utility of a mixed-methods research design in evaluation studies.

Overall, the individual level impact of the Body for Break program was low at 13.1 (reach * effectiveness; Glasgow et al., 2006). Does that mean it is not worth continuing to run the program annually? As far as public health impact, a more parsimonious intervention might better serve the student body. However, if the Body for Break program goals were to simply make small improvements to participants' physique and fitness for the upcoming spring break then, as evident in the outcome changes, the program served its purpose for approximately $25 \%$ of those who participated.

The benefits of such a program for college students should not be lost in that it is in line with public health initiatives such as Healthy Campus 2010 (ACHA, 2006) and addresses the population of young adults that is neglected in the research (Gokee-Larose et al., 2009a; GokeeLarose et al., 2009b; Nelson et al., 2008). Through incorporating suggested changes, the Body 
for Break program and other similar programs for college students could increase reach, effectiveness, adoption, implementation and maintenance and thus, increase the overall impact.

Research suggests that the most effective programs for increasing fitness and health utilize multiple components via multiple modalities (Dubbert, 2002; Dunn et al., 1999; Marcus et al., 2006; NHLBI, 1998). However, such programs often suffer from diminished effectiveness when delivered in the real world, as evident in the present study. This lack of translation could be due to numerous reasons, including that the trained professionals that offer the intervention in controlled trials are more qualified to deliver than those who offer it in real-world settings. The Body for Break program is not unique in that it illustrates what is lost in the translation of research to practice, as is often the case with such programs. However, the emergence and growing popularity of using the RE-AIM framework for evaluation studies has shown promise in remediating the trend of omitting setting-level issues and long-term results of interventions. Reporting values on additional dimensions will increase the external validity of interventions when taken from research settings into practice. 


\section{References}

Abildso, C. (2008). Evaluating an insurance-sponsored weight management program using the RE-AIM model. Doctoral dissertation, West Virginia University, 2008.

American College of Sports Medicine. (2003). ACSM fitness book. ( $3^{\text {rd }}$ ed.) Champaign, IL: Human Kinetics Press.

American College Health Association. (2007). American College Health Association National college health assessment Spring 2006 reference group data report (Abridged). Journal of American College Health, 55(4), 195-206.

Anderson, D.A., Shapiro, J.R., \& Lundgren, J.D. (2003). The freshman year as a critical period for weight gain. Eating Behavior, 4, 363-367.

Behrens, T.K., Dinger, M.K., Heesch, K.C., \& Sisson, S.S. (2005). College students' understanding of moderate physical acticity: A qualitative study. American Journal of Health Studies, 20(3), 129-134.

Butler, S.M., Black, D.R., Blue, C.L., \& Gretebeck, R.J. (2004). Change in diet, physical activity, and body weight in female college freshman. American Journal of Health Behavior, 28, 24-32.

Bull, S.S., Gillette, C., Glasgow, R.E., \& Estabrooks, P. (2003). Work site health promotion Research: To what extent can we generalize the results and what is needed to translate research into practice? Health Education \& Behavior, 30 (5), 537-549.

Centers for Disease Control and Prevention. (2007). Behavior risk factor surveillance system: 2007 prevalence data. Retrieved January 3, 2009, from http://apps.nccd.cdc.gov/brfss/.

Cousineau, T.M., Franko, D.L., Ciccazzo, M., Goldstein, M., \& Rosenthal, E. (2006). Webbased nutrition education for college students: Is it feasible? Evaluation and Program 
Planning, 29, 23-33.

Courneya, K.S., Estabrooks, P.A., \& Nigg, C.R. (1997). A simple reinforcement strategy for increasing attendance at a fitness facility. Health Education \& Behavior, 24, 708-715.

Dubbert, P.M. (2002). Physical activity and exercise: Recent advances and current challenges. Journal of Consulting and Clinical Psychology, 70(3), 526-536.

Dunn, A.L., Marcus, B.H., Kampert, J.B., Garcia, M.E., Kohl, H.W., III, \& Blair, S.N. (1999). Comparison of lifestyle structured interventions to increase physical activity and cardiorespiratory fitness: A randomized trial. Journal of the American Medical Association, 281, 327-334.

Estabrooks, P.A., Dzetwaltowski, D.A., Glasgow, R.E., \& Klesges, L.M. (2003). Reporting of validity from school health promotion studies published in 12 leading journals, 19962000. Journal of School Health, 73(1), 21-28.

Ferrara, C., St.Laurent, C., \& Wilson, T. (2008). The benefits of a weight-loss contest in overweight and obese college students. Recreational Sports Journal, 32, 45-51.

Flegal, K.M., Carroll, M.D., Ogden, C.L., \& Johnson, C.L. (2002). Prevalence and trends in obesity among US adults, 1999-2000. Journal of the American Medical Association, 288(4), 1723-1727.

Franko, D.L., Cousineau, T.M., Trant, M., Green, T.C., Rancourt, D., Thompson, D. et al. (2008). Motivation, self-efficacy, physical activity and nutrition in college students: Randomized controlled trail of an internet-based education program. Preventive Medicine, 47, 369-377.

Glasgow, R.E., Klesges, L.M., Dzewaltowski, D.A., Bull, S.S., \& Estabrooks, P. (2004). The future of health behavior change research: What is needed to improve translation of 
research into health promotion practice? Annals of Behavioral Medicine, 27(1), 3-12.

Glasgow, R.E., Klesges, L.M., Dzewaltowski, D.A., Estabrooks, P.A., \& Vogt, T.M. (2006). Evaluating the impact of health promotion programs: using the RE-AIM framework to form summary measures for decision making involving complex issues. Health Education Research, 21(5), 688-694.

Glasgow, R.E., McKay, G.H., Piette, J.D., \& Reynolds, K.D. (2001). The RE-AIM framework for evaluating interventions: what can it tell us about approaches to chronic illness management? Patient Education and Counseling, 44, 119-127.

Glasgow, R.E., Vogt, T.M., \& Boles, .S.M. (1999). Evaluation the public health impact of health promotion interventions: The RE-AIM framework. American Journal of Public Health, 89, 1233-1327.

Gokee-LaRose, J., Gorin, A.A., Raynor, H.A., Laska, M.N., Jeffery, R.W., Levy, R.L., et al. (29 September 2009a). Are standard behavioral weight-loss programs effective for young adults? International Journal of Obesity. Advance online publication. doi: 10.1038/ijo.2009.185.

Gokee-LaRose, J., Gorin, A.A., Wing, R.R. (2009b). Behavioral self-regulation for weight loss in young adults: a randomized controlled study. International Journal of Behavioral Nutrition and Physical Activity, 6 (10). doi: 10.1186/1479-5868-6-10.

Graham, M.A, \& Jones, A.L. (2002). Freshman 15: A valid theory or harmful myth. Journal of American College Health, 50(4), 171-173.

Hoffman, D.J., Policastro, P., Quick, V., Lee, S. (2006). Changes in body weight and fat mass of men and women in the first year of college: A study of the "Freshman 15". Journal of American College Health, 55(1), 41-45. 
Holm-Denoma, J.M., Joiner, T.E., Vohs, K.D., \& Heatherton, T.F. (2008). The "freshman Fifteen" (the "freshman five" actually): Predictors and possible explanations. Health Psychology, 27(S1), S3-S9.

House, E.R. (1980). Evaluating with validity. Beverly Hills, CA: Sage Publications.

Hull, H.R., Morrow, M.L., Dinger, M.K., Han, J.L., \& Fields, D.A. (2007). Characterization of body weight and composition changes during the sophomore year of college. BMC Women's Health, 21(7), http://www.biomedcentral.com/1472-6874/7/21. Accessed January 20, 2009.

Jozkowski, K. (2007). Evaluation of a weight loss intervention program among college females. The Health Education Monograph Series, 24(2), 32-37.

Kolodinsky, J., Harvey-Berino, J.R., Berlin, L., Johnson, R.K., \& Reynolds, T.W. (2007). Knowledge of current dietary guidelines and food choice by college students: Better eaters have higher knowledge of dietary guidance. Journal of the American Dietetic Association, 107, 1409-1413.

Kruger, R.A., \& Casey, M.A. (2000). Focus groups: A practical guide for applied research. Thousand Oaks, CA: Sage Publications.

Larsen, J.K., Ouwens, M., Engels, R., Eisinga, R., \& van Strien, T. (2008). Validity of selfreported weight and height and predictors of weight bias in female college students. Appetite, 50, 386-389.

Levitsky, D.A., Halbmaier, C.A., \& Mrdjenovic, G. (2004). The freshman weight gain: A model for the study of the epidemic of obesity. International Journal of Obesity, 28, 1435-1442.

Lowry, R., Galuska, D.A., Fulton, J.E., Wechsler, H., Kann, L., \& Collins, J.L. (2000). 
Physical activity, food choice, and weight management goals and practices among U.S. college students. American Journal of Preventive Medicine, 18(1), 18-27.

Marcus, B.H., Williams, D.M., Dubbert, P.M., Sallis, J.F., King, A.C., Yancey, A.K., et al. (2006). Physical activity intervention studies: What we know and what we need to know. Circulation, 114, 2739-2752.

Matvienko, O., Lewis, S.L., \& Schafer, E. (2001). A college nutrition science course as an investment to prevent weight gain in female college freshmen. Journal of Nutrition Education and Behavior, 33, 95-101.

McArthur, L.H., \& Raedeke, T.D. (2009). Race and sex differences in college student physical activity correlates. American Journal of Health Behavior, 33(1), 80-90.

Mihalopoulos, N.L., Auinger, P., \& Klein, J.D. (2008). The Freshman 15: Is it real? Journal of American College Health, 56(5), 531-533.

Marcus, B., \& Forsyth, L.H. (2003). Motivating people to be physically active. Champaign, IL: Human Kinetics.

Mokdad, A.H., Ford, E.S., Bowman, B.A., Dietz, W.H., Vinicor, F., Bales, V.S., et al. (2003). Prevalence of obesity, diabetes, and obesity-related health risk factors, 2001. Journal of the American Medical Association, 289(1), 76-79.

Morrow, J.R., Jackson, A.W., Bazzarre, T.L., Milne, D., \& Blair, S.N. (1999). A one-year follow-up to physical activity and health: A report of the Surgeon General. American Journal of Preventive Medicine, 17, 24-30.

National Heart Lung and Blood Institute. (1998). Obesity Education Initiative Expert Panel: Clinical guidelines on the identification, evaluation and treatment of overweight and obesity in adults- The evidence report. Obesity Research, 6 
(Suppl.), 51-210.

Nelson, M.C., Story, M., Larson, N.I., Neumark-Sztainer, D., \& Lytle, L.A. (2008). Emerging Adulthood and college-aged youth: An overlooked age for weight-related behavior change. Obesity, 16, 2205-2211.

Nigg, C.R., Courneya, K.S., \& Estabrooks, P.A. (1997). Effects of differential self-monitoring on attendance at a fitness center. Avante, 3(3), 64-79.

Ogden, C.L., Carroll, M.D., Curtin, L.R., McDowell, M.A., Tabak, C.J., \& Flegal, K.M. (2006). Prevalence of overweight and obesity in the United States, 1999-2004. Journal of the American Medical Association, 295(13), 1549-1555.

Puhl, R.M., \& Heuer, C.A. (2009). The stigma of obesity: A review and update. Obesity, 17, 941-964.

Racette, S.B., Deusinger, S.S., Strube, M.J., Highstein, G.R., \& Deusinger, R.T. (2005). Weight changes, exercise, and dietary patterns during freshman and sophomore years of college. Journal of American College Health, 53(6), 245-251.

Robroek, S.J.W., van Lenthe, F.J., van Empelen, P., \& Burdoff, A. (2009). Determinants of participation in worksite health promotion programmes: a systematic review. International Journal of Behavioral Nutrition and Physical Activity, 6(26), 1-12.

Scott, D.M., Murray, W.J., Pellerito, P.A., Shaffer, L. (2000). Assessment of an exercise program on pharmacy students' fitness level. Journal of Pharmicoepidemiology, 8(1), 29-39.

Strong, K.A., Parks, S.L., Anderson, E., Winett, R., \& Davy, B.M. (2008). Weight gain prevention: Identifying theory-based targets for health behavior change in young adults. Journal of the American Dietetic Association, 108(10), 1708-1715. 
Sullum, J., Clark, M.M., \& King, T.K. (2000). Predictors of exercise relapse in a college Population. Journal of American College Health, 48, 175-180.

Tavares, L.S., \& Plotnikoff, R.C. (2008). Not enough time? Individual and environmental implications for workplace physical activity programming among women with and without young children. Health Care for Women International, 29, 244-281.

Toobert, D.J., Strycker, M.A., Glasgow, R.E., Barrera, M., \& Angell, K. (2005). Effects of the Mediterranean Lifestyle Program on multiple risk behaviors and psychosocial outcomes among women at risk for heart disease. Annals of Behavioral Medicine, 29(2), 128-137.

US Department of Education National Center for Education Statistics (2007). Digest of Education Statistics: 2007.

Weiss, E.C., Galuska, D.A., Kahn, L.K., \& Serdula, M.K. (2006). Weight-control practices among U.S. adults, 2001-2002. American Journal of Preventive Medicine, 31(1), 18-24.

Wing, R.R., \& Jeffrey, R.W. (1999). The benefits of recruiting participants with friends and increasing social support for weight loss and maintenance. Journal of Consulting and Clinical Psychology, 67(1), 133-138.

Zizzi, S., Ayers, S., Watson, J., \& Keeler, L. (2004). The impact of a new campus recreation center on physical activity patterns in college students. The NASPA Journal, 41(4), 588-630. 
Table 1

Participant baseline characteristics and physiological data.

$\underline{\text { All }(\mathrm{N}=405)}$

$$
\text { Women }(\mathrm{n}=336,83 \%) \quad \text { Men }(\mathrm{n}=69,17 \%)
$$

Age group (n, \%)

$17-19.9$

$20-21.9$

$22-23.9$

$24-25.9$

$26+$

Class Status

Freshman

Sophomore

Junior

Senior

Graduate/Professional

Measures $(\mathrm{M}+\mathrm{SD})$

Age

Height (inches)

Weight (pounds)

$\mathrm{BMI}^{\mathrm{a}}\left(\mathrm{kg} / \mathrm{m}^{2}\right)$

$\mathrm{RHR}^{\mathrm{b}}$ (bpm)

$\mathrm{SBP}^{\mathrm{c}}$ (mmHg)

$\operatorname{DPB}^{\mathrm{d}}(\mathrm{mmHg})$

Body Fat $\%$

Waist (inches)

$$
\begin{gathered}
138(34 \%) \\
147(36.1 \%) \\
73(17.9 \%) \\
15(3.5 \%) \\
33(8.1 \%)
\end{gathered}
$$

$97(24 \%)$

$73(18 \%)$

$70(20 \%)$

$97(24 \%)$

57 (14\%)

\begin{tabular}{clclcl}
$\mathrm{n}$ & & $\mathrm{n}$ & \multicolumn{3}{c}{$\mathrm{n}$} \\
405 & $21.06 \pm 3.4$ & 336 & $20.9 \pm 3.1$ & 69 & $22.0 \pm 4.5$ \\
405 & $65.8 \pm 3.5$ & 336 & $64.8 \pm 2.8$ & 69 & $70.5 \pm 3.1$ \\
405 & $167.7 \pm 92.1$ & 336 & $154.1 \pm 34.5$ & 69 & $233.8 \pm 198.0$ \\
404 & $26.4 \pm 59.1$ & 336 & $25.8 \pm 5.3$ & 68 & $29.7 \pm 7.5$ \\
400 & $83.9 \pm 14.0$ & 332 & $84.6 \pm 14.0$ & 68 & $80.6 \pm 13.5$ \\
403 & $129.5 \pm 14.6$ & 334 & $127.8 \pm 14.1$ & 69 & $137.6 \pm 14.5$ \\
403 & $79.4 \pm 10.9$ & 334 & $79.2 \pm 10.4$ & 69 & $80.9 \pm 13.0$ \\
391 & $28.0 \pm 8.9$ & 325 & $31.3 \pm 8.2$ & 66 & $23.2 \pm 9.2$ \\
405 & $32.9 \pm 6.2$ & 335 & $31.8 \pm 5.5$ & 69 & $38.0 \pm 7.0$ \\
\hline
\end{tabular}

Note. ${ }^{a}$ Body Mass Index, ${ }^{b}$ Resting Heart Rate, ${ }^{c}$ Systolic Blood Pressure, ${ }^{d}$ Diastolic Blood Pressure. 
Table 2

Focus Group and Interview Results Between Program Completers and Non-completers

\begin{tabular}{|c|c|c|c|c|}
\hline Question & \multicolumn{2}{|c|}{ Major Themes } & Amount & Concepts / Comments \\
\hline \multirow[t]{5}{*}{$\begin{array}{l}\text { 1. Initial } \\
\text { attractions to } \\
\text { program }\end{array}$} & \multicolumn{2}{|l|}{ Physical } & $\begin{array}{l}\mathrm{C}=3 \\
\mathrm{NC}=4\end{array}$ & $\begin{array}{l}\text { To get in shape; to lose weight; to } \\
\text { tone up }\end{array}$ \\
\hline & \multicolumn{2}{|c|}{$\begin{array}{l}\text { To use personal training } \\
\text { services }\end{array}$} & $\begin{array}{l}\mathrm{C}=3 \\
\mathrm{NC}=2\end{array}$ & $\begin{array}{l}\text { To increase knowledge on exercise; } \\
\text { get an exercise plan }\end{array}$ \\
\hline & \multicolumn{2}{|c|}{ To use nutrition services } & $\begin{array}{l}\mathrm{C}=2 \\
\mathrm{NC}=0\end{array}$ & $\begin{array}{l}\text { To increase knowledge on } \\
\text { nutrition; to get a diet plan }\end{array}$ \\
\hline & \multicolumn{2}{|c|}{ Contest/ Competition } & $\begin{array}{l}\mathrm{C}=5 \\
\mathrm{NC}=0\end{array}$ & $\begin{array}{l}\text { Contest/ competition appeals to } \\
\text { personality (e.g., "I'm a } \\
\text { competitive person so this was } \\
\text { attractive") }\end{array}$ \\
\hline & \multicolumn{2}{|c|}{ Extra motivation } & $\begin{array}{l}\mathrm{C}=5 \\
\mathrm{NC}=0\end{array}$ & $\begin{array}{l}\text { Seeing results of others; increased } \\
\text { accountability (e.g., a "reason to } \\
\text { go") }\end{array}$ \\
\hline \multirow[t]{2}{*}{ 2. Initial turnoffs } & \multicolumn{2}{|c|}{$\begin{array}{l}\text { Negative experience } \mathrm{w} / \\
\text { personal training }\end{array}$} & $\begin{array}{l}\mathrm{C}=5 \\
\mathrm{NC}=2\end{array}$ & $\begin{array}{l}\text { Hard to schedule; inconsistent; } \\
\text { general "negative experience" with } \\
\text { personal training component }\end{array}$ \\
\hline & \multicolumn{2}{|c|}{ Programmatic } & $\begin{array}{l}\mathrm{C}=2 \\
\mathrm{NC}=1\end{array}$ & $\begin{array}{l}\text { Misconception of program; } \\
\text { program not distinct }\end{array}$ \\
\hline \multirow[t]{5}{*}{$\begin{array}{l}\text { 3. Barriers to } \\
\text { success }\end{array}$} & \multicolumn{2}{|c|}{ Time Constraints } & $\begin{array}{l}\mathrm{C}=11 \\
\mathrm{NC}=6\end{array}$ & $\begin{array}{l}\text { Time constraints due to academic } \\
\text { tasks and work tasks }\end{array}$ \\
\hline & \multicolumn{2}{|l|}{ Diet } & $\begin{array}{l}\mathrm{C}=9 \\
\mathrm{NC}=2\end{array}$ & $\begin{array}{l}\text { Maintaining "willpower"; expense } \\
\text { of buying "healthy" foods }\end{array}$ \\
\hline & \multicolumn{2}{|c|}{ Decreased motivation } & $\begin{array}{l}\mathrm{C}=5 \\
\mathrm{NC}=2\end{array}$ & Not seeing results; boredom \\
\hline & \multicolumn{2}{|c|}{$\begin{array}{l}\text { Lack or negative social } \\
\text { support }\end{array}$} & $\begin{array}{l}\mathrm{C}=3 \\
\mathrm{NC}=2\end{array}$ & $\begin{array}{l}\text { Needing a "workout buddy"; } \\
\text { adverse temptations from peers }\end{array}$ \\
\hline & \multicolumn{2}{|c|}{ Rec center problems } & $\begin{array}{l}\mathrm{C}=3 \\
\mathrm{NC}=1\end{array}$ & $\begin{array}{l}\text { Crowds; hours of operation; } \\
\text { parking }\end{array}$ \\
\hline \multirow[t]{2}{*}{$\begin{array}{l}\text { 4. Contributors } \\
\text { to success }\end{array}$} & \multicolumn{2}{|c|}{ Cognitive } & $\begin{array}{l}\mathrm{C}=1 \\
\mathrm{NC}=2\end{array}$ & $\begin{array}{l}\text { Previous exercise } \\
\text { history/knowledge; getting } \\
\text { expectations in line with reality }\end{array}$ \\
\hline & \multicolumn{2}{|c|}{ Getting advice from staff } & $\begin{array}{l}\mathrm{C}=3 \\
\mathrm{NC}=0\end{array}$ & $\begin{array}{l}\text { Talking with trainers; getting } \\
\text { tips/advice }\end{array}$ \\
\hline \multirow[t]{2}{*}{ 5. Effectiveness } & Positive & $\begin{array}{l}\text { Physique } \\
\text { improvements }\end{array}$ & $\begin{array}{l}\mathrm{C}=8 \\
\mathrm{NC}=3\end{array}$ & $\begin{array}{l}\text { Weight loss, inches decreased, } \\
\text { increased muscle tone/ strength }\end{array}$ \\
\hline & & $\begin{array}{l}\text { Increased } \\
\text { knowledge }\end{array}$ & $\begin{array}{l}\mathrm{C}=6 \\
\mathrm{NC}=4\end{array}$ & $\begin{array}{l}\text { Increased general knowledge/ } \\
\text { information; learned different } \\
\text { exercise routines; learned how to }\end{array}$ \\
\hline
\end{tabular}




\begin{tabular}{|c|c|c|c|c|}
\hline & & & & use equipment \\
\hline & & $\begin{array}{l}\text { Increased } \\
\text { motivation }\end{array}$ & $\begin{array}{l}\mathrm{C}=7 \\
\mathrm{NC}=0\end{array}$ & $\begin{array}{l}\text { Increased desire to exercise/ adhere } \\
\text { to associated health behavior } \\
\text { changes }\end{array}$ \\
\hline & Negative & $\begin{array}{l}\text { Lack of } \\
\text { effectiveness }\end{array}$ & $\begin{array}{l}\mathrm{C}=7 \\
\mathrm{NC}=1\end{array}$ & $\begin{array}{l}\text { Not getting results; not getting } \\
\text { what participant needed; gaining } \\
\text { weight }\end{array}$ \\
\hline \multirow[t]{8}{*}{$\begin{array}{l}\text { 6. Component } \\
\text { implementation }\end{array}$} & $\begin{array}{l}\text { Personal } \\
\text { training }\end{array}$ & Did not use & $\begin{array}{l}\mathrm{C}=6 \\
\mathrm{NC}=1\end{array}$ & \\
\hline & & $\begin{array}{l}\text { Used } \\
\text { consistently }\end{array}$ & $\begin{array}{l}\mathrm{C}=7 \\
\mathrm{NC}=0\end{array}$ & \\
\hline & & $\begin{array}{l}\text { Used only } \\
\text { once }\end{array}$ & $\begin{array}{l}\mathrm{C}=1 \\
\mathrm{NC}=3\end{array}$ & \\
\hline & Dietician & Did not use & $\begin{array}{l}\mathrm{C}=5 \\
\mathrm{NC}=5\end{array}$ & \\
\hline & & $\begin{array}{l}\text { Used own diet } \\
\text { plan }\end{array}$ & $\begin{array}{l}\mathrm{C}=1 \\
\mathrm{NC}=3\end{array}$ & $\begin{array}{l}\text { Used a diet plan during the } \\
\text { program but did not get from B4B } \\
\text { dietician }\end{array}$ \\
\hline & Emails & Read fully & $\begin{array}{l}\mathrm{C}=4 \\
\mathrm{NC}=2\end{array}$ & \\
\hline & & $\begin{array}{l}\text { Read through } \\
\text { "a few" }\end{array}$ & $\begin{array}{l}\mathrm{C}=4 \\
\mathrm{NC}=1\end{array}$ & \\
\hline & & $\begin{array}{l}\text { Already aware } \\
\text { of information }\end{array}$ & $\begin{array}{l}\mathrm{C}=5 \\
\mathrm{NC}=0\end{array}$ & $\begin{array}{l}\text { Participants already knew } \\
\text { information that was being } \\
\text { presented }\end{array}$ \\
\hline \multirow[t]{7}{*}{$\begin{array}{l}\text { 7. Quality of } \\
\text { program } \\
\text { components }\end{array}$} & $\begin{array}{l}\text { Negative } \\
\text { personal } \\
\text { training }\end{array}$ & $\begin{array}{l}\text { Hard to } \\
\text { schedule }\end{array}$ & $\begin{array}{l}\mathrm{C}=11 \\
\mathrm{NC}=6\end{array}$ & $\begin{array}{l}\text { Hard to coordinate personal } \\
\text { availability with trainer } \\
\text { availability; trouble contacting } \\
\text { trainer }\end{array}$ \\
\hline & & $\begin{array}{l}\text { Lack of } \\
\text { knowledge }\end{array}$ & $\begin{array}{l}\mathrm{C}=4 \\
\mathrm{NC}=9\end{array}$ & $\begin{array}{l}\text { About training in general; about } \\
\text { program; about injury/ proper } \\
\text { technique }\end{array}$ \\
\hline & & $\begin{array}{l}\text { Disregard } \\
\text { clients } \\
\text { concerns } \\
\end{array}$ & $\begin{array}{l}\mathrm{C}=4 \\
\mathrm{NC}=3\end{array}$ & $\begin{array}{l}\text { Trainer not addressing clients } \\
\text { concerns about desired training } \\
\text { regimen; disregarding injury }\end{array}$ \\
\hline & & Inconsistent & $\begin{array}{l}\mathrm{C}=7 \\
\mathrm{NC}=1\end{array}$ & $\begin{array}{l}\text { Trainer was changed (due to any } \\
\text { number of reasons including } \\
\text { schedule incompatibilities) }\end{array}$ \\
\hline & & $\begin{array}{l}\text { Not happy } \\
\text { with training }\end{array}$ & $\begin{array}{l}\mathrm{C}=4 \\
\mathrm{NC}=3\end{array}$ & $\begin{array}{l}\text { Participant deemed trainer's } \\
\text { exercise plan ineffective, } \\
\text { insufficient and/or inappropriate }\end{array}$ \\
\hline & $\begin{array}{l}\text { Positive } \\
\text { personal } \\
\text { training }\end{array}$ & Was "good" & $\begin{array}{l}\mathrm{C}=9 \\
\mathrm{NC}=3\end{array}$ & $\begin{array}{l}\text { Participant characterized trainer as } \\
\text { being generally "nice", } \\
\text { knowledgeable, and/or motivating }\end{array}$ \\
\hline & & Liked & $\mathrm{C}=4$ & Participant deemed trainer's \\
\hline
\end{tabular}




\begin{tabular}{|c|c|c|c|c|}
\hline & & workout & $\mathrm{NC}=3$ & $\begin{array}{l}\text { exercise plan effective, sufficient } \\
\text { and/or appropriate }\end{array}$ \\
\hline & $\begin{array}{l}\text { Negative } \\
\text { dietician }\end{array}$ & Not helpful & $\begin{array}{l}\mathrm{C}=7 \\
\mathrm{NC}=0\end{array}$ & $\begin{array}{l}\text { Not happy with session; } \\
\text { information given was too basic } \\
\text { and/or "common sense" }\end{array}$ \\
\hline & & $\begin{array}{l}\text { Hard to } \\
\text { schedule }\end{array}$ & $\begin{array}{l}\mathrm{C}=1 \\
\mathrm{NC}=4\end{array}$ & $\begin{array}{l}\text { Difficultly in figuring out how to } \\
\text { contact dietician/ set up an } \\
\text { appointment }\end{array}$ \\
\hline & $\begin{array}{l}\text { Positive } \\
\text { dietician }\end{array}$ & & $\begin{array}{l}\mathrm{C}=4 \\
\mathrm{NC}=0\end{array}$ & $\begin{array}{l}\text { General "liked"; liked diet plan; } \\
\text { participant deemed dietician } \\
\text { knowledgeable }\end{array}$ \\
\hline & $\begin{array}{l}\text { Negative } \\
\text { email }\end{array}$ & $\begin{array}{l}\text { Too much in } \\
\text { them }\end{array}$ & $\begin{array}{l}\mathrm{C}=3 \\
\mathrm{NC}=0\end{array}$ & $\begin{array}{l}\text { Too many attachments; too much } \\
\text { information jammed into one email }\end{array}$ \\
\hline $\begin{array}{l}\text { 8. Post- program } \\
\text { implementation }\end{array}$ & \multicolumn{2}{|c|}{ Still exercising } & $\begin{array}{l}\mathrm{C}=6 \\
\mathrm{NC}=5\end{array}$ & $\begin{array}{l}\text { Still working out at the SRC; still } \\
\text { meeting with trainer/ using trainer's } \\
\text { workout plan }\end{array}$ \\
\hline & \multicolumn{2}{|c|}{ Still following diet plan } & $\begin{array}{l}\mathrm{C}=2 \\
\mathrm{NC}=1\end{array}$ & $\begin{array}{l}\text { Still following diet plan that was } \\
\text { used during program }\end{array}$ \\
\hline \multirow{2}{*}{$\begin{array}{l}\text { 9. Participation } \\
\text { in program next } \\
\text { year }\end{array}$} & \multicolumn{2}{|c|}{ Affirmative } & $\begin{array}{l}\mathrm{C}=2 \\
\mathrm{NC}=4\end{array}$ & $\begin{array}{l}\text { Ranged from "definitely yes", "I } \\
\text { think so", and "most likely" }\end{array}$ \\
\hline & \multicolumn{2}{|l|}{ Negative } & $\begin{array}{l}\mathrm{C}=2 \\
\mathrm{NC}=1\end{array}$ & "Probably not" \\
\hline \multirow{2}{*}{$\begin{array}{l}\text { 10. Would } \\
\text { participant } \\
\text { recommend } \\
\text { program }\end{array}$} & \multicolumn{2}{|c|}{ Affirmative } & $\begin{array}{l}\mathrm{C}=6 \\
\mathrm{NC}=5\end{array}$ & $\begin{array}{l}\text { Would recommend program to a } \\
\text { friend }\end{array}$ \\
\hline & \multicolumn{2}{|c|}{ Depends on... } & $\begin{array}{l}\mathrm{C}=4 \\
\mathrm{NC}=4\end{array}$ & $\begin{array}{l}\text { Participant would recommend to } \\
\text { friend if friend was willing to work } \\
\text { out alone, wanted to lose weight, or } \\
\text { if program changes }\end{array}$ \\
\hline \multirow[t]{4}{*}{$\begin{array}{l}11 . \\
\text { Improvements/ } \\
\text { suggestions }\end{array}$} & \multicolumn{2}{|c|}{ Increase social support } & $\begin{array}{l}\mathrm{C}=8 \\
\mathrm{NC}=5\end{array}$ & $\begin{array}{l}\text { Setting participants up with a } \\
\text { "buddy" in the program; } \\
\text { conducting training in groups; } \\
\text { advertising for support groups }\end{array}$ \\
\hline & \multicolumn{2}{|c|}{ Increase dose of program } & $\begin{array}{l}\mathrm{C}=4 \\
\mathrm{NC}=5\end{array}$ & $\begin{array}{l}\text { Need for more and better quality } \\
\text { dieticians and personal trainers; } \\
\text { more encouragement to utilize } \\
\text { components }\end{array}$ \\
\hline & \multicolumn{2}{|c|}{ Increase variety of offerings } & $\begin{array}{l}\mathrm{C}=12 \\
\mathrm{NC}=2\end{array}$ & $\begin{array}{l}\text { Offer different track programs; } \\
\text { specific activities and/or utilizing } \\
\text { the other programs that the student } \\
\text { recreation center offers into the } \\
\text { program; incorporate home } \\
\text { exercise }\end{array}$ \\
\hline & \multicolumn{2}{|c|}{ Increase feedback } & $\mathrm{C}=4$ & More assessments throughout; \\
\hline
\end{tabular}


Nutrition Education \& Fitness Program Evaluation 60

\begin{tabular}{|l|l|l|l|}
\hline & & $\mathrm{NC}=4$ & include a fitness assessment \\
\hline $\begin{array}{l}\text { 12. Advice to } \\
\text { others }\end{array}$ & Have specific goals & $\mathrm{C}=4$ & Have specific goals set before \\
& & $\mathrm{NC}=3$ & entering program \\
\hline & Utilize all components & $\mathrm{C}=2$ & Use all components offered by \\
& & $\mathrm{NC}=1$ & program, even if only once \\
\hline & Do with friends & $\mathrm{C}=1$ & Increase social support and \\
& & $\mathrm{NC}=2$ & accountability by doing with friend \\
\hline
\end{tabular}

Note. $C=$ completers $(n=11), N C=$ non-completers $(n=6)$. 
Table 3

RE-AIM concept calculations and values

\begin{tabular}{|c|c|c|c|}
\hline Concept & Abbrev. & Calculation & Value \\
\hline $\begin{array}{l}\text { Individual } \\
\text { Participation Rate }\end{array}$ & IPR & $\begin{array}{c}\text { \# B4B participants / } 24986 \\
\text { eligible participants }\end{array}$ & $405 / 24986=.016$ \\
\hline $\begin{array}{l}\text { Demographic } \\
\text { Representativness }\end{array}$ & $\begin{array}{l}\text { DR } \\
\text { (chi square) }\end{array}$ & $\begin{array}{l}\text { mean ES of gender, year in } \\
\text { school, compared with } \\
\text { those of WVU student } \\
\text { population }\end{array}$ & $\begin{array}{l}([.033+.089] / 2)= \\
\quad .061\end{array}$ \\
\hline Outcome $_{\text {Eff }}$ & $\mathrm{O}_{\text {Eff }}$ & $\begin{array}{l}\text { average ES from paired t- } \\
\text { test of changes among } \\
\text { DVs (fat loss, RHR, } \\
\text { knowledge*) }\end{array}$ & $\begin{array}{l}([.61+.155] / 2)= \\
\quad .38\end{array}$ \\
\hline $\begin{array}{l}\text { Individual Completion } \\
\text { Rate }\end{array}$ & $\mathrm{ICR}=$ & $\begin{array}{l}\text { \# of participants returning } \\
\text { for final assessment/ \# } \\
\text { of participants that } \\
\text { began the program }\end{array}$ & $93 / 405=.23$ \\
\hline Differential Impact ${ }_{\text {Eff }}$ & $\mathrm{DI}_{1 \mathrm{Eff}}$ & $\begin{array}{l}\text { Differential Impact- mean } \\
\text { ES from } 2 \text { RM- } \\
\text { ANOVA's (IV: time * } \\
\text { gender, DV: fat loss), } \\
\text { (IV: time * year in } \\
\text { school, DV: fat loss) }\end{array}$ & $\begin{array}{l}([.013+.015] / 2)= \\
\quad .014\end{array}$ \\
\hline Differential Impact Eff & $\mathrm{DI}_{2 \mathrm{Eff}}$ & $\begin{array}{c}\mathrm{DI}_{2}=\text { Differential Impact- } \\
\text { mean ES from } 2 \text { RM- } \\
\text { ANOVA's (IV: time * } \\
\text { gender, DV: RHR), (IV: } \\
\text { time * year in school, } \\
\text { DV: RHR) }\end{array}$ & $\begin{array}{l}([.089+.004] / 2)= \\
\quad .047\end{array}$ \\
\hline Differential Impact ${ }_{\text {Eff }}$ & $\mathrm{DI}_{3 \mathrm{Eff}}$ & $\begin{array}{c}\mathrm{DI}_{3}=\text { Differential Impact- } \\
\text { mean ES from } 2 \text { RM- } \\
\text { ANOVA's (IV: time * } \\
\text { gender, DV: } \\
\text { knowledge*), (IV: time } \\
\text { * year in school, DV: } \\
\text { knowledge*) }\end{array}$ & removed \\
\hline $\begin{array}{l}\text { Component } \\
\text { Participation Rate }\end{array}$ & CPR & $\begin{array}{l}\text { sum \% implementation of } \\
\text { each of } 4 \text { components }\end{array}$ & $73+37+72+0=182$ \\
\hline Quality & $\mathrm{Q}$ & $\begin{array}{l}\text { quality rating of each } \\
\text { component on a 1-5 } \\
\text { scale, take average }\end{array}$ & $\begin{array}{c}([4.56+3.54+3.71] / \\
3)=3.94\end{array}$ \\
\hline Differential Impact ${ }_{\text {Maint }}$ & $\mathrm{DI}_{1 \text { Maint }}$ & $\begin{aligned} \mathrm{DI}_{1} & =\text { Differential Impact- } \\
& \mathrm{ES} \text { from RM-ANOVA } \\
& (\mathrm{IV}: \text { time } \\
& * \text { gender, DV: }\end{aligned}$ & $\mathrm{DI}_{1}=.3$ \\
\hline
\end{tabular}




\begin{tabular}{|c|c|c|c|}
\hline & & weight loss), & \\
\hline Differential Impact Maint & $\mathrm{DI}_{2 \text { Maint }}$ & $\begin{array}{l}\mathrm{DI}_{2}=\text { Differential Impact- } \\
\text { mean ES from } 2 \text { Chi } \\
\text { Square analyses: } \\
\text { Meeting PA } \\
\text { recommendations for } \\
\text { time and gender, }\end{array}$ & $\mathrm{DI}_{2}=.11$ \\
\hline Differential Impact $_{\text {Maint }}$ & $\mathrm{DI}_{3 \text { Maint }}$ & $\begin{array}{l}\mathrm{DI}_{3}=\text { Differential Impact- } \\
\text { ES from RM- ANOVA } \\
\text { (IV: time * gender, DV: } \\
\text { SE survey score) }\end{array}$ & $\mathrm{DI}_{3}=.003$ \\
\hline Differential Impact Maint & $\mathrm{DI}_{4 \text { Maint }}$ & $\begin{array}{r}\mathrm{DI}_{3}=\text { Differential Impact- } \\
\text { ES from RM- ANOVA } \\
\text { (IV: time * gender, DV: } \\
\text { Barrier SE survey score) }\end{array}$ & $\mathrm{DI}_{4}=.053$ \\
\hline Outcome $_{\text {Maint }}$ & $\mathrm{O}_{\text {Maint }}$ & $\begin{array}{l}\text { average ES from RM- } \\
\text { ANOVA's \& chi square } \\
\text { of changes among DVs } \\
\text { (weight, SE, barrier SE, } \\
\text { physical activity levels) } \\
\text { over time }\end{array}$ & $\begin{array}{l}([.093+.17+.048 \\
\quad+.054] / 4)= \\
\quad .09\end{array}$ \\
\hline $\begin{array}{l}\text { Individual Completion } \\
\text { Rate }\end{array}$ & ICR & $\begin{array}{l}\text { Individual Completion } \\
\text { Rate- \# of participants } \\
\text { completing all follow- } \\
\text { ups/ potential \# of those } \\
\text { eligible to participate in } \\
\text { follow-up }\end{array}$ & $32 / 93=.28$ \\
\hline
\end{tabular}

Note. *Knowledge was dropped from Outcome (Effectiveness) calculation. 
Table 4

RE-AIM Index Calculations

\begin{tabular}{|c|c|c|}
\hline Dimension & Formula & Value \\
\hline Reach & $\begin{array}{c}\mathrm{R}=(\mathrm{IPR} *[1-\mathrm{DR}]) * \\
100\end{array}$ & $(.016 *[1-.061]) * 100=1.5$ \\
\hline Effectiveness & $\begin{aligned} \mathrm{E}= & \left(\mathrm{ICR}_{\mathrm{Eff}} * \mathrm{O}_{\mathrm{Eff}}\right) * \\
& 100\end{aligned}$ & $(.23 * .38 *[1-.97]) * 100=8.5$ \\
\hline Implementation $_{\text {Ind }}$ & $\mathrm{I}_{\text {indiv }}=(\mathrm{CPR} / 4)$ & $(182 / 4) * 100=45.5$ \\
\hline Implementation $\mathrm{Org}$ & $\mathrm{I}_{\mathrm{org}}=(\operatorname{avg} \mathrm{Q} * .2)$ & $(3.94 * .2) * 100=79$ \\
\hline Maintenance & $\begin{array}{c}\mathrm{M}_{1}=\left(\mathrm{ICR}_{\text {maintenance }} *\right. \\
\mathrm{O}_{\text {maintenance }} *[1- \\
\left.\left.\mathrm{DI}_{1}\right]\right) \\
\mathrm{M}_{2}=\left(\mathrm{ICR}_{\text {maintenance }} *\right. \\
\mathrm{O}_{\text {maintenance }} *[1- \\
\left.\left.\mathrm{DI}_{2}\right]\right) \\
\mathrm{M}_{3}=\left(\mathrm{ICR}_{\text {maintenance }} *\right. \\
\mathrm{O}_{\text {maintenance }} *[1- \\
\left.\left.\mathrm{DI}_{3}\right]\right) \\
\mathrm{M}_{4}=\left(\mathrm{ICR}_{\text {maintenance }} *\right. \\
\mathrm{O}_{\text {maintenance }} *[1- \\
\left.\left.\mathrm{DI}_{4}\right]\right)\end{array}$ & $\begin{array}{l}(.28 * .09 *[1-.3]) * 100=.017 \\
(.28 * .09 *[1-.11]) * 100=.027 \\
(.28 * .09 *[1-.003]) * 100=.03 \\
(.28 * .09 *[1-.053]) * 100=.03\end{array}$ \\
\hline & $\mathrm{M}=$ average $\mathrm{M}_{1-4}$ & $\begin{array}{l}{[(.017+.027+.03+.03) / 4] *} \\
\quad 100=2.6\end{array}$ \\
\hline
\end{tabular}


Table 5

Program completer characteristics and physiological data $(T=1$ to $T=2)$.

$\underline{\text { All }(\mathrm{N}=93)}$

Women $(n=71,76.3 \%) \quad$ Men $(n=22,23.7 \%)$

Program Completion Rate

$23 \%$
$23(24.7 \%)$
$37(39.8 \%)$
$21(22.6 \%)$
$2(2.2 \%)$
$10(10.8 \%)$

$21.1 \%$

$32.4 \%$

Age group (n, \%)

17-19.9

20-21.9

$22-23.9$

24-25.9

$26+$

$19(26.8 \%)$
$30(42.3 \%)$
$16(22.5 \%)$
$1(1.4 \%)$
$5(7.0 \%)$

$4(18.2 \%)$

$7(31.8 \%)$

$5(22.7 \%)$

$1(4.5 \%)$

$5(22.7 \%)$

$\underline{\text { Class Status }}$

Freshman

Sophomore

$17(18.3 \%)$

$12(16.9 \%)$

$18(19.4 \%)$

$16(22.5 \%)$

$5(22.7 \%)$

Junior

$15(16.1 \%)$

$11(15.5 \%)$

$2(9.1 \%)$

Senior

$22(23.7 \%)$

$18(25.4 \%)$

$4(18.2 \%)$

Graduate/Professional

$21(22.6 \%)$

$14(19.7 \%)$

$4(18.2 \%)$

$7(31.8 \%)$

\begin{tabular}{|c|c|c|c|c|c|c|}
\hline Measures $(\mathrm{M}+\mathrm{SD})$ & $\mathrm{n}$ & & $\mathrm{n}$ & & $\mathrm{n}$ & \\
\hline Weight (pounds) & 93 & $164.4 \pm 47.4$ & 71 & $152.7 \pm 37.9$ & 22 & $202.2 \pm 55.5$ \\
\hline $\mathrm{BMI}^{\mathrm{a}}\left(\mathrm{kg} / \mathrm{m}^{2}\right)$ & 92 & $26.0 \pm 5.4$ & 70 & $25.4 \pm 4.9$ & 22 & $28.0 \pm 6.4$ \\
\hline $\mathrm{RHR}^{\mathrm{b}}(\mathrm{bpm})$ & 91 & $73.6 \pm 15.8$ & 69 & $75.0 \pm 16.3$ & 22 & $69.3 \pm 13.8$ \\
\hline $\mathrm{SBP}^{\mathrm{c}}(\mathrm{mmHg})$ & 90 & $124.9 \pm 11.7$ & 68 & $123.5 \pm 11.9$ & 22 & $129.1 \pm 10.0$ \\
\hline $\mathrm{DPB}^{\mathrm{d}}(\mathrm{mmHg})$ & 90 & $74.6 \pm 8.9$ & 68 & $75.4 \pm 8.6$ & 22 & $72.2 \pm 9.8$ \\
\hline Body Fat \% & 89 & $28.5 \pm 9.1$ & 69 & $30.6 \pm 8.1$ & 20 & $21.6 \pm 9.1$ \\
\hline Waist (inches) & 92 & $32.4 \pm 5.6$ & 70 & $31.1 \pm 4.2$ & 22 & $36.7 \pm 7.1$ \\
\hline Self efficacy & 93 & $3.6 \pm .79$ & 72 & $3.5 \pm .77$ & 21 & $3.6 \pm .87$ \\
\hline Barrier Self efficacy & 92 & $17.3 \pm 3.5$ & 71 & $17.1 \pm 3.5$ & 21 & $18.1 \pm 3.6$ \\
\hline Meeting PA & 92 & $64(\overline{69} .6 \%)$ & 71 & $49(\overline{76} .6 \%)$ & 21 & $15(7 \overline{1} .4 \%)$ \\
\hline \multicolumn{7}{|l|}{ Changes in Measures } \\
\hline Weight (pounds) & 92 & $-3.8 \pm 5.9$ & 70 & $-3.0 \pm 4.2$ & 22 & $-6.4 \pm 9.2$ \\
\hline $\mathrm{BMI}^{\mathrm{a}}\left(\mathrm{kg} / \mathrm{m}^{2}\right)$ & 92 & $-.57 \pm 5.4$ & 70 & $-0.5 \pm 0.7$ & 22 & $-0.9 \pm 1.3$ \\
\hline $\mathrm{RHR}^{\mathrm{b}}(\mathrm{bpm})$ & 90 & $-8.8 \pm 15.8$ & 68 & $-8.2 \pm 17.5$ & 22 & $-10.7 \pm 15.0$ \\
\hline $\mathrm{SBP}^{\mathrm{c}}(\mathrm{mmHg})$ & 90 & $-5.8 \pm 11.7$ & 68 & $-5.6 \pm 13.2$ & 22 & $-6.4 \pm 13.2$ \\
\hline $\mathrm{DPB}^{\mathrm{d}}(\mathrm{mmHg})$ & 90 & $-4.4 \pm 8.9$ & 68 & $-3.6 \pm 11.4$ & 22 & $-7.0 \pm 12.9$ \\
\hline Body Fat \% & 89 & $-1.4 \pm 9.1$ & 69 & $-1.2 \pm 2.2$ & 20 & $-2.0 \pm 4.1$ \\
\hline Waist (inches) & 92 & $-0.8 \pm 5.6$ & 70 & $-0.6 \pm 2.0$ & 22 & $-1.2 \pm 2.4$ \\
\hline
\end{tabular}

Note. ${ }^{a}$ Body Mass Index, ${ }^{b}$ Resting Heart Rate, ${ }^{c}$ Systolic Blood Pressure, ${ }^{d}$ Diastolic Blood Pressure. 
Table 6

Measures at follow-up $(T=3)$ of characteristics and physiological data $(T=2$ to $T=3)$.

All $(\mathrm{N}=41)$

Women $(\mathrm{n}=30,73.2 \%) \quad$ Men $(\mathrm{n}=11,26.8 \%)$

Follow-up Completion Rate

Age group (n, \%)

17-19.9

20-21.9

22-23.9

24-25.9

$26+$

$\underline{\text { Class Status }}$

Freshman

Sophomore

Junior

Senior

Graduate/Professional

$\underline{\text { Measures }(\mathrm{M}+\mathrm{SD})}$

Weight (pounds)

Self efficacy

Barrier Self efficacy

Meeting PA

Changes in Measures

Weight (pounds)

Self efficacy

Barrier Self efficacy

Meeting PA

$$
46.2 \%
$$

$8(19.5 \%)$

$13(31.7 \%)$

$11(26.8 \%)$

$3(7.3 \%)$

$6(14.6 \%)$

$$
4(9.8 \%)
$$

$8(19.5 \%)$

$7(17.1 \%)$

$10(24.4 \%)$

$12(29.3 \%)$

n

41

41

41
$171.1 \pm 53.1$

$3.3 \pm .78$

$16.0 \pm 3.5$

$30(73.2 \%)$
$73.2 \%$

$$
\begin{gathered}
19(26.8 \%) \\
30(42.3 \%) \\
16(22.5 \%) \\
1(1.4 \%) \\
5(7.0 \%)
\end{gathered}
$$

$12(16.9 \%)$

$16(22.5 \%)$

$11(15.5 \%)$

$18(25.4 \%)$

$14(19.7 \%)$

$\mathrm{n}$

30
30

30

30

30

$152.0+28.1$

$$
3.3 \pm .83
$$

$15.9 \pm 3.2$

$20(66.7 \%)$

29

30

$-.08 \pm 2.7$

$30-1.2 \pm 2.0$

$-9.9 \%$

30
$-.27 \pm .88$

$5(22.7 \%)$

$2(9.1 \%)$

$4(18.2 \%)$

$4(18.2 \%)$

$7(31.8 \%)$

$4(18.2 \%)$

$7(31.8 \%)$

$5(22.7 \%)$

$1(4.5 \%)$

$5(22.7 \%)$

$11--.40 \pm 4.5$

11

n

$11 \quad 223.1 \pm 70.1$

$11 \quad 3.4 \pm .67$

$11 \quad 16.2 \pm 4.2$

$23 \quad 10(90.9 \%)$
$41-1.2 \pm 2.5$

$11-.27 \pm .90$

$11-1.0 \pm 3.8$

$41+3.6 \%$ 
Table 7

Measures at follow-up $(T=4)$ of characteristics and physiological data $(T=3$ to $T=4)$.

\section{$\underline{\operatorname{All}(\mathrm{N}=32)}$}

$$
\text { Women }(\mathrm{n}=23,71.9 \%) \quad \text { Men }(\mathrm{n}=9,28.1 \%)
$$

\begin{tabular}{|c|c|c|c|c|c|c|}
\hline $\begin{array}{l}\text { Follow-up Completio } \\
\text { Age group }(\mathrm{n}, \%)\end{array}$ & Rate & $78.0 \%$ & & $71.9 \%$ & & $28.1 \%$ \\
\hline $17-19.9$ & & $3(9.4 \%)$ & & $0(0.0 \%)$ & & $1(11.1 \%)$ \\
\hline $20-21.9$ & & $10(31.3 \%)$ & & $9(39.1 \%)$ & & $1(11.1 \%)$ \\
\hline $22-23.9$ & & $10(31.3 \%)$ & & $9(39.1 \%)$ & & $1(11.1 \%)$ \\
\hline $24-25.9$ & & $4(12.5 \%)$ & & $1(4.3 \%)$ & & $3(33.3 \%)$ \\
\hline $26+$ & & $5(15.6 \%)$ & & $2(8.7 \%)$ & & $3(33.3 \%)$ \\
\hline Class Status & & & & & & \\
\hline$\overline{\text { Freshman }}$ & & $0(0.0 \%)$ & & $0(0.0 \%)$ & & $0(0.0 \%)$ \\
\hline Sophomore & & $5(15.6 \%)$ & & $4(17.4 \%)$ & & $1(11.1 \%)$ \\
\hline Junior & & $3(9.4 \%)$ & & $2(8.7 \%)$ & & $1(11.1 \%)$ \\
\hline Senior & & $11(34.4 \%)$ & & $8(34.8 \%)$ & & $3(33.3 \%)$ \\
\hline Graduate/Professiona & & $13(40.6 \%)$ & & $9(39.1 \%)$ & & $4(44.4 \%)$ \\
\hline Measures $(\mathrm{M}+\mathrm{SD})$ & $\mathrm{n}$ & & $\mathrm{n}$ & & $\mathrm{n}$ & \\
\hline$\overline{\text { Weight (pounds) }}$ & 32 & $170.6 \pm 38.5$ & 23 & $157.4 \pm 31.0$ & 9 & $204.4 \pm 36.3$ \\
\hline Self efficacy & 32 & $3.1 \pm .87$ & 23 & $3.0 \pm .93$ & 9 & $3.3 \pm .71$ \\
\hline Barrier Self efficacy & 32 & $14.9 \pm 4.3$ & 23 & $14.2 \pm 4.3$ & 9 & $16.9 \pm 4.0$ \\
\hline Meeting PA & 32 & $16(\overline{5} 0 \%)$ & 23 & $12(\overline{57} .2 \%)$ & 9 & $4(4 \overline{4} .4 \%)$ \\
\hline Changes in Measures & & & & & & \\
\hline$\overline{\text { Weight (pounds) }}$ & $26^{*}$ & $1.78 \pm 5.0$ & 18 & $.89 \pm 4.1$ & 8 & $3.8 \pm 6.6$ \\
\hline Self efficacy & $26^{*}$ & $-.07 \pm .80$ & 18 & $-.06 \pm .73$ & 8 & $-.13 \pm 1.0$ \\
\hline Barrier Self efficacy & $26^{*}$ & $-1.4 \pm 3.9$ & 18 & $-2.1 \pm 3.9$ & 8 & $.00 \pm 4.0$ \\
\hline Meeting PA & $26^{*}$ & $-23.2 \%$ & 18 & $-9 . \overline{5} \%$ & 8 & $-46.5 \%$ \\
\hline
\end{tabular}

Note. *The change in measures were calculated from participants with data at both Time 3 and Time 4 
Figure 1. Study timeline outlining delivery of assessments.

$\underline{\text { Start of B4B }}$

Fitness Assessments

$(1 / 15 / 09-1 / 17 / 09)$

Pre- Nutr \& Exercise Assessment

(online)

\section{B4B Program Ends} Ex \& Nutr. Behavior Survey

Fitness Assessments (3/11/09-3/12/09)

Program Evaluation Survey (online)

Post- Nutr \& Exercise Assessment (online)

[*Recruit participants for focus groups]
Follow-up Assessment (I)

Ex \& Nutr. Behavior Survey (online) Ex \& Nutr. Behavior Survey

Focus Groups (completers)

(online)

Focus Groups (program non-completers) Incentive Distribution

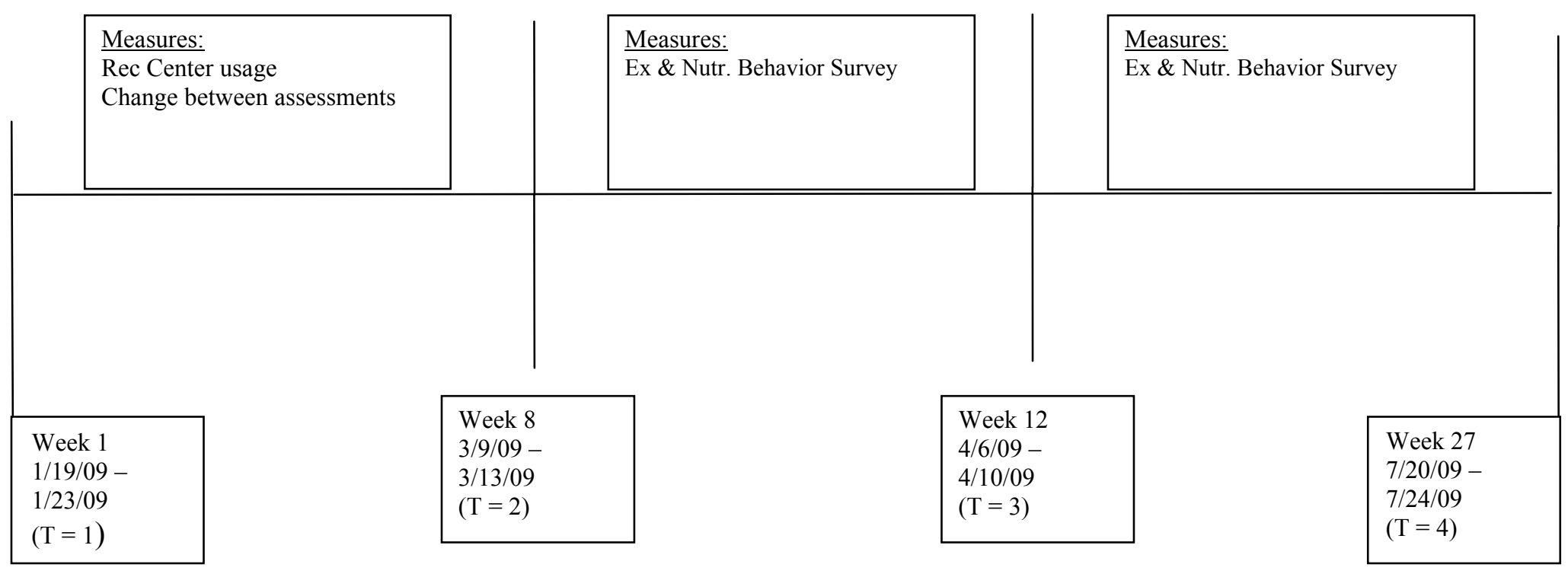


Figure 2. RE-AIM index values for the Body for Break program.

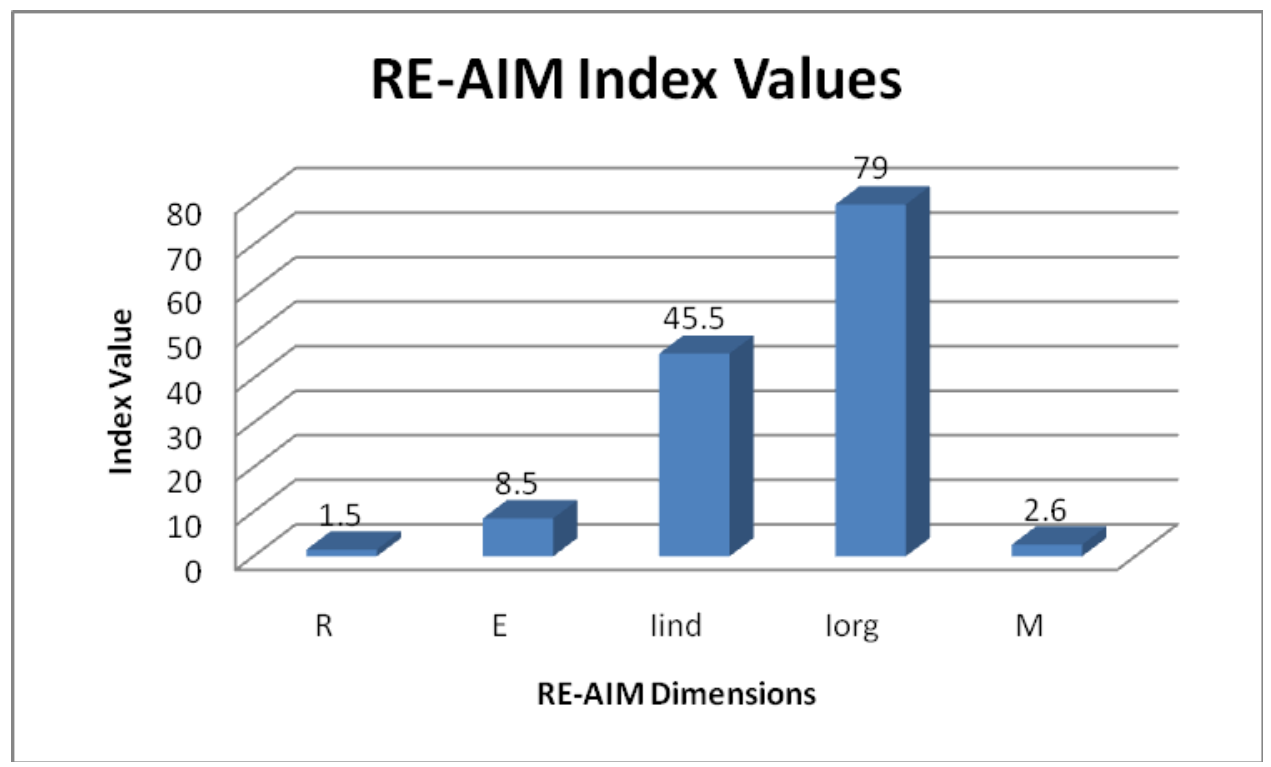




\section{APPENDIX A}

Review of the Literature

Introduction

Once thought to be an active, healthy and low risk population, college students are not immune to weight gain and obesity. Only recently have practitioners and researchers targeted the population of college students in studying weight gain, obesity, and interventions aimed at improving health behaviors to reduce the incidence and impact of those conditions on health and well-being. There is evidence that a proportion of college students are making attempts on their own to remedy weight gain and poor physical fitness with little or no guidance. However, highlighted are many shortcomings of those personal attempts, as evident in consistently rising obesity rates in the population of college students throughout the country, illustrating the need for organized, programmatic interventions. There is ample substantiation that college campuses could provide the archetypal setting for that provision. In fact, the literature contains several examples of these programs/interventions. However, the effectiveness and efficacy of many of these programs/interventions remain questionable due to a lack of systematic evaluation. This review of the literature seeks to outline the problem of inactivity, poor diet and overweight/obesity among college students, including a discussion of the antecedents that make this population especially vulnerable. Further, several relevant programs and/or interventions for college students will be discussed in supporting the need for the evaluation of these and similar programs. The literature review will conclude with a discussion of the RE-AIM framework as a potential model for such evaluations.

Basically, weight gain results when a person consumes more calories than he/she burns. Genetic, behavioral and environmental factors also contribute. Currently, $61.6 \%$ of US adults 
are currently overweight or obese (CDC, 2007). Over the past 20 years there has been a significant increase in the prevalence of obesity and overweight. Among all children and adolescents aged 2-19 years, $17.1 \%$ were overweight with $33.6 \%$ being at risk of overweight or overweight (Ogden, Caroll, \& Curtin, et al. 2006). Data from the National Health and Nutrition Examination Survey (NHANES) revealed that between 1980 and 2002, obesity prevalence doubled in adults aged 20 years or older and tripled in children and adolescents aged 6 to 19 years (Flegal, Caroll, Ogden, \& Johnson, 2002). As obesity levels are increasing, so are the associated health risk factors such as diabetes, high blood pressure, high cholesterol, asthma, arthritis, and poor health status. An estimated 300,000 adults die of causes related to obesity each year and ultimately, obesity and related risk factors generate vast health care costs (Mokdad et al., 2003). In fact, Wee et al. (2005) determined that mean per capita annual health care costs associated with BMI $>25$ are substantial, being within $4 \%$ and $9 \%$ of total US medical expenses and will become progressively higher for these individuals as age increases. If the current trends continue, by the year $2030,86.3 \%$ adults will be overweight or obese and total health care cost attributable to this would be $860.7-956.9$ billion US dollars, comprising $16-19 \%$ of total US health care costs (Wang, Beydoun, Liang, Caballero \& Kumanyika, 2008). Aside from the economic burden and health related problems, overweight and obesity can cause significant emotional distress, decreases in self-esteem and overall quality of life. Effective strategies aimed at reducing obesity and the consequent health risks are needed for all age groups in the United States.

College students are not impervious to the epidemic. The 2006 National College Health Risk Behavior Survey (NCHRBS) classified 31.4\% of college students as being overweight or obese (ACHA, 2007). According to the Behavioral Risk Factor Surveillance Survey System 
(BRFSS: CDC, 2007; Racette, Deusinger, Strube, Highstein, \& Deusinger, 2005), the greatest increases in overweight and obesity are occurring in persons between the ages of 18 and 29 years of age - at a time when many individuals are attending college. An examination of the height and weight data collected in the National Longitudinal Study of Adolescent Health of 1996-2001 revealed that during the five-year transitional period during adolescence and adulthood, over 1.9 million adolescents became obese adults and 1.5 million adolescents remained obese throughout the five-year study period, with only $1.6 \%$ converting from obese to non-obese (Gordon-Larsen, Adair, Nelson, \& Popkin, 2004). Another longitudinal study showed overweight, obesity and class II obesity all significantly rising among the nationally representative sample of four-year college students (Nelson, Gortmaker, Subramanian, Cheung, \& Wechsler, 2007). As national trend data illustrate, the transition from adolescence to adulthood is a heightened period of susceptibility for weight gain. A marked decrease in physical activity and changes in nutritional intake, among other factors, contribute to this occurrence during these risky transitional years.

\section{College Students \& Physical Activity}

Approximately $43 \%$ of college-age individuals in the United States are not engaging in enough physical activity to receive health benefits (McCracken, Jiles, \& Blanck, 2007), with other studies estimating that figure to be anywhere from $20 \%$ to as high as $68 \%$ (Desai, Miller, Staples, \& Bravender, 2008). There is a drastic decline from childhood to adulthood in physical activity levels, as demonstrated in a study by Casperson, Pereira and Curran (1999) where it was shown that physical activity decreases sharply between the ages of $15-18$, and continues to steadily decline to age 29 . Further, an examination of physical activity and sedentary behavior trends via data from the National Longitudinal Study of Adolescent Health showed that $66.4 \%$ of adolescents are not meeting recommended physical activity/per week guidelines, and an even 
larger proportion are not meeting those guidelines as adults (87.3\%) (Gordon-Larsen, Nelson, \& Popkin, 2004).

According to the American College Health Association National College Health Assessment (ACHA-NCHA; ACHA, 2006) self-reported participation in vigorous physical activity for at least 20-30 minutes on at least 3 of the past 7 days among college students is at approximately $44 \%$, falling from $64 \%$ for high school students (Lowry et al., 2000). Specifically looking at physical activity patterns of college students, Bray and Born (2004) also found that there are substantial disruptions of patterns of vigorous physical activity during the transition into college with approx. 1/3 of students becoming insufficiently active. Similarly, Huang et al. (2003) found that a majority of the college students in their study were not meeting physical activity guidelines with $16.1 \%$ reporting not engaging in any physical activity at all. Further, in a 2008 longitudinal study by Racette and colleagues, it was found that among the 204 participants, less than half of freshman who self-reported meeting guidelines for physical activity recommendations were still doing so during senior year. The authors cite that a major shortcoming of their study was a high dropout rate (73.3\%). Also, they neglected to explore the contributing factors for the decline but hypothesized that differences in living arrangements from freshman (100\% in dorms) to senior year $(15 \%$ in dorms) could be a factor. This decline in physical activity throughout the college years was also demonstrated in Buckworth and Nigg's study (2004) where, via questionnaires administered in a conditioning activity class in which they were enrolled, junior/senior undergraduate participants $(n=493)$ reported less purposeful physical activity (e.g. walking to class) and vigorous physical activity and more sedentary behavior (e.g. sitting at a computer, studying, watching TV) than freshman undergraduates. This trend may reflect the different academic demands between upper and lower level students. 
However, this study was correlational and the cause of the decrease in physical activity cannot be established.

\section{College Students and Dietary Intake}

Another leading factor in college student weight gain comes from the change in the dietary intake that many individuals encounter during the transition from adolescence to adulthood into a more independent lifestyle. For instance, according to an analysis of the 2003 Behavioral Risk Factor Surveillance System, $78.4 \%$ of 18 to 24 -year-olds in the United States consumed fewer than the recommended five servings of fruits and vegetables per day (McCracken, Jiles, \& Blanck, 2007). Healthy eating patterns tend to decline into adulthood as evident in a study using nationally representative data where it was shown that a significant increase in both eating fast food and skipping breakfast occurs between adolescence and adulthood and that both were associated with increased weight gain (Neimeier et al., 2006). Other national level longitudinal studies have also demonstrated that between adolescence and adulthood there is a marked decrease in the consumption of fruits and vegetables and a marked increase in the consumption of soft drinks (Lien, Lytle, \& Klepp, 2001) and a significant decrease in total fruit and vegetable intake during the transition period after high school (Larsen, Neumark-Sztainer, Hannan, \& Story, 2007).

Studies assessing the dietary intake of college students have demonstrated trends similar to that of the population in the college-age range. For example, a decrease in healthy eating between high school and college was evident in the 1995 National College Health Risk Behavior Survey where college students were shown as $18 \%$ more likely to consume 2 or more servings of high-fat foods/day than high school students (Lowry et al., 2000). According to the ACHANCHA, only $6 \%$ of students are consuming the recommended five or more daily servings of 
fruit/vegetables (ACHA, 2007). Huang et al. (2003) had less than 35\% of their college student participants report meeting daily recommended fruit/vegetable and fiber intake. Racette et al.'s 2008 study showed that less than one-third of the college student participants consumed recommended servings of fruit and vegetables in either freshman or senior year of college, as well. They also confirmed that more than $50 \%$ of this population ate fried or high-fat fast foods at least three times during the previous week (Racette et al., 2005). It is clearly evident that there is a lack of meeting dietary recommendations among college students.

\section{Possible Antecedents}

Understanding the behavioral changes contributing to weight gain during the adolescentto-adult developmental period is critical. During this time period in general, life events associated with an increase in independence, such as getting married, having children and starting work are all associated a decrease in physical activity and increase in body weight (Brown \& Trost, 2003). Many studies attempting to document the phenomenon of the "Freshman 15 " have shown that during the first year of college many students do, in fact, gain weight. Hoffman, Policastro, Quick, and Lee (2006) assessed the body compositions of 67 freshmen, during the first month and again during the six month of college. Three-quarters of the participants gained weight, with a mean increase in body weight of 6.82 pounds $(3.1 \pm 2.4 \mathrm{~kg})$, although whether the changes were significant is unclear. In another study, Mihalopoulos et al. (2008) used self-reported height and weight data from 125 college freshman to determine that there was a significant weight gain during the first seven months of college $(M=2.7 \mathrm{lbs}, S D=$ $6.4 ; p<.05)$. However, several limitations of this study include using potentially underestimated self-report height and weight data, as well as a retrospective account of the question "what was your weight in pounds at the beginning of freshman year?" Holm-Denoma, Joiner, Vohs, and 
Heatherton (2008) also used self-report data from surveys to determine that over a mean time of nine months, the 607 college freshmen in their study had gained a significant amount of weight averaging between $3.5(S D=8.5)$ and 4.0 pounds $(S D=6.3)$ without significant increases in height. Racette et al. (2008) used a prospective, longitudinal, observational study to assess the changes in height, weight, and BMI for college students from the first two weeks of freshman year until the end of their senior year. They found that among the 204 participants, the prevalence of obesity increased to $23 \%$ from $15 \%(p=.004$, relative to freshman year) with highly variable weight changes. Because the study did not assess weight at multiple time points throughout, it is unknown during which academic year weight changes occurred among the sample. While the authors did assess physical activity and nutrition, they commented on whether the sample was meeting recommendations but did not account any attempt toward associating those variables with weight gain. Levitsky, Halbmaier, and Mrdjenovid (2004) studied the change body weight of 68 freshman during their first semester, measuring from the first week to the twelfth, and noted a significant weight gain of 4.19 pounds $(p<.001)$ among their sample, however, they did not measure height which could enable them to rule out healthy weight gain. A major shortcoming of the research on the "Freshman 15 " is that an inadequate amount of studies actually investigate the causal factors. Many authors offer possible causes and contributing factors, such as college freshman facing new stressors and changes like eating in cafeteria-style buffets concurrent with a lack of knowledge/poor food choices, decreases in physical activity (Hoffman et al, 2006; Holm-Denoma et al., 2008; Hull, Morrow, Dinger, Han, \& Fields, 2007; Levitsky et al., 2004), and increases in alcohol intake (ACHA, 2007; Hoffman et al., 2006) and thus, they are more likely to gain weight and body fat (e.g. Anderson, Shapiro, \& Lundgren, 2003; Butler, Black, Blue \& Gretebeck, 2004; Graham \& Jones, 2002; Hoffman et al., 
2006, etc). More specifically, Holm-Denoma et al. (2008) investigated possible predictors of weight gain in freshmen college students and found that for men, the highest predictors of weight gain were Exercise/Sports participation $(p r=.14, \mathrm{p}<.05)$ and Relationship with Parents (how satisfied participants were with their relationship with parents) $(p r=.13, \mathrm{p}<.05)$, in that a negative relationship with parents was associated with weight gain. For women, although still very low, the only significant predictor was Relationship with Parents ( $p r=-.11, \mathrm{p}<.05)$, in that women who gained weight had a positive relationship with parents. Levitsky et al. (2004) also explored some of the factors thought to contribute to college student weight gain. In a multiple regression model, including initial body weight as a covariate, the variance accounted for by variables included in the model was $71 \%$. The variable that could explain of the weight gain the most was consumption of junk food accounting for $24 \%$ of the total variance, followed by meal frequency on weekends (17\%), recent dieting (9\%), amount of evening snacks consumed $(6 \%)$, eating lunch at a restaurant (5\%), eating lunch at a 'pay with cash' facility (4\%), hours of sleep (4\%) and initial weight (2\%). Surprisingly, the variable of dining at 'all you can eat' facilities was not included in the model when initial body weight co-varied. It was also surprising that physical activity was not included in the model. The authors hypothesized that the measure used to assess physical activity may not have been sensitive enough to detect a relationship. As demonstrated, while there are many suggested contributors, there is a lack of empirical support and a solid consensus concerning the causes of the 'Freshman 15' phenomenon. While some of the weight gain is likely attributable to normal growth and maturation at the end of adolescence (Racette et al., 2008), the average weight gain of the "Freshman 15" is approx. 4 lbs (Hull et al., 2007), which is still nearly 5 times what is reported for the general population and if such a rate 
was sustained within several years many would be obese (Mihalopoulos, Auinger, \& Klein, 2008).

\section{College Students and Weight Control}

Weight control is common concern in the U.S., yet most people attempting to do so, including college students, are not using recommended combinations of caloric restriction and adequate levels of physical activity to sufficiently achieve this (Weiss, Galuska, Kahn, \& Serdula, 2006). Thus, general recommendations for long-term reductions in weight and prevention of obesity include multicomponent interventions that combine education, a healthy diet, and exercise in conjunction with behavioral modifications (e.g. self-monitoring, stimulus control, problem solving, and cognitive restructuring) (NHLBI, 1998). However, The 1995 National College Health Risk Behavior Survey (NCHRBS) indicated that among the $46.6 \%$ of college students trying to lose weight, more than half of all students (53.6\%) reported using only exercise to lose weight and $30.8 \%$ reported using only diet to do so, with $53.8 \%$ of females and $40.9 \%$ of males reporting the use of both diet and exercise to do so (Lowry et al., 2000). While female students were less likely to be overweight than male students, they were more likely to be trying to lose weight and more likely to perceive themselves to be overweight. Approximately $60 \%$ of female college students were trying to lose weight compared with $48 \%$ of women in the general population (Lowry et al., 2000; Weiss et al., 2006). In addition, female students (15\%) were found to be using potentially harmful methods to lose weight such as diet pills, vomiting or laxatives. In another study of college women, $83 \%$ of participants reporting dieting to lose weight, with unhealthy dieting behaviors also reported such as smoking cigarettes (5-14\%), using laxatives (2-6\%), vomiting (4-6\%), and 7\% skipping meals (Malinauskas, Raedeke, Aeby, Smith, \& Dallas, 2006). Lowry et al. (2000) also found that neither moderate physical activity or 
consuming 5 or more servings of fruits/vegetables per day were associated with trying to lose weight among college students.

In the US, $67 \%$ of obese young adults (18-24 years) are trying to lose weight, yet only $24.3 \%$ have received professional advice on how to go about doing so (McCracken, Jiles, \& Blanck, 2007). In concordance, Lowry et al. (2000) determined nearly half of all college students were trying to lose weight, yet only about one-third of students reported receiving information from their university on topics of nutrition and physical activity recommendations and in result, many fail to adopt successful, sustainable, and healthy weight-management methods. In conjunction with utilizing unhealthy dieting practices, the lack of knowledge among college students concerning health practices is evident in several studies. In example, McArthur and Raedeke (2009) determined that only $40 \%$ of the 636 college students in their study were aware that adults should accumulate 30 minutes of moderate intensity physical activity on most days of the week for health benefits. In a study to examine college students' understanding of physical activity and the moderate physical activity recommendations, Behrens, Dinger, Heesch and Sission (2005) used qualitative methods to show that college students expressed considerable confusion pertaining to physical activity recommendations, especially on frequency and duration. Benefits of using focus groups to gather information allowed the researchers to assess not only if the participants have heard of the recommendations, but also how well they understood them. Although the study had a small sample of 30, they suggest that the recommendations still may not be reaching college students, referencing Morrow et al. (1999), where through a nationwide telephone survey, it was shown that only $16 \%$ of those aged $18-25$ years have heard of the recommendations. Concerning nutrition, using an internet-based survey tailored to sex and activity level, Kolodinsky, Harvey-Berino, Berlin, Johnson, and Reynolds (2007) observed that, 
among the 200 first-year college students in the cross-sectional study, an increased nutritional knowledge is related to an increased likelihood of meeting dietary guidelines among college students and that overall, healthier eaters have higher nutrition knowledge than unhealthy eaters. In another study of dieting practices by Malinauskas et al. (2006), among 184 normal weight, overweight, and obese female college students, $83 \%$ reported having consciously tried to lose weight. The most common method reported was exercising (80\%), although only $19 \%$ reported meeting physical activity guidelines. Maladaptive weight loss strategies were also used, such as cigarette smoking (9\%), vomiting (5\%), and using laxatives (3\%). Using over-the-counter weight-loss supplements (e.g. Hydroxycut ${ }^{\circledR}$, Xenedrine ${ }^{\circledR}$ ), which may be maladaptive, was reported by $26 \%$ of the respondents. However, the study did not assess quantity used to discern if these were being abused. Further, the study did not assess whether participants perceived their unhealthy weight loss practices as unhealthy. The authors do suggest that many maladaptive weight loss practices have become so mainstream that a majority of college students may be unaware of the health consequences of their methods. Collective results indicated that female college students, regardless of weight status could benefit from discussions with health educators pertaining to healthy weight management practices. Evidently, if college students do not know how much physical activity they should be getting or how to manage their dietary intake appropriately, they are even less likely to do so, highlighting the importance of interventions aiming to increase knowledge pertaining to health behaviors among college students. The Role of Colleges in Preventing and Treating Obesity

While there appears to be a general consensus on the causes of weight gain among the college student population, there is less of a consensus on what can and should be done to reduce the problem. However, there is an abundance of support in the literature (e.g. Adderley-Kelly, 
2007; Buckworth, 2001; Desai et al., 2008; Huang et al., 2003; Jozkowski, 2007; Lowry et al., 2000; Malinauskas et al., 2006; Nelson, Story, Larson, Neumark-Sztainer, \& Lytle, 2008;

Racette et al., 2008, etc) to conclude that colleges need to intervene and implement programs that teach college students healthy weight management, focusing on nutrition and physical activity. This need has been recognized on a national level as evident in The Healthy Campus 2010 campaign (ACHA, 2006). In concordance with the US Department of Health and Human Services Healthy People 2010 campaign, which is a set of national health objectives designed to identify significant threats to health and establish goals to reduce those threats within 10 years (USDHHS, 2005), Healthy Campus 2010 seeks to parallel those national initiatives among the college student population. Of the leading public health issues for the nation, physical activity (Objectives: 22-2 \& 22-7) and overweight and obesity (Objectives: 19-2 \&19-3c) are \#1 and \#2 respectively (USDHHS, 2007). Healthy Campus 2010 aims to increase the proportion of college students who have received information on physical activity and fitness from $33.5 \%$ to $55 \%$ and increase the proportion of college students meeting physical activity guidelines from $40.3 \%$ to $55 \%$ by 2010 . Simultaneously addressed is the issue of overweight and obesity by aiming to increase the proportion of college students who have received information on dietary behaviors and nutrition from $32.7 \%$ to $55 \%$ and reduce the proportion of adolescents and college students who are overweight and obese from $29.5 \%$ to $16 \%$ by 2010 (Grizzell, Moses, \& Nelson, 2002).

The college years can be an ideal time for implementing programs to decrease inactivity, increase nutritional and physical activity knowledge and decrease obesity. The poor health outcomes of obesity usually manifest later in life, however the behavioral patterns contributing to such conditions can begin during childhood, adolescence, and young adulthood. McTigue, Garrett and Popkin (2002) demonstrated the importance of obesity interventions targeting young 
adults by illustrating that over $80 \%$ of the obese adults in their longitudinal study of 9179 participants, became obese during early adulthood and that it is during this time that social patterning in obesity strongly emerges. Considering that many college students are still developing their lifestyle patterns and self-management skills, the college years may provide the last good opportunity to provide wide-reaching, cost-effective interventions necessary for healthy lifestyle changes (Adderley-Kelly, 2007; Buckworth, 2001; Nelson et al., 2008).This transitional period during the age of 18-25 has been referred to as "emerging adulthood" (Arnett, 2000), marked by the transition out of the home to semi-independent living and an increased autonomy in decision-making. At this time, individuals are also developing identity and refining their value system, with less interpersonal influence from the family of origin. Conducive to identity development and refining values, there is an increase in the exploration of ideologies and alternate perspectives/ behaviors. Therefore, "emerging adulthood" may be a prime time for minimizing the effects of adverse health behaviors developed during childhood via consciousness-raising concerning health behaviors, followed by an integration of a healthy lifestyle into one's identity and thus, establishing long-term health behaviors and patterns. In 2007, there were approximately 17.5 million students enrolled in postsecondary degree-granting institutions with 39\% of all 18-24 year-olds enrolled in college (US Department of Education, 2007). With access to a large proportion of young adults, as well as adequate resources and funding, college campuses provide a foremost medium for reaching a large number of diverse young adults with education and preventative programs for weight management.

\section{Psychosocial Factors Related to Weight Loss Among College Students}

There has been much research done investigating the individual factors that influence exercise/diet adherence and weight loss in general. Generally, a variety of constructs have been 
identified that contribute to successful weight management. Those factors deemed to be most effective throughout the literature include knowledge, self-efficacy and social support (Wharton, Adams, \& Hampl, 2008).

Self-efficacy can be defined as one's belief's pertaining to their ability to perform a specific action, such as exercising, dieting, and adhering to a weight-loss plan. According the Social Cognitive Theory, knowledge about a health behavior and the benefits of it can increase self-efficacy and self-efficacy is the primary determinant of whether the person will execute the behavior (Bandura, 1997). In fact, self-efficacy has received the most support for any variable in predicting exercise adherence (Sallis, Hovell, \& Hofstetter, 1992) and has shown a strong association with the successful use of diet-related behavioral strategies (Nothwehr, 2008).

In addition to increasing knowledge to foster self-efficacy and thus, success in increasing physical activity, dieting and weight-loss, social support has been consistently shown as a primary psychosocial variable for increasing success in individuals making health behavior changes, especially in the adoption of exercise by sedentary women (Sallis, Hovell, \& Hofstetter, 1992) and a supportive social environment has been shown to increase the maintenance of a behavior change (Kahn et al., 2002).

Among college students, social support was significantly related to exercise adherence in a sample of 62 students participating in various exercise classes (Courneya \& McAuley, 1995) and social support for exercise and healthful dietary habits were associated with health behaviors in a sample of 43 college students interviewed about their eating behaviors, physical activity behaviors and priorities (Strong et al., 2008). In an exploratory study of factors influencing physical activity, Rovniak, Anderson, Winett, and Stephens (2002) found that among college students ( $\mathrm{N}=227$ ), higher levels of self-efficacy were associated with higher levels of exercise 
participation $(\beta[$ total $]=.71, p<.001)$ and that social support mediated this effect. Therefore, increasing the knowledge that college students have about how to lose weight and increase fitness and the benefits of doing so, could potentially result in a better outcome. This result was demonstrated in a study where 23 small group lectures aimed at increasing knowledge on weight gain, risks, dietary/physical activity recommendations and benefits held over two years prevented the weight gain usually observed upon entering college (Hivert, Langlois, Berard, Cuerrier, \& Carpentier, 2008). The program was delivered to an experimental group of first and second year normal weight and overweight college students by various health professionals including an endocrinologist, a dietitian and a physical education specialist. The change in weight between the control groups and the experimental group was significant over the followup $(p=.04)$, with the experimental group BMI becoming significantly lower $(p=.01)$. Another program used an internet-based platform for nutrition and physical activity education for college students ( $\mathrm{N}=476)$, which lead to significant changes in participants on measures of social support $(p<.05)$, self-efficacy for dietary change $(p<.05)$, and encouragement for dietary change $(p<.01)$, and knowledge $(\mathrm{p}<.05)$ versus the control group (Franko et al., 2008). This evidence should be taken into consideration concerning programs addressing weight loss for college students.

Generally, obesity prevention and weight management programs have been difficult to design and implement during the "emerging adult" years, as there is insufficient epidemiologic literature on the determinants of weight gain for this population and even less on effective interventions (Nelson et al., 2008). There is a scarcity of literature on the effects of nutrition education and specific weight control programs on college students' ability to lose weight (Ferrara, St. Laurent, \& Wilson, 2008; Nelson et al., 2008; Strong, Parks, Anderson, Winett, \& Davy, 2008) with fewer examples of studies systematically evaluating those programs. 


\section{Programs Addressing Weight Loss for College Students}

As well, Hunt, Bogle, Gillentine, \& Daughtrey (2007) suggest that weight loss programs designed for college students take into account the unique characteristics of the target audience such as convenience of access/accessibility, students' time/financial limitations, ethnic diversity, and campus setting. Similar to others (e.g. Adderley- Kelly, 2007; Strong et al., 2008) they also stress the importance of providing behavioral therapy and recommend that programs for young adults include learning new skills - not just facts - and opportunities to practice new skills and participate in activities that are fun and innovative. Other studies have examined components potentially contributing to the effectiveness of weight loss/ fitness programs among college students. Pinto, Cherico, Szymanski, \& Marcus (1998) examined specific types of program components that students endorsed and found monthly educational newsletters to be the most popular option among students and that most students recognized a need for additional structure (e.g. one-on-one nutritional counseling, personal training) as they began to incorporate health behaviors into their lifestyle.

There are several examples of weight loss and behavior modifications programs among college students with varying effectiveness. In example, Jozkowski (2007) evaluated such a weight loss program. Follow Me: Students Helping Students to Better Health was designed as an 8 week-long peer-led weight loss intervention geared toward college students using social support as the main built-in component. The program consisted of weekly educational meetings addressing various avenues of weight loss such as nutrition, physical activity, and how to incorporate those health behaviors into a daily routine in addition to weekly weigh-ins. Results of the program indicated a high attrition rate, with 12 of the original 26 participants staying in the program, noted by the author as being consistent with previous research on weight loss and 
behavioral modification programs. Although none of the participants gained weight, significant weight-loss was not achieved. However, participants agreed that the program increased their selfefficacy for healthy eating/exercising and $100 \%$ were satisfied with the program material, format, peer-lead facilitation and provided social support. The lack of significant weight loss among participants could be due to the inadequate length of the program, as 8 weeks may not be long enough for behavioral changes to manifest into measurable weight loss. This may have lead the authors to focus on other factors, such as $75 \%$ of participants reporting that they had met at least one of the nutrition and exercise goals that they had set and $100 \%$ reporting satisfaction with the program material, to insinuate semi-effectiveness. It is possible that this program may have demonstrated significant weight loss among participants had a larger sample been used, thereby minimizing the effects of attrition and allowing for stronger statistical analyses. As the program was peer-led (denoted by the sole qualification that they had a personal history with weight loss), it is also possible that the leaders may have lacked the professional knowledge needed to ensure effective dissemination of valid information.

Another study was conducted by Ferrara, St.Laurent, and Wilson (2008) evaluating a 3 month-long weight loss contest for overweight and obese college students. The contest consisted of monthly weigh-ins, education sessions (focusing on nutrition, healthy eating, and exercise) and exercise sessions with a prize (gift certificate worth $\$ 150$ to $\$ 500$ ) for the top three finishers as determined by reductions in body weight, BMI, percent body fat and circumference measurements. Results indicated that weight loss was significantly correlated with attending the educational classes $(r=-.39 p<.05)$ and exercise sessions $(r=-.41, p<.05)$, although the authors do not state the overall average weight loss of participants in the program. Also, less than half $(40 \%)$ of the participants attended the monthly weigh-ins, educational classes, and exercise 
sessions. The authors concluded that it is necessary to determine why the contest incentive worked for some, but not all, of the participants and cautioned that a contest format may foster unhealthy weight loss behaviors in order to win. Further, they suggest that future research on college weight loss programs examine the factors that contribute to any observed weight loss and adherence to the program, as well the long-term effects of the program.

Another program aiming to specifically increase exercise self-efficacy among college age females via exercise sessions, performance feedback, informational materials and motivational emails demonstrated that exercise self-efficacy and barrier self-efficacy was associated with higher attendance (D’Alonzo, Stevenson, \& Davis, 2004). However, neither group showed significant changes in fitness measures or body fat percentage, likely because participation in the program was still well below recommendations for physical activity for both groups. Overall, as a result of their study, D’Alonzo, Stevenson, and Davis (2004) suggest that programs that combine structured exercise sessions along with opportunities for self-monitoring of physical activity could be useful for increasing college students' self-efficacy and thus, physical activity. They did not include an examination of nutritional factors in their study.

Summarized from the previous studies, components of programs that have been consistently supported as effective include education sessions/lectures and/or counseling on exercise and proper diet in order to increase knowledge and foster self-efficacy. This component also reflects the aim of Healthy Campus 2010 toward increasing the proportion of students having received information on meeting physical activity and dietary behavior/ nutrition guidelines. Therefore, it would be salient for such programs aiming to be effective amongst college students to include the aforementioned components. Further, in determining program 
effectiveness, knowledge gained and self-efficacy changes, as well as resulting behavior changes should also be assessed.

As there is an undeniable need for effective programs and interventions that promote healthy living and weight management among college students, coupled with the mediocre results of some programs, it is vital that those already in existence are evaluated. Generally, programs are evaluated for several reasons including: to determine if desired outcomes of the program were achieved, to improve program implementation, to contribute to the scientific base for similar interventions, and to inform decisions pertaining to the program's existence (Capwell, Butterfoss, \& Francisco, 2000). Further, even fewer weight loss programs are evaluated from the participants' perspective. In the absence of systematic evaluation, 'effectiveness' is merely a speculation. Although there have been advances in program evaluation models and research, relevant literature reveals a lack of addressing the systematic evaluation of weight loss programs for college students.

\section{RE-AIM Framework}

The RE-AIM framework (see Estabrooks \& Gyurcsik, 2003; Glasgow, Vogt, \& Boles, 1999) provides an outline for program evaluation. It serves to evaluate interventions on two levels: (1) individual, and (2) organizational, and on five dimensions: (1) reach, (2) efficacy/effectiveness, (3) adoption, (4) implementation and (5) maintenance, with reach and efficacy/effectiveness comprising the individual level and adoption, implementation, and maintenance comprising the organizational level of the assessment. Implementation (e.g. Nigg, Courneya, \& Estabrooks, 1997) and maintenance (e.g. Dunn et al., 1999) can be assessed at the individual level, as well (Glasgow et al., 1999). Each of the five dimensions is assessed on a 0-1 
scale (or a $0 \%$ to $100 \%$ scale). A central tenet of the RE-AIM model is that the ultimate impact of an intervention is the combination of its effects across all five dimensions.

Reach is an individual level measure of participation that includes the percentage of and characteristics of participants in a program, as well as their representativeness of the intended population. An important question addressed in this domain is "Does the intervention reach those in the population that need it?" Effectiveness/efficacy is an individual level measure of the degree in which target variables (e.g. behavioral, quality of life, physiological) changed among participants receiving the intervention. Specifically, it is important to assess positive and possible unanticipated negative outcomes of the program.

On the organizational level, adoption is measure of participation that includes the percentage of and characteristics of sites that adopt a program, as well as their representativeness of the intended population. Also included may be the barriers encountered by those sites that did not implement the program. Implementation refers to the extent that a program is executed as anticipated. It can be measured on the individual level via measuring participants' adherence to intervention protocol. It can be measured on the organizational level via measuring the extent to which those that were delivering the program did so as intended. This dimension serves to determine the practicality of effectively delivering an intervention in representative settings. Glasgow et al. (1999) suggest a minimum of 6 months to 1 year for this data to be collected. Maintenance is the dimension in which long-term effects are assessed following the completion of the actual delivery of the intervention. This dimension can also be evaluated on both the individual level - via assessing individual outcomes, and the organizational level - via a measure of the time that the intervention is sustained in real-world settings. Glasgow et al. (1999) suggest a minimum of 2 years or longer for the length of time for this date to be collected. 
Ultimately, the data collected via the RE-AIM model can be used for several appraisals: an intervention's overall impact; noting the intervention's effects over settings or time; comparing two or more interventions across one or more of the dimensions; guiding decisions pertaining to effective resource allocation (Glasgow at al., 1999).

The RE-AIM model has been applied to several programs to assess the overall public health impact. The RE-AIM model has also been sufficiently used to evaluate the impact of interventions to increase physical activity as well as lifestyle management interventions.

In the evaluation of the Walk Kansas program (Estabrooks, Bradshaw, Dzewaltowski, \& Smith-Ray, 2008), the RE-AIM model was used to assess the individual level impact of the intervention on the dimensions of reach, effectiveness, and maintenance (Phase 1), and the organizational level impact on the dimensions of adoption and maintanence, or the continued delivery over time after the initial implementation (Phase 2). In Phase 1, the researchers determined the reach by assessing the number of participants, the proportion of the target population reached and their overall representativeness based on demographic variables. Effectiveness was determined by analyzing if the intervention was able to increase physical activity in insufficiently or moderately active participants and maintain the level of physical activity in vigorously individuals. The maintenance dimension was analyzed by assessing if participants continued to engage in regular physical activity 6 months after the completion of the program. In Phase 2, the researchers determined the adoption by comparing the counties that implemented the program versus those who did via census data; the sustainability by assessing the number of counties that chose to continue with the intervention after the initial delivery. Although RE-AIM values were not provided on a 0-1 scale, the researchers concluded that the RE-AIM model successfully enabled conclusions to be drawn on the impact of the intervention 
including that Walk Kansas was efficacious in that vigorous physical activity levels were increased significantly among inactive $(p<.001)$, insufficiently active $(p<.001)$, and active $(p$ $<.001$ ) individuals from baseline to 8 weeks; among whom (participants and counties) the intervention was adopted ( 48 of Kansas' 105 counties adopted the program in the first year (2002), with 97 having adopted it 4 years later); and among which participants and counties the intervention was and was not maintained (moderate physical activity levels were maintained by both inactive $(p<.001)$ and insufficiently active $(p<.001)$ individuals, but not already active individuals 6 months into the study and $76 \%$ of counties continued to offer the program for four of the five study years). Interestingly, participants in the program accounted for $1 \%$ of the total population of the counties where the program was offered, indicating a low reach on the individual level.

The Health-e-AME 3-year physical activity intervention in churches also used the REAIM framework for evaluation (Bopp et al., 2007). The primary method used to gather information pertaining to the 5 dimensions was qualitative interviews. The reach of the intervention was assessed by the program staff's estimates of participation and description of the participant demographics. The effectiveness of the intervention was assessed by interviewing participants on their self-reported PA. Adoption, implementation and maintenance were also assessed by use of interviews among program staff. The study concluded mixed results on the overall impact of the program, including a reach of between $2 \%$ and $100 \%$ of members at each of the 303 churches in the study (a total of 889 congregants) and lack of effectiveness in getting people to follow physical activity recommendations $(P=.08)$. More churches adopted the program in the first year of it being offered (80\%) versus the second year (52\%), with major challenges to adopting the program consisting of a lack of motivation or commitment from 
leaders and the congregation from churches that adopted the program (45\%) and churches that did not (60\%). Further, of the 25 churches adopting during the first year, only 13 of the churches were still offering some component of the intervention at the conclusion of the 2 year study. While some valuable information was obtained via interview, such as the problems encountered with the program on the RE-AIM dimensions, there are inherent limitations (e.g. bias, social desirability, erroneous recall) with using only qualitative data. Results may have been more definitive had the researchers combined qualitative and quantitative methods in their study.

The Mediterranean Lifestyle Program aimed to change behavioral risk factors (eating patterns, physical activity, stress management and social support) of postmenopausal women with type 2 diabetes. Using the RE-AIM framework for evaluation, it was determined that the program consistently produced significant improvements compared to the treatment-as-usual group on most measures, including the four diverse risk factors targeted. The program was adopted by $70 \%$ of physicians approached and $51 \%$ of eligible participants participated (Toobert, Strycker, Glasgow, Barrera, \& Angell, 2005). However, although the authors mention using the RE-AIM model to guide the evaluation, results were not specifically reported on any of the REAIM dimensions.

Recently, an evaluation of the public health impact of an insurance-sponsored weight management program was conducted using qualitative (archival; survey) and quantitative methods (focus groups) along the dimensions of the RE-AIM framework (Abildso, 2008). The RE-AIM model was determined to be suitable for this evaluation because the weight loss intervention was implemented by individuals at multiple sites over a statewide network, illustrating a need for evaluation on both the individual and organizational levels. Using a mixture of qualitative and quantitative methods, Abildso (2008) was able to determine not only 
the index scores on each dimension of the model, but was able to suggest factors that may have contributed to the values. In example, the reach and the adoption of the program were found to be low $(\mathrm{R}=5.4$ and $\mathrm{R}=8.8$, respectively). The reach was low mostly due to low participation by potentially eligible members. The adoption was low due to scarce resources, usually on the part of staff and administration. The effectiveness of the program was moderate $(\mathrm{E}=43.8)$ and was determined to be like that of other similar weight management programs, with a majority of participants $(78.5 \%)$ achieving a 1 pound per week weight-loss, with a somewhat higher attrition rate $(22.5 \%)$ - about $10 \%$ higher than other behavioral programs. Implementation of the components of the program was shown to be high $(I=91.4)$, although with questionable quality and frequency. Information gathered from focus groups denoted that participant social support, site environment, and program transition and translation were important moderating factors in the effectiveness and implementation of the program. Site maintenance was determined to be high $\left(\mathrm{M}^{\mathrm{s}}=77.8\right)$, which provided support that the program was sustainable over time at the sites. However, it was shown that individual maintenance was low $\left(\mathrm{M}_{\mathrm{s}}=21.2\right)$, with slightly over half over the program participants maintaining weight loss after the first 12 weeks of the program. A moderate rate of attrition was evident with $42 \%$ of participants still enrolled in the program one year later. While this study illustrated a thorough application of the RE-AIM model and the importance of complementing quantitative data with qualitative data, several limitations were noted including the use of non-standardized measures and partially incomplete archival data. Further, Abildso (2008) pointed out the possibility of social desirability in site responses in surveys and focus groups.

Therefore, previous researchers have demonstrated that the RE-AIM is sufficient to use for the evaluation of physical activity interventions and lifestyle management interventions and 
that using qualitative methods may enhance quantitative data gathered on the 5 RE-AIM dimensions. In a targeted review of school health promotion studies, Estabrooks, Dzewaltowski, Glasgow \& Klesges (2003) reported that although well-controlled studies of these programs show that they have positive effects, little evidence suggests that these programs translate into sustained programs or general practice due to a lack of evaluation on all 5 RE-AIM dimensions. Further, relatively little research has been conducted to test interventions changing multiple lifestyle behaviors simultaneously (e.g. changing diet, increasing physical activity, and decreasing body fat) (Glasgow, Klesges, Dzewaltowski, Bull, \& Estabrooks, 2004; Toobert et al., 2005).

\section{Summary}

The RE-AIM model has been used in several in studies demonstrating its application in program evaluation, especially concerning issues related to representativeness and generalization for broader translation. The RE-AIM model is most commonly used as an evaluation framework to assess the effects of a new, ongoing or concluded program and thus far, has been used mostly to assess health interventions on a multi-site (e.g. community or state wide) basis. A primary interest for most of these interventions concerns the public health impact and real-world feasibility, including "what difference a program made, how those effects were achieved, why they occurred and whether they can be maintained over time" (McKenzie, 2005, p.2). Currently, only one study (Abildso, 2008) has used the RE-AIM model to evaluate a weight management program. Although the RE-AIM model has not yet been used to evaluate single-site university sponsored college-student weight-loss programs, it is relevant to use as a framework in that it will answer the questions of what, how, why and what/why over time pertaining to the impact of the program. 


\section{References}

Abildso, C. (2008). Evaluating an insurance-sponsored weight management program using the RE-AIM model. Doctoral dissertation, West Virginia University, 2008.

Adderley- Kelly, B. (2007). The prevalence of overweight and obesity among undergraduate health sciences students. The ABNF Journal, 18(2), 46-50.

American College Health Association. (2006). American College Health Association National college health assessment (ACHA-NCHA) Spring 2005 reference group data report (Abridged). Journal of American College Health, 55(1), 5-16.

American College Health Association. (2007). American College Health Association National College Health Assessment Spring 2006 Reference Group data report (abridged). Journal of American College Health, 55(4), 195-206.

Anderson, D.A., Shapiro, J.R., \& Lundgren, J.D. (2003). The freshman year as a critical period for weight gain. Eating Behavior, 4, 363-367.

Arnett, J.J. (2000). Emerging adulthood. A theory of development from the late teens through twenties. American Psychology, 55, 469-480.

Bandura, A. (1997). Self-efficacy: The Exercise of Control. New York: W.H. Freeman and Co.

Behrens, T.K., Dinger, M.K., Heesch, K.C., \& Sisson, S.S. (2005). College students' understanding of moderate physical acticity: A qualitative study. American Journal of Health Studies, 20(3), 129-134.

Berger, B.G., Pargman, D., \& Weinberg, R.S. (2002). Foundations of Exercise Psychology. Fitness Information Technology: Morgantown, WV.

Bopp, M., Wilcox, S., Laken, M., Hooker, S.P., Saunders, R., Parra-Medina, D., et al. 
(2007).Using the RE-AIM framework to evaluate a physical activity intervention in churches. Preventing Chronic Disease, 4(4).

http://www.cdc.gov/pcd/issues/2007/oct/06_0155.htm.

Accessed November 17, 2008.

Bray, S.R., \& Born, H.A. (2004). Transition to university and vigorous physical activity: Implications for health and psychological well-being. Journal of American College Health, 52(4), 181-188.

Brown, W.J., \& Trost, S.G. (2003). Life transitions and changing physical activity patterns in young women. American Journal of Preventive Medicine, 25, 140-143.

Buckworth, J. (2001). Exercise adherence in college students: Issues and preliminary results. Quest, S3, 335-345.

Buckworth, J., \& Nigg, C. (2004). Physical activity, exercise, and sedentary behavior in college students. Journal of American College Health, 53(1), 28-34.

Butler, S.M., Black, D.R., Blue, C.L., \& Gretebeck, R.J. (2004). Change in diet, physical activity, and body weight in female college freshman. American Journal of Health Behavior, 28, 24-32.

Capwell, E.M., Butterfoss, F. \& Francisco, V.T. (2000). Why evaluate? Health Promotion Practice, 1(1), 15-20.

Casperson, C.J., Pereira, M.A., \& Curran, K.M. (1999). Changes in physical activity patterns in the United States, by sex and cross-sectional age. Medicine \& Science in Sports \& Exericise, 32(9), 1601-1609.

Centers for Disease Control and Prevention. (2007). Behavior risk factor surveillance system: 2007 prevalence data. Retrieved January 3, 2009, from http://apps.nccd.cdc.gov/brfss/. 
Courneya, K.S., \& McAuley, E. (1995). Cognitive mediators of the social influenceexercise adherence relationship: A test of the theory of planned behavior. Journal of Behavioral Medicine, 18(5), 499-515.

D’Alonzo, K.T., Stevenson, J.S., \& Davis, S.E. (2004). Outcomes of a program to enhance exercise self-efficacy and improve fitness in Black and Hispanic college-age women. Research in Nursing \& Health, 27(5), 357-369.

Desai, M.N., Miller, W.C., Staples, B., \& Bravender, T. (2008). Risk factors associated with overweight and obesity in college students. Journal of American College Health, 57(1), 109-114.

Dunn, A.L., Marcus, B.H., Kampert, J.B., Garcia, M.E., Kohl, H.W., III, \& Blair, S.N. (1999). Comparison of lifestyle structured interventions to increase physical activity and cardiorespiratory fitness: A randomized trial. Journal of the American Medical Association, 281, 327-334.

Estabrooks, P.A, Bradshaw, M., Dzewltowski, D.A., \& Smith-Ray, R.L. (2008). Determining the impact of Walk Kansas: Applying a team-building approach to community physical activity promotion. Annals of Behavioral Medicine, 36, 1-12.

Estabrooks, P.A., Dzetwaltowski, D.A., Glasgow, R.E., \& Klesges, L.M. (2003). Reporting of validity from school health promotion studies published in 12 leading journals, 19962000. Journal of School Health, 73(1), 21-28.

Estabrooks, P.A., \& Gyurcsik, N.C. (2003). Evaluating the impact of behavioral interventions that target physical activity: issues of generalizability and public health. Psychology of Sport and Exercise, 4, 41-55.

Ferrara, C., St.Laurent, C., \& Wilson, T. (2008). The benefits of a weight-loss contest in 
overweight and obese college students. Recreational Sports Journal, 32, 45-51.

Flegal, K.M., Carroll, M.D., Ogden, C.L., \& Johnson, C.L. (2002). Prevalence and trends in obesity among US adults, 1999-2000. Journal of the American Medical Association, 288(4), 1723-1727.

Franko, D.L., Cousineau, T.M., Trant, M., Green, T.C., Rancourt, D, et al. (2008). Motivation, self-efficacy, physical activity and nutrition in college students: Randomized controlled trial of an internet-based education program. Preventive Medicine, 47, 369-377.

Glasgow, R.E., Klesges, L.M., Dzewaltowski, D.A., Bull, S.S., \& Estabrooks, P. (2004). The future of health behavior change research: What is needed to improve translation of research into health promotion practice? Annals of Behavioral Medicine, 27(1), 3-12.

Glasgow, R.E., Vogt, T.M., \& Boles, .S.M. (1999). Evaluation the public health impact of health promotion interventions: The RE-AIM framework. American Journal of Public Health, 89, 1233-1327.

Gordon-Larsen, P., Adair, L.S., Nelson, M.C., \& Popkin, B.M. (2004). Five-year obesity incidence in the transition period between adolescence and adulthood: the National Longitudinal Study of Adolescent Health. American Journal of Clinical Nutrition, 80, $869-875$.

Gordon-Larsen, P., Nelson, M.C., \& Popkin, B.M. (2004). Longitudinal physical activity and sedentary behavior trends: Adolescence to adulthood. American Journal of Preventive Medicine, 27(4), 277-283.

Graham, M.A, \& Jones, A.L. (2002). Freshman 15: A valid theory or harmful myth. Journal of American College Health, 50(4), 171-173.

Grizzell, J., Moses, K., \& Nelson, G. (2002). Healthy Campus 2010: Making it happen. 
Retrieved January 22, 2009 from http://www.acha.org/Info_resources/hc2010.cfm.

Haberman, S. \& Luffey, D. (1998). Weighing in college students' diet and exercise behaviors. Journal of American College Health, 46(4), 189-191.

Hivert, M.F., Langlois, M.F., Berard, P., Cuerrier, J.P., \& Carpentier, A.C. (2008). Prevention of weight gain in young adults through a seminar-based intervention program. International Journal of Obesity, 31, 1268-1269.

Hoffman, D.J., Policastro, P., Quick, V., Lee, S. (2006). Changes in body weight and fat mass of men and women in the first year of college: A study of the "Freshman 15". Journal of American College Health, 55(1), 41-45.

Holm-Denoma, J.M., Joiner, T.E., Vohs, K.D., \& Heatherton, T.F. (2008). The "freshman Fifteen" (the "freshman five" actually): Predictors and possible explanations. Health Psychology, 27(S1), S3-S9.

Huang, T.K, Harris, K.J., Lee, R.E., Nazir, N., Born, W., \& Kaur, H. (2003). Assessing overweight, obesity, diet, and physical activity in college students. Journal of American College Health, 52(2), 83-86.

Hull, H.R., Morrow, M.L., Dinger, M.K., Han, J.L., \& Fields, D.A. (2007). Characterization of body weight and composition changes during the sophomore year of college. BMC Women's Health, 21(7), http://www.biomedcentral.com/1472-6874/7/21. Accessed January 20, 2009.

Hunt, B.P., Bogle, V., Gillentine, A., \& Daughtrey, C. (2001). Weight loss 101: A healthy weight loss program for college students. American Journal of Health Studies, 17(1), 26-30.

Jozkowski, K. (2007). Evaluation of a weight loss intervention program among college females. 
The Health Education Monograph Series, 24(2), 32-37.

Kahn, E.B., Ramsey, L.T., Brownson, R.C., Heath, G.W., Howze, E.H., Powell, K.E., et al. (2002). The effectiveness of interventions to increase physical activity: A systematic review. American Journal of Preventative Medicine, 22(4S), 73-107.

Kolodinsky, J., Harvey-Berino, J.R., Berlin, L., Johnson, R.K., \& Reynolds, T.W. (2007). Knowledge of current dietary guidelines and food choice by college students: Better eaters have higher knowledge of dietary guidance. Journal of the American Dietetic Association, 107, 1409-1413.

Larson, N.I., Neumark- Sztainer, D., Hannan, P.J., \& Story, M. (2007). Trends in adolescent fruit and vegetable consumption, 1999-2004: Project EAT. American Journal of Preventative Medicine, 32, 147-150.

Levitsky, D.A., Halbmaier, C.A., \& Mrdjenovic, G. (2004). The freshman weight gain: A model for the study of the epidemic of obesity. International Journal of Obesity, 28, $1435-1442$.

Lien, N., Lytle, L.A., \& Klepp, K. (2001). Stability in consumption of fruit, vegetables, and sugary foods, in a cohort from age 14 to age 21. Preventive Medicine, 33, 217-226.

Lowry, R., Galuska, D.A., Fulton, J.E., Wechsler, H., Kann, L., \& Collins, J.L. (2000). Physical activity, food choice, and weight management goals and practices among U.S. college students. American Journal of Preventive Medicine, 18(1), 18-27.

Malinauskas, B.M., Raedeke, T.D., Aeby, V.G., Smith, J.L., \& Dallas, M.B. (2006). Dieting practices, weight perceptions, and body composition: A comparison of normal weight, overweight, and obese college females. Nutrition Journal, 5:11. http://www.pubmedcentral.nih.gov/picrender.fcgi?artid=1456978\&blobtype=pdf. 
Accessed January 20, 2009.

McArthur, L.H., \& Raedeke, T.D. (2009). Race and sex differences in college student physical activity correlates. American Journal of Health Behavior, 33(1), 80-90.

McCracken, M., Jiles, R., \& Blanck, H.M. (2007). Health behaviors of the young adult US population: Behavioral risk factor surveillance system, 2003. Preventing Chronic Disease, 4(2). http://www.cdc.gov/pcd/issues/2007/apr/06_0090.htm. Accessed January 18, 2009.

McKenzie, R. (2005, October). Targeting what matters in health promotion evaluation - using the RE-AIM approach to identify success in 'real world' settings. Paper presented at the Australasian Evaluation Society 2005 International Conference, Brisbane, AU.

McTigue, K.M., Garrett, J.M., \& Popkin, B.M. (2002). The natural history of the development of obesity in a cohort of young adults between 1981 and 1998. Annals of Internal Medicine, 136(12), 857-864.

Mihalopoulos, N.L., Auinger, P., \& Klein, J.D. (2008). The Freshman 15: Is it real? Journal of American College Health, 56(5), 531-533.

Mokdad, A.H., Ford, E.S., Bowman, B.A., Dietz, W.H., Vinicor, F., Bales, V.S., et al. (2003). Prevalnce of obesity, diabetes, and obesity-related health risk factors, 2001. Journal of the American Medical Association, 289(1), 76-79.

Morrow, J.R., Jackson, A.W., Bazzarre, T.L., Milne, D., \& Blair, S.N. (1999). A one-year follow-up to physical activity and health: A report of the Surgeon General. American Journal of Preventive Medicine, 17, 24-30.

National Heart Lung and Blood Institute. (1998). Obesity Education Initiative Expert Panel: Clinical guidelines on the identification, evaluation and treatment of 
overweight and obesity in adults- The evidence report. Obesity Research, 6 (Suppl.), 51-210.

Neimeier, H.M., Raynor, H.A., Lloyd-Richardson, E.E., Rogers, M.L., \& Weng, R. (2006). Fast food consumption and breakfast skipping: Predictors of weight gain from adolescence to adulthood in a nationally representative sample. Journal of Adolescent Health, 39(6), 842-849.

Nelson, M.C., Story, M., Larson, N.I., Neumark-Sztainer, D., \& Lytle, L.A. (2008). Emerging Adulthood and college-aged youth: An overlooked age for weight-related behavior change. Obesity, 16, 2205-2211.

Nelson, T.B., Gortmaker, S.L., Subramanian, S.V., Cheung, L., \& Wechsler, H. (2007). Disparities in overweight and obesity among US college students. American Journal of Health Behavior, 31(4), 363-373.

Nigg, C.R., Courneya, K.S., \& Estabrooks, P.A. (1997). Effects of differential self-monitoring on attendance at a fitness center. Avante, 3(3), 64-79.

Nothwehr, F. (2008). Self-efficacy and its association with use of diet-related behavioral strategies and reported dietary intake. Health Education \& Behavior, 35(5), 698-706.

Ogden, C.L., Carroll, M.D., Curtin, L.R., McDowell, M.A., Tabak, C.J., \& Flegal, K.M. (2006). Prevalence of overweight and obesity in the United States, 1999-2004. Journal of the American Medical Association, 295(13), 1549-1555.

Pinto, B.M., Cherico, N.P., Szymanski, L., \& Marcus, B.H. (1998). Longitudinal changes in college students' exercise participation. Journal of American College Health, 47(1), $23-28$.

Racette, S.B., Deusinger, S.S., Strube, M.J., Highstein, G.R., \& Deusinger, R.T. (2005). 
Weight changes, exercise, and dietary patterns during freshman and sophomore years of college. Journal of American College Health, 53(6), 245-251.

Racette, S.B., Deusinger, S.S., Strube, M.J., Highstein, G.R., \& Deusinger, R.T. (2008). Changes in weight and health behaviors from freshman through senior year of college. Journal of Nutrition Education and Behavior, 40(1), 39-42.

Rovniak, L.S., Anderson, E.S., Winett, R.A., \& Stephens, R.S. (2002). Social cognitive determinants of physical activity in young adults: A prospective structural equation analysis. Annals of Behavioral Medicine, 24(2), 149-156.

Sallis J.F., Hovell M.F., Hofstetter C.R. (1992). Predictors of adoption and maintenance of vigorous physical activity in men and women. Preventative Medicine, 21, 237251.

Strong, K.A., Parks, S.L., Anderson, E., Winett, R., \& Davy, B.M. (2008). Weight gain prevention: Identifying theory-based targets for health behavior change in young adults. Journal of the American Dietetic Association, 108(10), 1708-1715.

Toobert, D.J., Strycker, M.A., Glasgow, R.E., Barrera, M., \& Angell, K. (2005). Effects of the Mediterranean Lifestyle Program on multiple risk behaviors and psychosocial outcomes among women at risk for heart disease. Annals of Behavioral Medicine, 29(2), 128-137.

US Department of Education National Center for Education Statistics (2007). Digest of Education Statistics: 2007.

US Department of Health and Human Services (2005). Healthy People 2010: The cornerstone for prevention. [Brochure] Retrieved on January 22, 2009, from http://www.healthypeople.gov/Publications/Cornerstone.pdf.

US Department of Health and Human Services (2007). Healthy People 2010. Retrieved January 
22, 2009 from http://www.cdc.gov/nchs/about/otheract/hpdata2010/2010indicators.htm Wang, Y., Beydoun, M.A., Liang, L., Caballero, B., \& Kumanyika, S.K. (2008). Will all Americans become overweight or obese? Estimating the progression and cost of the US obesity epidemic. Obesity, 16(10), 2323-2330.

Wee, C.C., Phillips, R.S., Legedza, A.T., Davis, R.B., \& Soukup, J.R. et al. (2005). Health care expenditures associated with overweight and obesity among US adults: Importance of age and race. American Journal of Public Health, 95(1), 159-165.

Weiss, E.C., Galuska, D.A., Kahn, L.K., \& Serdula, M.K. (2006). Weight-control practices among U.S. adults, 2001-2002. American Journal of Preventive Medicine, 31(1), 18-24.

Wharton, C.M., Adams, T., \& Hampl, J.S. (2008). Weight loss practices and body weight perceptions among US college students. Journal of American College Health, 56(5), 579-584. 


\section{APPENDIX B}

Pre-Program Nutrition and Exercise Assessment

(Adapted from Simpleforms online survey)

Please indicate if you are competing in the "Team Challenge":

First name:

Middle Initial:

Last Name:

I verify that I am a full-time student and would like to participate in Body for Break:

Mix email address:

Please enter a phone number at which you can be reached:

Approximate height:

Approximate weight:

Age:

Gender:

Male

Female

School year:

Freshman

Sophmore

Junior

Senior

Graduate

Please set a short term goal for yourself....

Do you want a personal trainer?

Yes

No

If so, would you prefer a male or a female?

Male

Female 


\section{No preference}

[Questions pertaining to time scheduling/ availability]

Do you want to meet with a dietician?

Yes

No

Would you like to meet with a social support group?

Yes

No

[Questions pertaining to exercise and health history]

How many days a week do you perform cardiovascular exercise?

$0-1$

2-3

$3-4$

4-5

$5+$

How long do you normally do cardiovascular exercise?

10-15 minutes

15-20 minutes

25-35 minutes

35-45 minutes

$45+$ minutes

How many days a week do you perform strength training?

$0-1$

$1-2$

2-3

$3-4$

$4+$

How long do you normally do strength training exercises?

$0-10$ minutes

10-20 minutes

20-30 minutes

30-40 minutes

40-60 minutes

How many days a week do you perform flexibility exercises?

None

$1-2$

2-3 
How long do you normally spend performing flexibility exercises?

5-10 minutes

10-20 minutes

20-30 minutes

$30+$ minutes

How often do you smoke, if at all?

Never

1-10 cigarettes a week

1-2 packs a week

4 packs a week

1 pack a day

How much water do you drink per day?

None

$10-30 \mathrm{oz}$

$30-60 \mathrm{oz}$

$60-90 \mathrm{oz}$

$120 \mathrm{oz}$ or more

How many meals do you eat per day?

$1-2$

2-3

$3-4$

$4-5$

$5-6$

How many fruits and vegetables do you eat per day?

$1-2$

2-3

$3-4$

4-5

Do you eliminate an entire food group from your diet?

Yes

No

[Nutrition Knowledge Assessment]

To decrease the risk of many diseases, a person should get what portion of their dietary calories from fat? 
$50 \%$ of total calories

$41-49 \%$ of total calories

$31-40 \%$ of total calories

Less than $30 \%$

A certain amount of unsaturated fat is essential for health

True

False

Foods labeled as 'no sugar added' have:

No sugar

Only naturally occurring sugars

Less sugars than products that don't have this...

In order to decrease your cholesterol levels, you should increase:

Sodium

Saturated fat

Fiber

Fruits and vegetables 


\section{APPENDIX C \\ Post-Program Evaluation Survey \& Nutrition and Exercise Assessment \\ (Adapted from Simpleforms online survey)}

1. Did you achieve the personal objective you set for yourself with this program? Yes No

2. Did you stick with the program until the end date of March 13th? Yes No

3. If no, what factors influenced your decision to stop participating?

4. What did you learn from the program?

5. What did you like about the program?

6. What did you dislike about the program?

7. What changes would you recommend for the program?

8. Do you have suggestions for other programs related to health and fitness?

9. Please rate on a scale of 1 (strongly disagree) to 5 (strongly agree)

Personal Trainers were knowledgeable

Personal Trainers were friendly and helpful

Personal Trainers motivated me to workout

Personal Trainers were reliable

Personal Trainers showed me correct exercise technique

Personal Trainers could answer my questions

Dietician(s) were knowledgeable

Nutrition counseling session(s) met my needs

Nutrition counseling session motivated me to eat healthier foods

The support group was helpful

The support group helped me feel comfortable

The support group provided the support I needed

The weekly handouts were helpful

The weekly handouts educated me about fitness and nutrition 
The weekly handouts helped me make healthier choices

9. (cont'd) Please rate on a scale of 1 (strongly disagree) to 5 (strongly agree)

The weekly prizes motivated me to exercise at least 3 times a week

The grand prizes motivated me to stick with the program for the entire 8 weeks

10. Please expand on any rating that were 3 and below:

11. What are your plans for continuing exercising and eating healthy?

12. What weekly prizes would you like to see offered next year?

13. What grand prizes would you like to see offered next year?

[Questions pertaining to exercise and health history]

How many days a week do you perform cardiovascular exercise?

$0-1$

$2-3$

$3-4$

4-5

$5+$

How long do you normally do cardiovascular exercise?

10-15 minutes

15-20 minutes

25-35 minutes

35-45 minutes

$45+$ minutes

How many days a week do you perform strength training?

$0-1$

$1-2$

$2-3$

3-4

$4+$

How long do you normally do strength training exercises?

$0-10$ minutes

10-20 minutes

20-30 minutes 
30-40 minutes

40-60 minutes

How many days a week do you perform flexibility exercises?

None

$1-2$

2-3

$3-4$

4-5

$5+$

How long do you normally spend performing flexibility exercises?

5-10 minutes

10-20 minutes

20-30 minutes

$30+$ minutes

How often do you smoke, if at all?

Never

1-10 cigarettes a week

1-2 packs a week

4 packs a week

1 pack a day

How much water do you drink per day?

None

$10-30 \mathrm{oz}$

$30-60 \mathrm{oz}$

$60-90 \mathrm{oz}$

$120 \mathrm{oz}$ or more

How many meals do you eat per day?

$1-2$

2-3

$3-4$

4-5

$5-6$

How many fruits and vegetables do you eat per day?

$1-2$

2-3

$3-4$

4-5

Do you eliminate an entire food group from your diet? 
Yes

No

[Nutrition Knowledge Assessment]

To decrease the risk of many diseases, a person should get what portion of their dietary calories from fat?

$50 \%$ of total calories

$41-49 \%$ of total calories

$31-40 \%$ of total calories

Less than $30 \%$

A certain amount of unsaturated fat is essential for health

True

False

Foods labeled as 'no sugar added' have:

No sugar

Only naturally occurring sugars

Less sugars than products that don't have this...

In order to decrease your cholesterol levels, you should increase:

Sodium

Saturated fat

Fiber

Fruits and vegetables 


\section{APPENDIX D}

Exercise \& Nutrition Behavior Survey

Directions: Please respond to the following questions by circling the answer that best corresponds to your opinion. Your honest and complete answers are appreciated. All responses are totally confidential and your name is not needed. It will take about 10 minutes to complete the survey.

SRC $=$ Student Recreation Center

1. Did you participate in high school athletics?

2. Do you currently exercise regularly ( 5 or more times per week for a total of 30 minutes each day)?

3. Did you exercise regularly ( 5 or more times per week for a total of 30 minutes each day) before you started using the SRC?

Yes No

Decreased
Considerably

No Change Increased

4. How has your frequency of exercise changed since you began using the Student Recreation Center?

5. Compared to high school, in general, how has your overall level of physical activity changed?

\begin{tabular}{|l|l|l|l|l|}
\hline 1 & 2 & 3 & 4 & 5 \\
\hline 1 & 2 & 3 & 4 & 5 \\
\hline
\end{tabular}

6. How important is it for you to maintain a healthy lifestyle that includes proper nutrition, weight control, and regular physical activity?
A. Not at all important
B. Slightly important
C. Moderately important
D. Very important

7. In the next month, how physically active do you intend to be?
A. Not at all or very infrequently
B. Slightly active (1-2 days a week)
C. Moderately active (3-4 days a week)
D. Very active ( 5 or more days a week)

8. During the last month of the fall semester how many times per week did you use the SRC?

9. During the last month, on average, how many times per week were you physically active outside of the SRC?

10. Which of the following statements most closely reflects your exercising status? NOTE: Regular exercise $\mathbf{=} \mathbf{5}$ or more times per week for a total of $\mathbf{3 0}$ minutes each day.
A. I currently do not exercise, and I do not intend to start exercising in the next 6 months.
B. I currently do not exercise, but I am thinking about starting in the next 6 months.
C. I exercise sometimes, but not regularly.
D. I currently exercise regularly, but I have only begun in the last 6 months.
E. I currently exercise regularly, and I have done so for longer than 6 months. 
11. How sure or confident are you that you can start or continue to exercise for 30 minutes or more at a moderate intensity at least 5 times per week? Very unsure, ___ somewhat unsure, somewhat sure, very sure

12. How much could you count on those close to you for support and help if you wanted to become more physically active? not at all, very little, somewhat, A lot

13. How much could you count on those close to you for support and help if you wanted to eat a healthier diet?

not at all, very little, somewhat A lot

For the next 5 items, state the degree to which you are confident that you could be physically active in each of the following situations:

\begin{tabular}{|c|c|c|c|c|c|}
\hline I am confident I could be physically active ... & $\begin{array}{l}\text { Not at all } \\
\text { Confident }\end{array}$ & & $\begin{array}{l}\text { odera } \\
\text { onfid }\end{array}$ & & $\begin{array}{l}\text { Extremely } \\
\text { Confident }\end{array}$ \\
\hline 14. When I am tired. & 1 & 2 & 3 & 4 & 5 \\
\hline 15. When I am in a bad mood. & 1 & 2 & 3 & 4 & 5 \\
\hline 16. When I feel I don't have time. & 1 & 2 & 3 & 4 & 5 \\
\hline 17. When I am on vacation. & 1 & 2 & 3 & 4 & 5 \\
\hline 18. When it is raining or snowing. & 1 & 2 & 3 & 4 & 5 \\
\hline When exercising, I feel most successful when ... & $\begin{array}{l}\text { Strongly } \\
\text { Disagree }\end{array}$ & & eutral & & $\begin{array}{r}\text { Strongly } \\
\text { Agree }\end{array}$ \\
\hline 19. I exercise longer than other people & 1 & 2 & 3 & 4 & 5 \\
\hline 20. I am clearly superior & 1 & 2 & 3 & 4 & 5 \\
\hline 21. I am the best & 1 & 2 & 3 & 4 & 5 \\
\hline 22. I work hard & 1 & 2 & 3 & 4 & 5 \\
\hline 23. I show clear personal improvement & 1 & 2 & 3 & 4 & 5 \\
\hline 24. I accomplish something others cannot do & 1 & 2 & 3 & 4 & 5 \\
\hline 25. I reach a goal & 1 & 2 & 3 & 4 & 5 \\
\hline 26. I overcome difficulties & 1 & 2 & 3 & 4 & 5 \\
\hline 27. I master something I couldn't do before & 1 & 2 & 3 & 4 & 5 \\
\hline 28. I show other people I am the best & 1 & 2 & 3 & 4 & 5 \\
\hline 29. I perform to the best of my ability & 1 & 2 & 3 & 4 & 5 \\
\hline
\end{tabular}

Please rate how important each of these statements is in deciding whether or not you choose to be physically active.

Not at all Moderately Extremely Important Important Important

30. I would have more energy for my family and friends if I were regularly physically active.

31. Regular physical activity would help me relieve tension.

32. I think I would be too tired to do my daily work after being physically active.

33. I would feel more confident if I were regularly physically active.

34. I would sleep more soundly if I were regularly physically active.

35. I would feel good about myself if I kept my commitment to be regularly physically active.

\begin{tabular}{|l|l|l|l|l|}
\hline 1 & 2 & 3 & 4 & 5 \\
\hline 1 & 2 & 3 & 4 & 5 \\
\hline 1 & 2 & 3 & 4 & 5 \\
\hline 1 & 2 & 3 & 4 & 5 \\
\hline 1 & 2 & 3 & 4 & 5 \\
\hline 1 & 2 & 3 & 4 & 5 \\
\hline
\end{tabular}




\begin{tabular}{|c|c|c|c|c|c|c|}
\hline & $\begin{array}{l}\text { I would find it difficult to find a physical activity that I enjoy and } \\
\text { that is not affected by bad weather. }\end{array}$ & 1 & 2 & 3 & 4 & 5 \\
\hline 37. & I would like my body better if I were regularly physically active. & 1 & 2 & 3 & 4 & 5 \\
\hline 38. & $\begin{array}{l}\text { It would be easier for me to perform routine physical tasks if I } \\
\text { were regularly physically active. }\end{array}$ & 1 & 2 & 3 & 4 & 5 \\
\hline 39. & I would feel less stressed if I were regularly physically active. & 1 & 2 & 3 & 4 & 5 \\
\hline 40. & $\begin{array}{l}\text { I feel uncomfortable when I am physically active because I get } \\
\text { out of breath and my heart beats very fast. }\end{array}$ & 1 & 2 & 3 & 4 & 5 \\
\hline 41. & $\begin{array}{l}\text { I would feel more comfortable with my body if I were regularly } \\
\text { physically active. }\end{array}$ & 1 & 2 & 3 & 4 & 5 \\
\hline 42. & Regularly physical activity would take too much of my time. & 1 & 2 & 3 & 4 & 5 \\
\hline 43. & $\begin{array}{l}\text { Regular physical activity would help me have a more positive } \\
\text { outlook on life. }\end{array}$ & 1 & 2 & 3 & 4 & 5 \\
\hline 44. & $\begin{array}{l}\text { I would have less time for my family and friends if I were regularly } \\
\text { physically active. }\end{array}$ & 1 & 2 & 3 & 4 & 5 \\
\hline 45. & At the end of the day, I am too exhausted to be physically active. & 1 & 2 & 3 & 4 & 5 \\
\hline
\end{tabular}

46. In the last seven days, on how many days did you eat at a fast food type place - McDonalds, Kentucky

Fried Chicken, Pizza Hut, Taco Bell, etc?

47. In the last seven days, on how many days did you eat breakfast?

48. How often do you intend to visit the SRC over the next 4 weeks (e.g. times per week):

49. Did you attend the final Body for Break assessment? If not, why?

Tell us a little about yourself . . .

\begin{tabular}{|c|c|c|c|c|c|}
\hline & A & B & C & D & $\mathbf{E}$ \\
\hline 53. Gender & Male & Female & & & \\
\hline 54. Race & $\begin{array}{l}\text { African } \\
\text { American }\end{array}$ & $\begin{array}{c}\text { Asian } \\
\text { American }\end{array}$ & Caucasian & $\begin{array}{l}\text { Hispanic } \\
\text { American }\end{array}$ & Other \\
\hline $\begin{array}{l}\text { 55. Are you an } \\
\text { international student? }\end{array}$ & Yes & No & & & \\
\hline 56. Class Status & Freshman & Sophomore & Junior & Senior & $\begin{array}{l}\text { Graduatel } \\
\text { Professional }\end{array}$ \\
\hline 57. Age & $18-19$ & $20-21$ & $22-23$ & $24-25$ & $26+$ \\
\hline 58. Overall GPA & $<2.0$ & $2.0-2.5$ & $2.51-3.0$ & $3.01-3.5$ & $>3.5$ \\
\hline
\end{tabular}

Please write down your 700\#:

Please write down your height

Please write down your weight 


\author{
APPENDIX E \\ Body for Break Focus Group Script
}

Introduction $(<5$ mins $)$

Welcome

Introduction of staff

Describe what a focus group is

I will be talking with you today about your participation in the WVU SRC's Body for Break program- your thoughts on it, what worked, what did not work, and what you would like to see offered by a program like this in the future.

Go over group ground rules:

- Please feel free to share your ideas and opinions even if they differ from others in the group.

- There are not right or wrong answers.

- The purpose is to get as many different points of view as possible.

- All views and ideas are important.

Please feel free to talk about any component of the Body for Break program.

Everything that we say here today is confidential. Individual names will not be shared with anyone. I am independent of the WVU SRC and the Body for Break program, reports will only be given in terms of common response themes. In turn, I would like to ask you all to not share anything that we discuss here today outside of this room.

This session should last about 45 minutes.

I am tape-recording this session to ensure that I do not miss any of your comments, in conjunction with my note taking. Your names will not be recorded.

Since this is a group discussion you do not have to wait for me to call on you to speak but please remember to be courteous to all members of the group.

\title{
Let's start with a discussion of some of the reasons that you had for participating in the Body for Break program.
}

1. What was it about the program that initially attracted you to join?

2. Was there anything about the program that you were initially turned off by?

\section{Now I want you to specifically think about your earlier weeks in the program:}

3. What did you think of the program when you first started out?

4. Were there any parts of the program that you were not sure about? 
5. Was there any other information about the program or from the program that you think you could have benefited from during that time?

\section{Now I want you to specifically think about the program during the 8 weeks you} were involved:

6. What barriers did you experience toward your success in the program?

7. What were some factors that contributed to your success in the program (note whether they were personal characteristics or programmatic).

8. To what extent to you implement the program components (e.g. trainers, dieticians, support groups, motivational emails)?

9. What negative experiences, if any, did you encounter during the program?

\section{Now I want you to specifically think about the program during the 4 weeks since you were involved:}

6. To what extent did to you continue to implement what you did/learned during the program?

7. What barriers did you experience toward acting on your intentions in the past 4 weeks?

7. What were some factors that contributed to your success in maintaining your adherence to your intended behaviors? (note whether they were personal characteristics or programmatic).

9. What negative experiences, if any, did you encounter during the past 4 weeks

as a result of your participation in the program?

\section{Finally, let's talk about your general experiences with the Body for Break program:}

10. How would you rate your overall satisfaction with the Body for Break and Beyond program? $(0-100 \%)$
a. Why?

11. Would you participate in the program next year?

a. Why/ why not?

12. Would you recommend this program to a friend?

a. Why/ why not?

13. What improvements would you like to see to this program in the future?

14. What, if any, of the Body for Break program components should be reduced or eliminated?

\section{Lastly:}

15. What advice would you give to others thinking about participating in the Body for Break program next year? 
APPENDIX F

Follow-up Study Cover Letter

Dear WVU Student,

The purpose of this research project is to understand how much the "Body for Break" program changes your attitude and behavior towards physical activity and nutrition.

This survey will only take 5-10 minutes to complete and it is important that you respond honestly. Your involvement in this project will be kept as confidential as legally possible. All data will be reported in the aggregate. You must be 18 years of age or older to participate. Any identifying information collected (700\# or mix email) will be kept separate from your survey to maintain your confidentiality. Your participation is completely voluntary. You may skip any question that you do not wish to answer and you may discontinue at any time. Your class standing will not be affected if you decide either not to participate or to withdraw. West Virginia's University's Institutional Review Board acknowledgement of this project is on file.

We are requesting your student ID \# only so we can access how many times you use the student recreation center this semester and we will never have access to your name. All data will be password protected and access is limited to Michelle Bartlett and Dr. Sam Zizzi, the co-principal investigators of this study. If you have questions about the study, you may contact Michelle Bartlett at XXX-XXX-XXXX.

Thank you for your participation in this important project.

Sincerely,

Michelle Bartlett, M.S.

Sport and Exercise Psychology Doctoral Student 


\section{APPENDIX G}

\section{Focus Group Cover Letter}

Dear WVU Student,

The purpose of this focus group is to understand the Body for Break program's impact at West Virginia University.

This group discussion will take approximately 45-90 minutes to complete and you will not be forced to answer all questions. Your participation is voluntary and your academic status will not be affected by refusing to participate. You do not have to answer every question, but responding completely will provide more valuable information.

Your responses to this discussion will remain completely confidential. The discussion is being audio taped so we can fully understand the messages that you share with us. Your name will not be included in the recording. All of the information will be transcribed and then will be stored in a locked file cabinet with access limited to Michelle Bartlett and Dr. Sam Zizzi, the co-principal investigators of this study. If you have questions about the study, you may contact Michelle Bartlett at XXX-XXX-XXXX. For information about your rights as a research subject, you may call the Executive Secretary of the WVU Research Compliance Office at (304) 293-7073.

Thank you for your participation in this important project.

Sincerely,

Michelle Bartlett, M.S.

Sport and Exercise Psychology Doctoral Student 
College of Physical Activity and Sport Sciences

\section{APPENDIX H}

Focus Group Brief Demographic Questionnaire

Please circle the answer that best fits. All responses are optional.

\begin{tabular}{|l|c|c|c|c|c|}
\hline \multicolumn{1}{|c}{} & \multicolumn{2}{c}{ A } & \multicolumn{2}{c}{ B } & \multicolumn{2}{c|}{ D } \\
\hline Gender & Male & Female & & Hispanic & Other \\
\hline Race & $\begin{array}{c}\text { African } \\
\text { American }\end{array}$ & $\begin{array}{c}\text { Asian } \\
\text { American }\end{array}$ & Caucasian & $\begin{array}{c}\text { American } \\
\text { Amican }\end{array}$ & \\
\hline $\begin{array}{l}\text { Are you an } \\
\text { international student? }\end{array}$ & Yes & No & & Senior & $\begin{array}{c}\text { Graduate/ } \\
\text { Professional }\end{array}$ \\
\hline Class Status & Freshman & Sophomore & Junior & $24-25$ & $26+$ \\
\hline Age & $18-19$ & $20-21$ & $22-23$ & $2.01-3.5$ & $>3.5$ \\
\hline Overall GPA & $<2.0$ & $2.0-2.5$ & $2.51-3.0$ & 3.0 & \\
\hline
\end{tabular}

Please write down your 700\#:

Please write down your height

Please write down your weight 


\section{APPENDIX I}

Qualitative Data Code Book and Definition of Codes

\begin{tabular}{|c|c|c|}
\hline Code Word & Parent Code & Definition \\
\hline$\$$ & BARRIERS & $\begin{array}{l}\text { anything pertaining to cost, expenses, } \\
\text { money-related }\end{array}$ \\
\hline - SOCIAL SUPPORT & BARRIERS & negative or lacking social support \\
\hline ACCOUNTABILITY & CONTRIBUTE TO SUCCES & $\begin{array}{l}\text { something holding an individual to } \\
\text { their actions }\end{array}$ \\
\hline ADVICE FROM STAFF & CONTRIBUTE TO SUCCES & advice from trainers/dietician \\
\hline ADVICE TO OTHERS & & $\begin{array}{l}\text { what advice would participant offer to } \\
\text { others participating in the program }\end{array}$ \\
\hline B4B SPECIFIC ACTIVIT & INCREASE VARIETY & $\begin{array}{l}\text { Have activities specific for program } \\
\text { participants e.g. group exercise, }\end{array}$ \\
\hline BARRIERS & EFFECTIVENESS & $\begin{array}{l}\text { anything getting in the way of } \\
\text { intended action }\end{array}$ \\
\hline BOREDOM & BARRIERS & lacking stimulation/variety \\
\hline COMMUTE & ENVIRONMENTAL & traveling to rec center \\
\hline COMPETITION & REASONS FOR PARTIC & having a competitive element \\
\hline CONT. DIET/PLAN & POST-PROGRAM IMPL & continued to follow diet plan \\
\hline CONT. EXERCISE/PLAN & POST-PROGRAM IMPL & $\begin{array}{l}\text { continued to exercise or use training } \\
\text { plan }\end{array}$ \\
\hline CONTRIBUTE TO SUCCES & EFFECTIVENESS & $\begin{array}{l}\text { what contributed to your success in } \\
\text { the program }\end{array}$ \\
\hline CONVENIENCE & CONTRIBUTE TO SUCCES & ease of use high \\
\hline CURIOSITY & INTEREST IN PROGRAM & a desire to know about something \\
\hline DECREASED MOTIVATION & BARRIERS & lack of or waning motivation \\
\hline DIDNT WANT XTRA HELP & IMPL- INDIV & $\begin{array}{l}\text { participants did not use components; } \\
\text { felt that (component) was unneeded }\end{array}$ \\
\hline DIET & BARRIERS & $\begin{array}{l}\text { issues dealing with dietary/nutritional } \\
\text { intake }\end{array}$ \\
\hline DIFFERENT TRACKS & INCREASE VARIETY & $\begin{array}{l}\text { Program provides different tracks for } \\
\text { participants at different levels }\end{array}$ \\
\hline DISCIPLINE & CONTRIBUTE TO SUCCES & $\begin{array}{l}\text { maintaining/developing a regimen to } \\
\text { stick with program/behavior }\end{array}$ \\
\hline DISLIKE PLAN/ROUTINE & NEG-PT & $\begin{array}{l}\text { did not like the training plan/ routine } \\
\text { given by trainer }\end{array}$ \\
\hline DISREGARD CLIENT & NEG-PT & $\begin{array}{l}\text { did not pay attention or incorporate } \\
\text { clients wishes. Trainer not listening to } \\
\text { client }\end{array}$ \\
\hline DO WITH FRIENDS & ADVICE TO OTHERS & $\begin{array}{l}\text { Utilize friends for accountability \& } \\
\text { social support }\end{array}$ \\
\hline DVLP'D HABIT/ROUTINE & MAINTENANCE- INDIV & $\begin{array}{l}\text { developed habit(s) and/or routine } \\
\text { during program that is still maintained }\end{array}$ \\
\hline EFFECTIVENESS & & $\begin{array}{l}\text { Results (both positive \& negative) } \\
\text { experienced by participants during } \\
\text { their time in program }\end{array}$ \\
\hline ELIMINATE COMPONENTS & IMPROVEMENT-PROG & $\begin{array}{l}\text { need for the elimination of program } \\
\text { components (PT, dietician, emails, } \\
\text { etc) }\end{array}$ \\
\hline ENVIRONMENTAL & BARRIERS & environmental barriers \\
\hline
\end{tabular}




\begin{tabular}{|c|c|c|}
\hline EXERCISE HISTORY & CONTRIBUTE TO SUCCES & $\begin{array}{l}\text { person has experience with exercise; } \\
\text { has exercised in the past and has } \\
\text { knowledge about }\end{array}$ \\
\hline EXERCISED AT HOME & INCREASE VARIETY & $\begin{array}{l}\text { exercised at home as opposed to at } \\
\text { the SRC }\end{array}$ \\
\hline GETTING INTO ROUTINE & CONTRIBUTE TO SUCCES & $\begin{array}{l}\text { doing the same behaviors over and } \\
\text { over, makes comfortable }\end{array}$ \\
\hline GOAL-SETTING & CONTRIBUTE TO SUCCES & $\begin{array}{l}\text { as an intervention, setting goals to } \\
\text { reach }\end{array}$ \\
\hline GOOD VALUE & INTEREST IN PROGRAM & good money's worth \\
\hline GROUP TRAINING & INCREASE SOC SUPPORT & schedule training in groups \\
\hline HARD TO SCHED- NUTR & NEG- NUTR & Difficult to access/schedule appt \\
\hline HARD TO SCHEDULE PT & NEG-PT & $\begin{array}{l}\text { hard to schedule personal training } \\
\text { appointments }\end{array}$ \\
\hline HEALTH & INTEREST IN PROGRAM & $\begin{array}{l}\text { health reasons, e.g. decrease blood } \\
\text { pressure }\end{array}$ \\
\hline HEALTH IMPROVEMENTS & EFFECTIVENESS & $\begin{array}{l}\text { increased health e.g. more energy, } \\
\text { better blood pressure, feel "better" }\end{array}$ \\
\hline IMPL- INDIV & IMPLEMENTATION & $\begin{array}{l}\text { The extent to which participants used } \\
\text { the program components offered to } \\
\text { them }\end{array}$ \\
\hline IMPL-ORG-QUAL & IMPLEMENTATION & $\begin{array}{l}\text { The quality of the components } \\
\text { delivered by the program }\end{array}$ \\
\hline IMPLEMENT PROG COMP & IMPL- INDIV & Implement program components \\
\hline IMPLEMENT- SPPRT GRP & IMPLEMENT PROG COMP & $\begin{array}{l}\text { when participant described the level } \\
\text { to which they would/would have } \\
\text { utilized component of support groups }\end{array}$ \\
\hline IMPLEMENT-EMAILS & IMPLEMENT PROG COMP & $\begin{array}{l}\text { when participant described the level } \\
\text { to which they would/would have } \\
\text { utilized component of reading the } \\
\text { emails and/or incorporating the info } \\
\text { provided }\end{array}$ \\
\hline IMPLEMENT-NUTR & IMPLEMENT PROG COMP & $\begin{array}{l}\text { when participant described the level } \\
\text { to which they would/would have } \\
\text { utilized component of the dietician }\end{array}$ \\
\hline IMPLEMENT-PT & IMPLEMENT PROG COMP & $\begin{array}{l}\text { when participant described the level } \\
\text { to which they would/would have } \\
\text { utilized component of the personal } \\
\text { trainer }\end{array}$ \\
\hline IMPLEMENTATION & & $\begin{array}{l}\text { How the program is utilized by } \\
\text { participants and delivered by program }\end{array}$ \\
\hline IMPROVEMENT-PROG & & $\begin{array}{l}\text { suggestions for improvements to the } \\
\text { program }\end{array}$ \\
\hline INC QUALITYIDOSE & IMPROVEMENT-PROG & $\begin{array}{l}\text { Increase quality of program } \\
\text { components or program in general, } \\
\text { e.g. hire more trainers/ dietician, train } \\
\text { them better to deliver services, hire } \\
\text { athletic trainers, etc }\end{array}$ \\
\hline INCENTIVES & INTEREST IN PROGRAM & additional benefits of joining program \\
\hline INCONSISTENT & NEG- EMAIL & $\begin{array}{l}\text { emails were not consistently delivered } \\
\text { throughout program }\end{array}$ \\
\hline INCONSISTENT-PT & NEG-PT & $\begin{array}{l}\text { personal trainers were switched up; } \\
\text { different trainers were provided to one } \\
\text { indiv }\end{array}$ \\
\hline
\end{tabular}




\begin{tabular}{|c|c|c|}
\hline INCREASE FEEDBACK & IMPROVEMENT-PROG & $\begin{array}{l}\text { Suggestions for program to provide } \\
\text { more feedback and information to } \\
\text { participants }\end{array}$ \\
\hline INCREASE KNOWLEDGE & REASONS FOR PARTIC & $\begin{array}{l}\text { wanted tol increased knowledge of } \\
\text { participant on relevant info }\end{array}$ \\
\hline INCREASE SOC SUPPORT & IMPROVEMENT-PROG & $\begin{array}{l}\text { increase social support or } \\
\text { opportunities for participants to } \\
\text { interact with each other }\end{array}$ \\
\hline INCREASE VARIETY & IMPROVEMENT-PROG & $\begin{array}{l}\text { Increase variety of what program } \\
\text { offers }\end{array}$ \\
\hline INITIAL TURNED OFF & REACH & $\begin{array}{l}\text { what, if anything was the participant } \\
\text { initially turned off by }\end{array}$ \\
\hline INJURY & BARRIERS & injury to self during/ due to program \\
\hline INNACURATE & NEG-MEASUREMENT & measurement was inaccurate; rushed \\
\hline INTEREST IN PROGRAM & REACH & $\begin{array}{l}\text { what factors lead to an interest in the } \\
\text { program }\end{array}$ \\
\hline LACK OF KNOWLEDGE & NEG-PT & $\begin{array}{l}\text { trainers lack of knowledge on how to } \\
\text { train }\end{array}$ \\
\hline LIFESTYLE CHANGE & CONTRIBUTE TO SUCCES & $\begin{array}{l}\text { incorporating behavior change into } \\
\text { lifestyle }\end{array}$ \\
\hline LIKED DIET PLAN & POS- NUTR & liked plan given by dietician \\
\hline LIKED THE WORKOUT & POS-PT & $\begin{array}{l}\text { liked the training plan/ routing given } \\
\text { by/done with trainer }\end{array}$ \\
\hline MAINTENANCE- INDIV & & $\begin{array}{l}\text { The extent to which participants are } \\
\text { upholding the effects from the } \\
\text { program }\end{array}$ \\
\hline MET GOALS & EFFECTIVENESS & $\begin{array}{l}\text { participants met goals set via } \\
\text { participation in program }\end{array}$ \\
\hline MISPERCEPTIONS OF PR & NEG EXPERIENCES & $\begin{array}{l}\text { anything that may have been unclear } \\
\text { about the program }\end{array}$ \\
\hline MORE WEIGH-INSIASSMT & INCREASE FEEDBACK & $\begin{array}{l}\text { suggestion: have more weigh- } \\
\text { ins/assessments throughout the } \\
\text { program }\end{array}$ \\
\hline MOTIVATING & POS-PT & trainer provided motivation to client \\
\hline MOTIVATION & CONTRIBUTE TO SUCCES & $\begin{array}{l}\text { anything mentioned about } \\
\text { motivational techniques or lack } \\
\text { thereof }\end{array}$ \\
\hline NEED TO FULLY USE & ADVICE TO OTHERS & use all components of program \\
\hline NEG EFFECTIVENESS & EFFECTIVENESS & gained weight or saw no results \\
\hline NEG EXPERIENCES & IMPL-ORG-QUAL & any general negative experience \\
\hline NEG- EMAIL & NEG EXPERIENCES & $\begin{array}{l}\text { negative experience specifically } \\
\text { related to email }\end{array}$ \\
\hline NEG- NUTR & NEG EXPERIENCES & $\begin{array}{l}\text { negative experience specifically } \\
\text { related to the dietician }\end{array}$ \\
\hline NEG-MEASUREMENT & NEG EXPERIENCES & $\begin{array}{l}\text { negative experiences with } \\
\text { measurement- e.g. inaccuracy, } \\
\text { procedure, etc }\end{array}$ \\
\hline NEG-PT & NEG EXPERIENCES & $\begin{array}{l}\text { negative experience specifically } \\
\text { related to the personal trainers } / \\
\text { personal training }\end{array}$ \\
\hline NO OPTIONS & NEG- EMAIL & $\begin{array}{l}\text { No options to either opt out of } \\
\text { receiving emails or use an acct other } \\
\text { than the 'mix' acct }\end{array}$ \\
\hline
\end{tabular}




\begin{tabular}{|c|c|c|}
\hline NOT PLANNING AHEAD & BARRIERS & $\begin{array}{l}\text { not planning ahead for potential } \\
\text { barriers (e.g. not packing a healthy } \\
\text { meal) }\end{array}$ \\
\hline NOT RELATED TO PROG & NEG- NUTR & $\begin{array}{l}\text { Service did not seem related to } \\
\text { program }\end{array}$ \\
\hline NUTR-KNOWLEDGEABLE & POS- NUTR & $\begin{array}{l}\text { staff had knowledge on pertinent } \\
\text { topics }\end{array}$ \\
\hline OVERALL SATISFACTION & IMPLEMENTATION & opinion of program \\
\hline PARTICIPATE NEXT YR & & $\begin{array}{l}\text { Would you participate in B4B next } \\
\text { year }\end{array}$ \\
\hline PERSONAL & REASONS FOR PARTIC & personal reasons - general \\
\hline PHYSICAL & INTEREST IN PROGRAM & $\begin{array}{l}\text { physical reasons- e.g. weight loss, } \\
\text { toning, increase fitness }\end{array}$ \\
\hline PHYSICAL IMPROVMENTS & EFFECTIVENESS & $\begin{array}{l}\text { improvements to physique e.g. inc } \\
\text { strength, inc tone/muscle mass, lose } \\
\text { weight/inches }\end{array}$ \\
\hline POS EXPERIENCE & IMPL-ORG-QUAL & positive experience- general \\
\hline POS- EMAILS & POS EXPERIENCE & $\begin{array}{l}\text { positive experience- specifically } \\
\text { related to the emails }\end{array}$ \\
\hline POS- NUTR & POS EXPERIENCE & $\begin{array}{l}\text { positive experience- specifically } \\
\text { related to the dietician }\end{array}$ \\
\hline POS-PT & POS EXPERIENCE & $\begin{array}{l}\text { positive experience- specifically } \\
\text { related to the personal training }\end{array}$ \\
\hline POST-PROGRAM IMPL & MAINTENANCE- INDIV & $\begin{array}{l}\text { Implementation of program } \\
\text { components after program ended }\end{array}$ \\
\hline PRIZES & INTEREST IN PROGRAM & $\begin{array}{l}\text { referring to the prizes offered by the } \\
\text { program }\end{array}$ \\
\hline PROGRAM NOT DSTINCT & INITIAL TURNED OFF & $\begin{array}{l}\text { participants thought program would } \\
\text { be bigger than it was }\end{array}$ \\
\hline PROGRAM-EXTRA INFO & INCREASE FEEDBACK & $\begin{array}{l}\text { extra information needed by } \\
\text { participants about the program }\end{array}$ \\
\hline PROGRAM-NOT SURE ABT & INCREASE FEEDBACK & $\begin{array}{l}\text { parts of program that participants } \\
\text { were not sure about }\end{array}$ \\
\hline PROGRAMMATIC & REASONS FOR PARTIC & things referring tol about the program \\
\hline PT-KNOWLEDGEABLE & POS-PT & $\begin{array}{l}\text { trainer provided knowledge on how to } \\
\text { use machines, get fit, techniques, etc. }\end{array}$ \\
\hline REACH & & $\begin{array}{l}\text { How participants are attracted to or } \\
\text { repelled from program }\end{array}$ \\
\hline REASONS FOR PARTIC & REACH & $\begin{array}{l}\text { participant reasons for participating in } \\
\text { program }\end{array}$ \\
\hline RECOMMEND TO FRIEND & & $\begin{array}{l}\text { whether participants would } \\
\text { recommend program to friends }\end{array}$ \\
\hline SERVICE NOT HELPFUL & NEG- NUTR & $\begin{array}{l}\text { Participants did not find service/ diet } \\
\text { plan helpful }\end{array}$ \\
\hline SET GOALS & ADVICE TO OTHERS & $\begin{array}{l}\text { Have specific goals set for what want } \\
\text { out of program }\end{array}$ \\
\hline SHOULD HAVE USED & IMPL- INDIV & $\begin{array}{l}\text { participants regret not using all } \\
\text { program components }\end{array}$ \\
\hline SLOW RESULTS & BARRIERS & $\begin{array}{l}\text { results intended to be achieved by } \\
\text { participating in the program did not } \\
\text { come to participants as quickly as } \\
\text { desired }\end{array}$ \\
\hline SOCIAL SUPPORT & CONTRIBUTE TO SUCCES & having support for behaviors from \\
\hline
\end{tabular}




\begin{tabular}{|l|l|l|}
\hline \multicolumn{1}{|l}{ STRESS } & BARRIERS & other important others \\
\hline TIME CONSTRAINTS & BARRIERS & $\begin{array}{l}\text { stress } \\
\text { busy }\end{array}$ \\
\hline TIME LINE OF PROGRAM & PROGRAMMATIC & $\begin{array}{l}\text { program being the } 8 \text { weeks before } \\
\text { spring break }\end{array}$ \\
\hline TO USE SERVICES & REASONS FOR PARTIC & $\begin{array}{l}\text { To take advantage of the services } \\
\text { offered by the program e.g. personal } \\
\text { training, dietician. }\end{array}$ \\
\hline TOO CROWDED & ENVIRONMENTAL & $\begin{array}{l}\text { rec center too crowded; } \\
\text { uncomfortable }\end{array}$ \\
\hline TOO MUCH & NEG- EMAIL & $\begin{array}{l}\text { Too many emails; too many } \\
\text { attachments on emails }\end{array}$ \\
\hline TRAINING BUDDY & INCREASE SOC SUPPORT & $\begin{array}{l}\text { set participants up with a buddy to } \\
\text { train with; an accountability partner }\end{array}$ \\
\hline UNCOMFORTABLE & NEG-MEASUREMENT & $\begin{array}{l}\text { measurements taken in front of } \\
\text { others- embarrassing, uncomfortable }\end{array}$ \\
\hline & & $\begin{array}{l}\text { when results due to program } \\
\text { participation are visibly evident to self } \\
\text { or others; or visible results of others } \\
\text { are visible }\end{array}$ \\
\hline WISABLE RESULTS & MOTIVATION & $\begin{array}{l}\text { wanted to know how they did in the } \\
\text { program after final assessment }\end{array}$ \\
\hline
\end{tabular}

